Prepared in cooperation with International Upper Great Lakes Study Board and U.S. Army Corps of Engineers

\title{
Detection of Conveyance Changes in St. Clair River Using Historical Water-Level and Flow Data with Inverse One- Dimensional Hydrodynamic Modeling
}

Scientific Investigations Report 2009-5080 



\section{Detection of Conveyance Changes in St. Clair River Using Historical Water-Level and Flow Data with Inverse One-Dimensional Hydrodynamic Modeling}

By David J. Holtschlag and C.J. Hoard

Prepared in cooperation with International Upper Great Lakes Study Board and U.S. Army Corps of Engineers

Scientific Investigations Report 2009-5080 


\section{U.S. Department of the Interior \\ KEN SALAZAR, Secretary \\ U.S. Geological Survey \\ Suzette M. Kimball, Acting Director}

U.S. Geological Survey, Reston, Virginia: 2009

For more information on the USGS - the Federal source for science about the Earth, its natural and living resources, natural hazards, and the environment, visit http://www.usgs.gov or call 1-888-ASK-USGS

For an overview of USGS information products, including maps, imagery, and publications, visit http://www.usgs.gov/pubprod

To order this and other USGS information products, visit http://store.usgs.gov

Any use of trade, product, or firm names is for descriptive purposes only and does not imply endorsement by the U.S. Government.

Although this report is in the public domain, permission must be secured from the individual copyright owners to reproduce any copyrighted materials contained within this report.

Suggested citation:

Holtschlag, D.J., and Hoard, C.J., 2009, Detection of conveyance changes in St. Clair River using historical water-level and flow data with inverse one-dimensional hydrodynamic modeling: U.S. Geological Survey Scientific Investigations Report 2009-5080, 39 p.

ISBN 978-1-4113-2435-0 


\section{Contents}

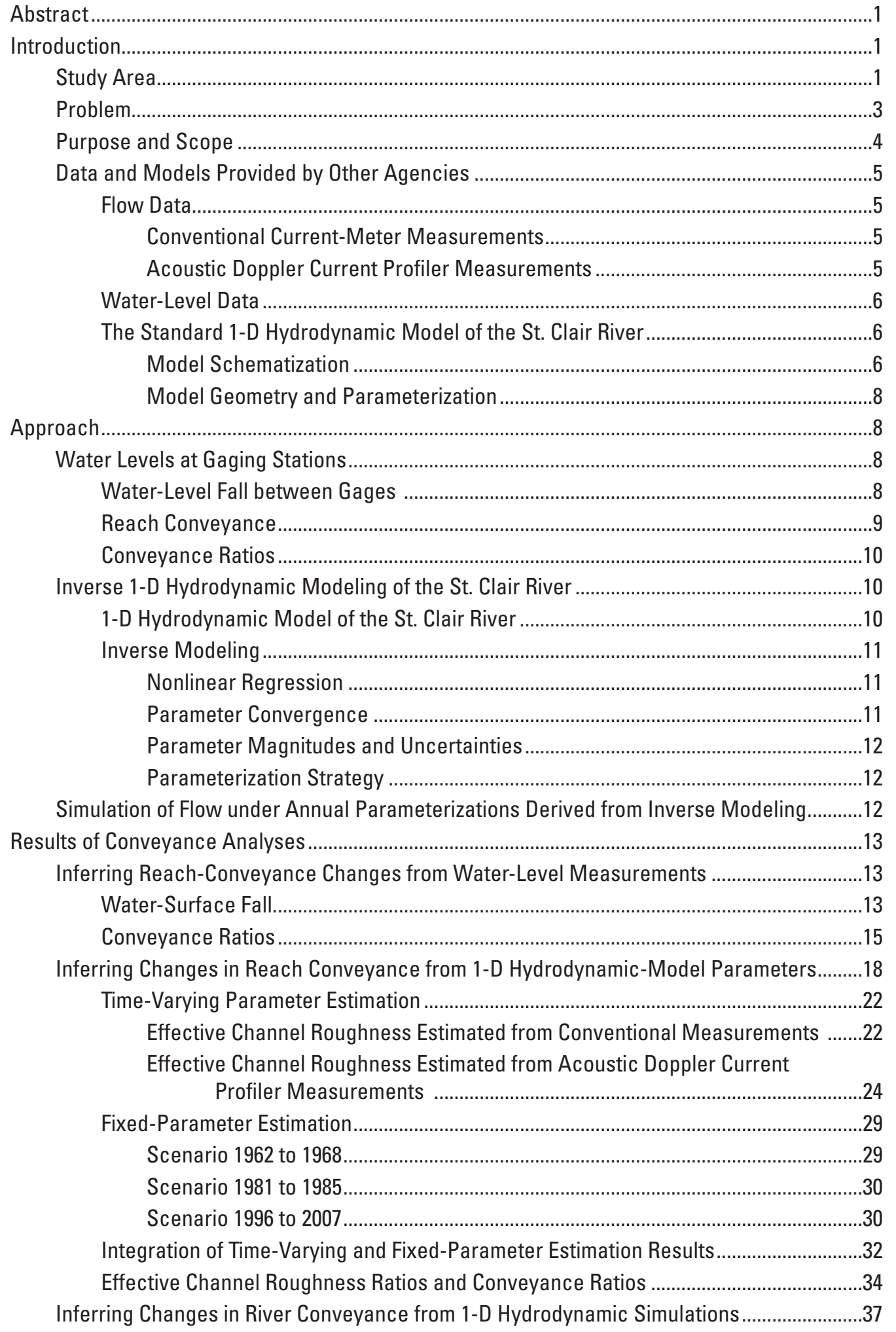




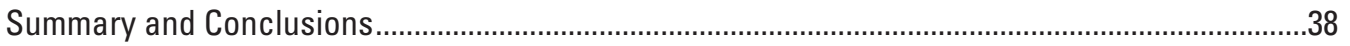

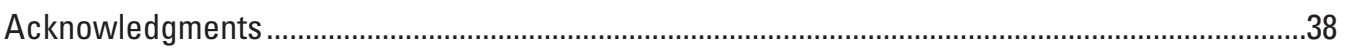

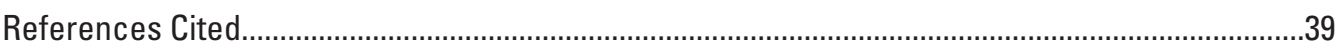

\section{Figures}

1. Map showing St. Clair River study area in southeastern Michigan and southern Ontario, Canada

2-23. Graphs showing:

2. Monthly historical water-level characteristics for 1918-2007 and 2007 water levels on Lake Michigan-Huron

3. Water levels and water-level differences between Lake Michigan-Huron and Lake St. Clair from 1962 to 2007.

4. Schematic of the St. Clair River Hydrologic Engineering Center-River Analysis System (HEC-RAS) model showing channels and junctions defined in the standard model

5. Differences in average April 1 to November 30 water levels between adjacent reaches on the St. Clair River

6. Lower diagonal scatter-plot matrix of conveyance-ratios from 1962 to 2007 for paired reaches on the St. Clair River

7. Average flow of the St. Clair River for 1962-2006 based on coordinated monthly flow estimates

8. Lower diagonal scatter-plot matrix of conveyance-ratio innovations from 1962 to 2006 for paired reaches on the St. Clair River.

9. Relation between simulated flow and flow measured on the St. Clair River from 1962 to 1985 using conventional current meters

10. Relation between simulated flow and flow measured on the St. Clair River from 1996 to 2007 using acoustic Doppler current profilers.

11. Annual estimates of effective channel roughness with 95-percent confidence intervals for the St. Clair River reach from Fort Gratiot to Dunn Paper, Michigan 26

12. Annual estimates of effective channel roughness with 95-percent confidence intervals for the St. Clair River reach from Dunn Paper, Michigan, to Point Edward, Ontario

13. Annual estimates of effective channel roughness with 95-percent confidence intervals for the St. Clair River reach from Point Edward, Ontario, to the mouth of Black River, Michigan

14. Annual estimates of effective channel roughness with 95-percent confidence intervals for the St. Clair River reach from the mouth of Black River to Dry Dock, Michigan

15. Annual estimates of effective channel roughness with 95-percent confidence intervals for the St. Clair River reach from Dry Dock to St. Clair State Police, Michigan

16. Annual estimates of effective channel roughness with 95-percent confidence intervals for the St. Clair River reach from St. Clair State Police, Michigan, to Port Lambton, Ontario

17. Annual estimates of effective channel roughness with 95-percent confidence intervals for the St. Clair River reach from Port Lambton, Ontario, to Algonac, Michigan 
18. Relation between measured flow and flow simulated on the St. Clair River by use of a fixed, seven-parameter version of the 1-D HEC-RAS (One-dimensional Hydrologic Engineering Center-River Analysis System) model developed using data obtained from 1962 and 1968

19. Relation between measured flow and flow simulated on the St. Clair River by use of a fixed, nine-parameter version of the hydrodynamic model for the period 1996-2007

20. Fixed-parameter channel roughness estimates for nine St. Clair River reaches for the periods 1996-2001 and 2002-2007.

21. Relation between annual conveyance ratios estimated on the basis of effective channel roughness estimates and measured water-level data for the period 1996 through 2007

22. Relation between annual model-parameter estimates and simulated average flow from 1962 to 2007 for 1962 and 2007 water-level boundary conditions . .37

23. Relation between annual parameter estimates and changes in average simulated flow from the 1962 parameterization

\section{Tables}

1. Selected water-level gaging stations along the St. Clair River .........................................

2. St. Clair River reaches delimited by water-level gaging stations and used for this study

3. Trends in water-level fall within St. Clair River reaches delimited by water-level gaging stations, 1962-2007.

4. Trends in conveyance ratios among paired reaches on the St. Clair River.............................17

5. Relation among estimated flow from April 1 to November 30 and conveyance ratios of reaches on St. Clair River.

6. Trends in conveyance ratio innovations among paired reaches on the St. Clair River.

7. Effective channel roughness estimated for reaches spanning the study area of the St. Clair River in years with one or more conventional flow measurements from 1962 to 1985

8. Estimates of effective channel-roughness values for reaches spanning the study area of the St. Clair River in years with one or more acoustic Doppler current profiler flow measurements from 1996 to 2007

9. Fixed-parameter estimates of effective channel roughness for St. Clair River reaches based on measurements from 1962 to 1968.

10. Fixed-parameter estimates of effective channel roughness on reaches of St. Clair River for the period 1996-2007

11. Lower diagonal elements of the symmetric correlation matrix for fixed-parameter estimates of effective channel roughness coefficients on St. Clair River for the period 1996-2007

12. Basis vectors selected in a stepwise-regression analysis of flow residuals from the 1996 to 2007 fixed, nine-parameter model of St. Clair River

13. Relation between ratios of effective channel roughness and conveyance ratios among reaches of the St. Clair River based on data from 1996 to 2007. 


\section{Conversion Factors and Abbreviations}

\begin{tabular}{|c|c|c|}
\hline Multiply & By & To obtain \\
\hline \multicolumn{3}{|c|}{ Length } \\
\hline millimeter $(\mathrm{mm})$ & 0.03937 & inch (in.) \\
\hline meter $(\mathrm{m})$ & 3.281 & foot $(\mathrm{ft})$ \\
\hline kilometer $(\mathrm{km})$ & 0.6214 & mile (mi) \\
\hline kilometer $(\mathrm{km})$ & 0.5400 & mile, nautical (nmi) \\
\hline meter $(\mathrm{m})$ & 1.094 & yard (yd) \\
\hline \multicolumn{3}{|c|}{ Area } \\
\hline square meter $\left(\mathrm{m}^{2}\right)$ & 0.0002471 & acre \\
\hline square kilometer $\left(\mathrm{km}^{2}\right)$ & 247.1 & acre \\
\hline square meter $\left(\mathrm{m}^{2}\right)$ & 10.76 & square foot $\left(\mathrm{ft}^{2}\right)$ \\
\hline square kilometer $\left(\mathrm{km}^{2}\right)$ & 0.3861 & square mile $\left(\mathrm{mi}^{2}\right)$ \\
\hline \multicolumn{3}{|c|}{ Volume } \\
\hline liter $(\mathrm{L})$ & 0.2642 & gallon (gal) \\
\hline cubic meter $\left(\mathrm{m}^{3}\right)$ & 264.2 & gallon (gal) \\
\hline cubic meter $\left(\mathrm{m}^{3}\right)$ & 0.0002642 & million gallons (Mgal) \\
\hline cubic meter $\left(\mathrm{m}^{3}\right)$ & 35.31 & cubic foot $\left(\mathrm{ft}^{3}\right)$ \\
\hline \multicolumn{3}{|c|}{ Velocity } \\
\hline centimeters per year $(\mathrm{cm} / \mathrm{yr})$ & 2.54 & inches per year (in.yr) \\
\hline \multicolumn{3}{|c|}{ Flow rate } \\
\hline meter per second $(\mathrm{m} / \mathrm{s})$ & 3.281 & foot per second $(\mathrm{ft} / \mathrm{s})$ \\
\hline cubic meter per second $\left(\mathrm{m}^{3} / \mathrm{s}\right)$ & 35.31 & cubic foot per second $\left(\mathrm{ft}^{3} / \mathrm{s}\right)$ \\
\hline $\begin{array}{l}\text { cubic meter per second per square kilo- } \\
\text { meter }\left[\left(\mathrm{m}^{3} / \mathrm{s}\right) / \mathrm{km}^{2}\right]\end{array}$ & 91.49 & $\begin{array}{l}\text { cubic foot per second per square mile } \\
{\left[\left(\mathrm{ft}^{3} / \mathrm{s}\right) / \mathrm{mi}^{2}\right]}\end{array}$ \\
\hline liter per second $(\mathrm{L} / \mathrm{s})$ & 15.85 & gallon per minute (gal/min) \\
\hline cubic meter per second $\left(\mathrm{m}^{3} / \mathrm{s}\right)$ & 22.83 & million gallons per day (Mgal/d) \\
\hline \multicolumn{3}{|c|}{ Mass } \\
\hline gram $(\mathrm{g})$ & 0.03527 & ounce, avoirdupois (oz) \\
\hline kilogram (kg) & 2.205 & pound avoirdupois (lb) \\
\hline megagram $(\mathrm{Mg})$ & 1.102 & ton, short $(2,000 \mathrm{lb})$ \\
\hline megagram $(\mathrm{Mg})$ & 0.9842 & ton, long $(2,240 \mathrm{lb})$ \\
\hline \multicolumn{3}{|c|}{ Density } \\
\hline kilogram per cubic meter $\left(\mathrm{kg} / \mathrm{m}^{3}\right)$ & 0.06242 & pound per cubic foot $\left(\mathrm{lb} / \mathrm{ft}^{3}\right)$ \\
\hline gram per cubic centimeter $\left(\mathrm{g} / \mathrm{cm}^{3}\right)$ & 62.4220 & pound per cubic foot $\left(\mathrm{lb} / \mathrm{ft}^{3}\right)$ \\
\hline
\end{tabular}


Temperature in degrees Celsius $\left({ }^{\circ} \mathrm{C}\right)$ may be converted to degrees Fahrenheit $\left({ }^{\circ} \mathrm{F}\right)$ as follows: ${ }^{\circ} \mathrm{F}=\left(1.8 x^{\circ} \mathrm{C}\right)+32$

Temperature in degrees Fahrenheit $\left({ }^{\circ} \mathrm{F}\right)$ may be converted to degrees Celsius $\left({ }^{\circ} \mathrm{C}\right)$ as follows: ${ }^{\circ} \mathrm{C}=\left({ }^{\circ} \mathrm{F}-32\right) / 1.8$

Vertical coordinate information is referenced to the International Great Lakes Datum of 1985 (IGLD 85).

Horizontal coordinate information is referenced to the Michigan South (zone 2113) State Plane Coordinate System of 1983 (SPCS 83).

Altitude, as used in this report, refers to distance above the vertical datum.

\section{Abbreviations}

$\begin{array}{ll}\text { 1-D } & \text { one-dimensional } \\ \text { ADCP } & \text { acoustic Doppler current profilers } \\ \text { CHS } & \text { Canadian Hydrographic Service } \\ \text { GLERL } & \text { Great Lakes Environmental Research Laboratory } \\ \text { GPS } & \text { global positioning system } \\ \text { HEC-RAS } & \text { Hydrologic Engineering Center's River Analysis System } \\ \text { IGLD85 } & \text { International Great Lakes Datum of 1985 } \\ \text { IJC } & \text { International Joint Commission } \\ \text { IUGLS } & \text { International Upper Great Lakes Study } \\ \text { NOAA } & \text { National Oceanic and Atmospheric Administration } \\ \text { SPCS } & \text { State Plane Coordinate System } \\ \text { UCODE } & \text { universal parameter estimate code } \\ \text { USACE } & \text { U.S. Army Corps of Engineers } \\ \text { USGS } & \text { U.S. Geological Survey }\end{array}$





\title{
Detection of Conveyance Changes in St. Clair River Using Historical Water-Level and Flow Data with Inverse One-Dimensional Hydrodynamic Modeling
}

\author{
By David J. Holtschlag and C.J. Hoard
}

\section{Abstract}

St. Clair River is a connecting channel that transports water from Lake Huron to the St. Clair River Delta and Lake St. Clair. A negative trend has been detected in differences between water levels on Lake Huron and Lake St. Clair. This trend may indicate a combination of flow and conveyance changes within St. Clair River. To identify where conveyance change may be taking place, eight water-level gaging stations along St. Clair River were selected to delimit seven reaches. Positive trends in water-level fall were detected in two reaches, and negative trends were detected in two other reaches. The presence of both positive and negative trends in water-level fall indicates that changes in conveyance are likely occurring among some reaches because all reaches transmit essentially the same flow. Annual water-level fall in reaches and reach lengths was used to compute conveyance ratios for all pairs of reaches by use of water-level data from 1962 to 2007. Positive and negative trends in conveyance ratios indicate that relative conveyance is changing among some reaches. Inverse one-dimensional (1-D) hydrodynamic modeling was used to estimate a partial annual series of effective channel-roughness parameters in reaches forming the St. Clair River for 21 years when flow measurements were sufficient to support parameter estimation. Monotonic, persistent but non-monotonic, and irregular changes in estimated effective channel roughness with time were interpreted as systematic changes in conveyances in five reaches. Time-varying parameter estimates were used to simulate flow throughout the St. Clair River and compute changes in conveyance with time. Based on the partial annual series of parameters, conveyance in the St. Clair River increased about 10 percent from 1962 to 2002. Conveyance decreased, however, about 4.1 percent from 2003 to 2007 , so that conveyance was about 5.9 percent higher in 2007 than in 1962.

\section{Introduction}

In February 2007, the International Joint Commission (IJC), a binational organization whose main purpose is to prevent and resolve disputes between Canada and the United States concerning trans-boundary water-quality and -quantity issues, initiated an International Upper Great Lakes Study (IUGLS). The purposes of the study were to (1) determine whether the regulation of Lake Superior outflows could be improved to address the evolving needs of the upper Great Lakes, and (2) investigate whether physical changes in the St. Clair River have occurred and are causing the difference between Lake Huron and Lake St. Clair water levels to decrease. The upper Great Lakes include lakes Superior, Michigan, Huron, and Erie, and the interconnecting channels of St. Marys River, St. Clair River, Lake St. Clair, Detroit River, and Niagara River. The study component described in this report addresses the second purpose of the study and uses historical water-level and flow ${ }^{1}$ data with inverse one-dimensional hydrodynamic modeling of the St. Clair River to infer possible temporal and spatial changes in conveyance characteristics.

\section{Study Area}

St. Clair River forms part of the international border between the United States and Canada in southeastern Michigan and southern Ontario (fig. 1). As a connecting channel on the Great Lakes Waterway, St. Clair River receives water from Lake Huron and discharges water to Lake St. Clair. Near the outlet of Lake Huron, St. Clair River has a drainage area of $583,000 \mathrm{~km}^{2}$. Between Lake Huron and Lake St. Clair, the St. Clair River flows generally from north to south a distance of about $64 \mathrm{~km}$; water-surface elevations along the St. Clair

\footnotetext{
${ }^{1}$ Flow is used synonymously with the term discharge or streamflow.
} 
$82^{\circ} 45^{\prime}$

$82^{\circ} 20^{\prime}$

\section{EXPLANATION}

$\Delta$ WATER-LEVEL GAGING STATION

CS-210 FLOW-MEASUREMENT CROSS SECTION AND NUMBER

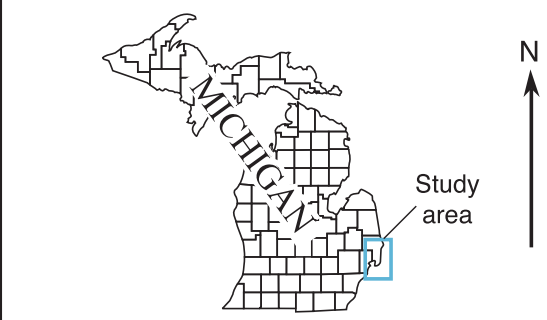

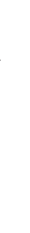

Fort Gratiot gage

\section{LAKE HURON}

Dunn Paper gage Arnia

CS-202 4 Point Edward

Black River 1 Point Edward gage

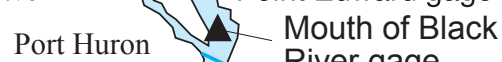

Dry Dock gage

Marysville
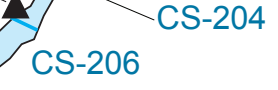

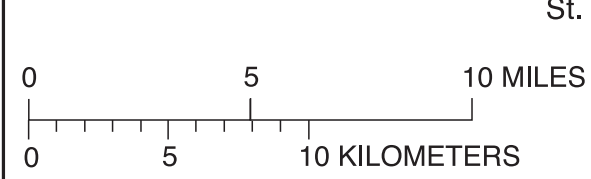

St. Clair State Police gage

CS-212

MICHIGAN

点
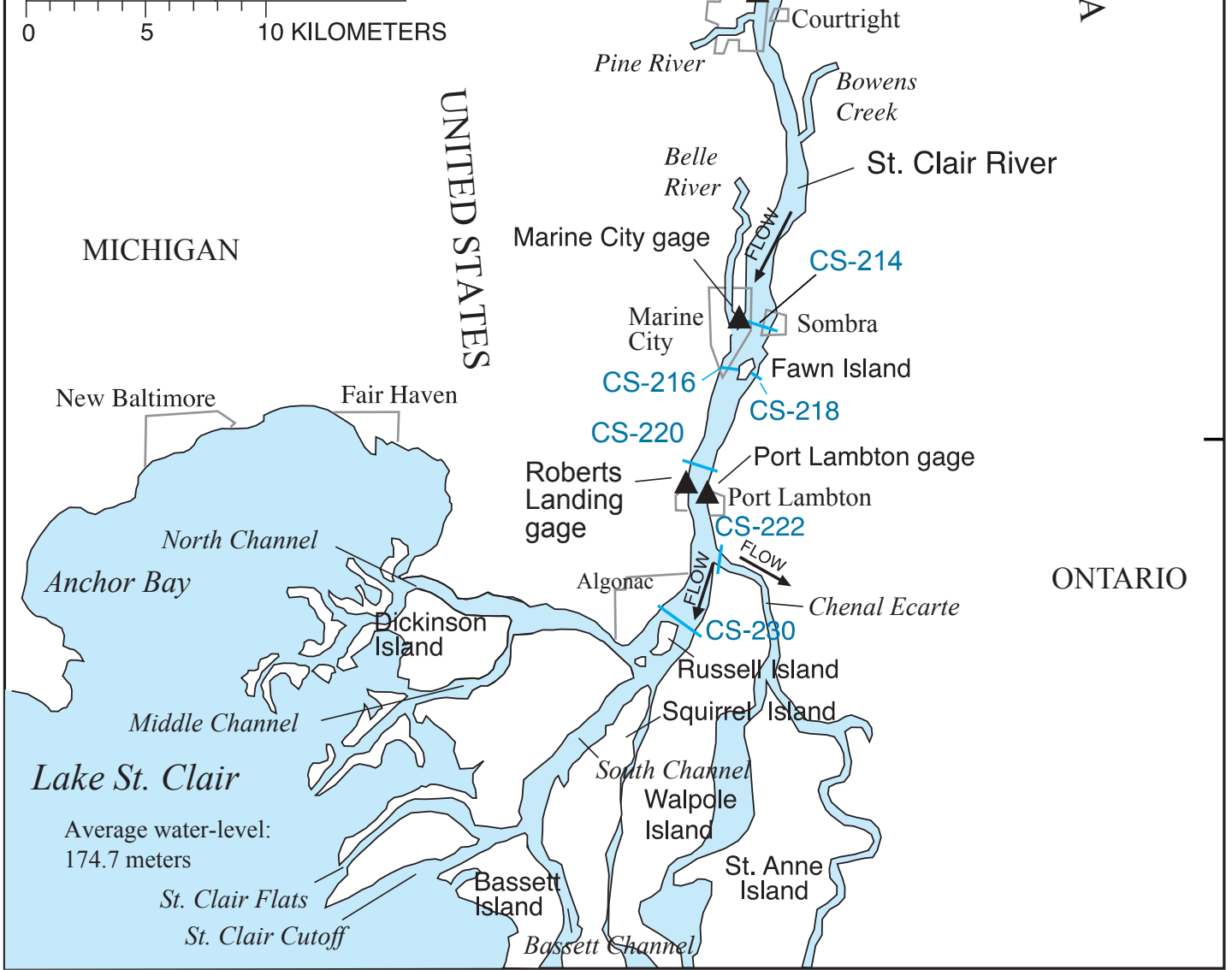

Base from National Oceanic and Atmospheric Administration, 1999. Lake elevations are shown in meters.

Figure 1. St. Clair River study area in southeastern Michigan and southern Ontario, Canada. 
River fall about $1.5 \mathrm{~m}$. The St. Clair River has an average flow of $5,150 \mathrm{~m}^{3} / \mathrm{s}$ and an average water yield of $28.2 \mathrm{~cm} / \mathrm{yr}$ from the contributing basin.

Minor tributaries contributing flow to the St. Clair River include Black River, Pine River, and Belle River. Streamflow records at the U.S. Geological Survey (USGS) gaging station (04160075) Black River near Port Huron, Mich., which is about $16 \mathrm{~km}$ upstream from the mouth of Black River at the confluence with St. Clair River, indicate an average flow of $8.2 \mathrm{~m}^{3} / \mathrm{s}$ when the station was operated continuously from 1932-43. The drainage area at the Black River gaging station is about $1,620 \mathrm{~km}^{2}$. Streamflow records at the USGS gaging station (04160398) Pine River near Marysville, Mich., which is about $13 \mathrm{~km}$ upstream from the mouth of the Pine River, indicate an average flow of $4.7 \mathrm{~m}^{3} / \mathrm{s}$ during water year 2005 , the only year of continuous record. The drainage area at the Pine River gaging station is $440 \mathrm{~km}^{2}$. Streamflow records at the USGS gaging station (04160625) Belle River near Marine City, Mich., indicate an average flow of $5.2 \mathrm{~m}^{3} / \mathrm{s}$ in 2005, the only year of continuous record data. The drainage area at the Belle River gaging station, which is about $10 \mathrm{~km}$ upstream from the mouth of the Belle River, is $552 \mathrm{~km}^{2}$. Flows from all tributaries along the St. Clair River are thought to contribute less than 1 percent of the total flow of St. Clair River. Chenal Ecarte is the most upstream distributary of the St. Clair River Delta near the mouth of the St. Clair River. Chenal Ecarte delivers about 3.8 percent of the flow from the St. Clair River through the Walpole Island First Nation Reserve to Lake St. Clair (Holtschlag and Koschik, 2001).

St. Clair River is part of the navigational waterway on the upper Great Lakes. Dredging the navigational channel from minimum depths of 7.6 to $8.2 \mathrm{~m}$ in 1962 increased the conveyance in some reaches of the St. Clair River by increasing the cross-sectional area for flow. Quinn (1985) discusses the effects of St. Clair River dredging on lake levels and flows.

\section{Problem}

Lakes Michigan and Huron (Michigan-Huron) are connected by the deep Straits of Mackinac and are considered to be one lake hydraulically with lake levels rising and falling together (U.S. Army Corps of Engineers and Great Lakes Commission, 1999). In 2007, monthly water levels on Lake Michigan-Huron averaged $0.5-\mathrm{m}$ lower than average levels during 1918-2007 (fig. 2) (U.S. Army Corps of EngineersDetroit District, 2008). Low water levels and locally shallow depths reduce the effective cargo capacity of freighters, and increase the hazards of running aground for recreational boaters. During 1918-2007 on Lake Michigan-Huron, minimum water levels during the selected period occurred in 1964-65; maximum water-levels occurred in 1986-87. Hitt and Miller (1986) discuss effects of high water levels.

Lake-wide average monthly water-level data from 1962 to 2007 were retrieved for Lakes Michigan-Huron and Lake St. Clair (U.S. Army Corps of Engineers-Detroit District, 2006). No trends were detected $\left({ }^{2} \alpha=0.05\right)$ in monthly water levels for Lake Michigan-Huron or Lake St. Clair based on the non-parametric Kendall's tau test for trend (Gilbert, 1987).

${ }^{2}$ The Greek letter $\alpha$ indicates the pre-specified probability of rejecting the null hypothesis, known as type I error, when it is true.

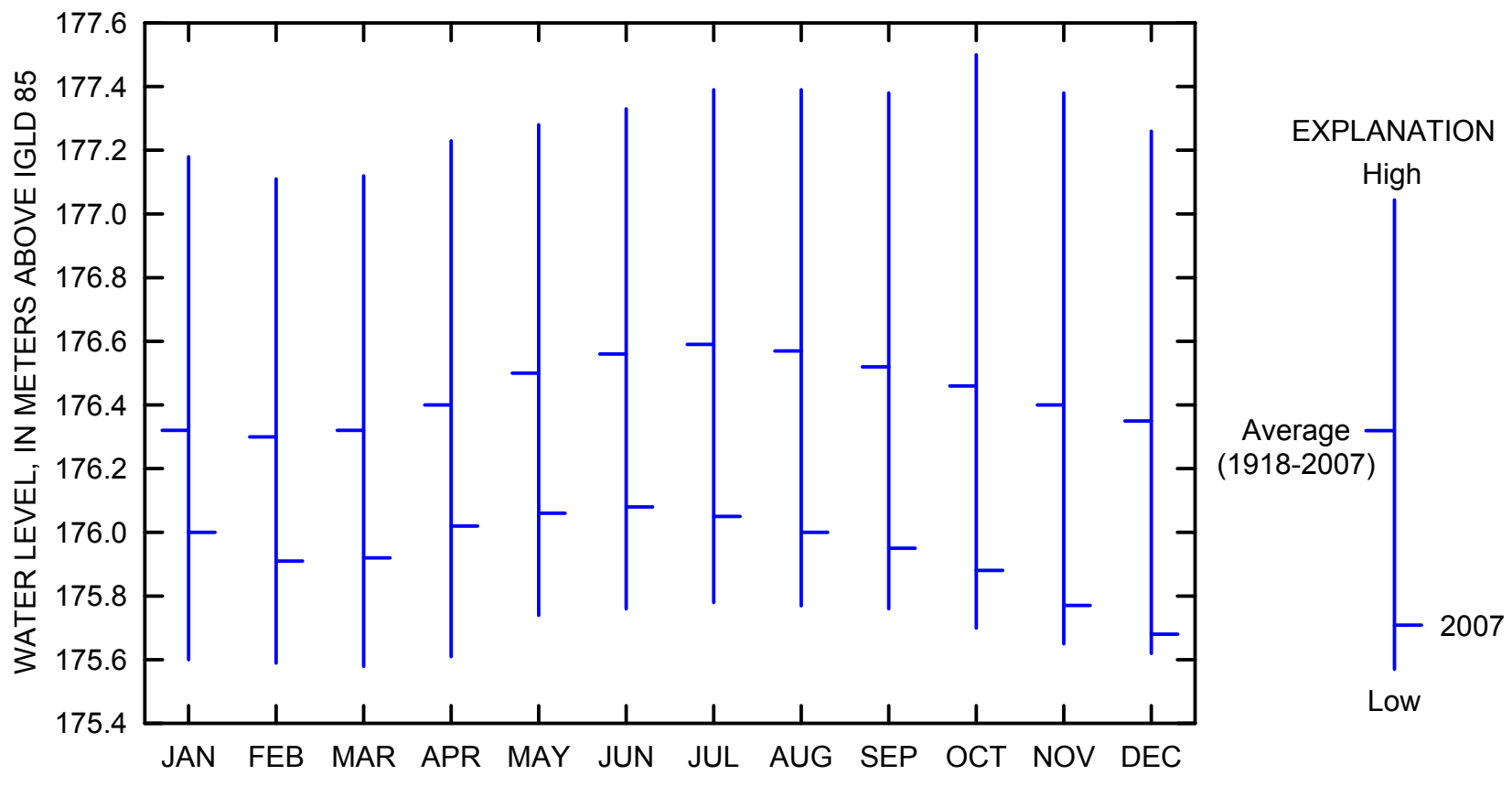

Figure 2. Monthly historical water-level characteristics for 1918-2007 and 2007 water levels on Lake Michigan-Huron. 
Trends were detected, however, in water-level differences between Lake Michigan-Huron and Lake St. Clair (fig. 3). These trends indicate that decreases in average flow or increases in conveyance, or both, may be occurring. Such trends may indicate that lake levels may change in the future. Using Sen's non-parametric slope estimator (Gilbert, 1987), the annual average of monthly water-level differences changed ( $p$-value $<0.0001)$ at an average rate of $-6.17 \mathrm{~mm} / \mathrm{yr}$ for the period 1962 to 2007. Similarly, significant decreases ( $p$-value $<0.0001$ ) also were detected in all months individually. A decrease in water-level differences between Lake MichiganHuron and Lake St. Clair indicates that the conveyance of St. Clair River is increasing if the flow rate is constant, or that that the outflow rate from Lake Michigan-Huron to Lake St. Clair is decreasing if the conveyance in St. Clair River is constant. There is insufficient information currently (2009) available on historical changes in conveyance or flow characteristics of St. Clair River to describe the possible contribution that changes in conveyance or changes in flow may be having on these water-level differences.

\section{Purpose and Scope}

The purpose of this report is to ascertain possible conveyance changes in St. Clair River between Fort Gratiot and Algonac, Michigan, from 1962 to 2007 by use of hydraulic information. Interpretations are based on (1) analysis of reach conveyance investigated by use of water-level measurements at eight gaging stations on St. Clair River, (2) analysis of reach conveyance described by inverse modeling of flows and water levels with a 1-D fixed-geometry hydrodynamic model, and (3) analysis of river conveyance investigated by flow simulations using water-level boundary conditions from 1962 to 2007 and annual parameterizations based on inverse modeling results.

Channel-roughness characteristics, which cannot be measured directly in the field, are only one component affecting conveyance that also includes channel cross-sectional area and hydraulic radius. Historical measurements of bathymetry and shoreline conditions, however, are not sufficient to fully characterize changes in cross-sectional area or hydraulic radius

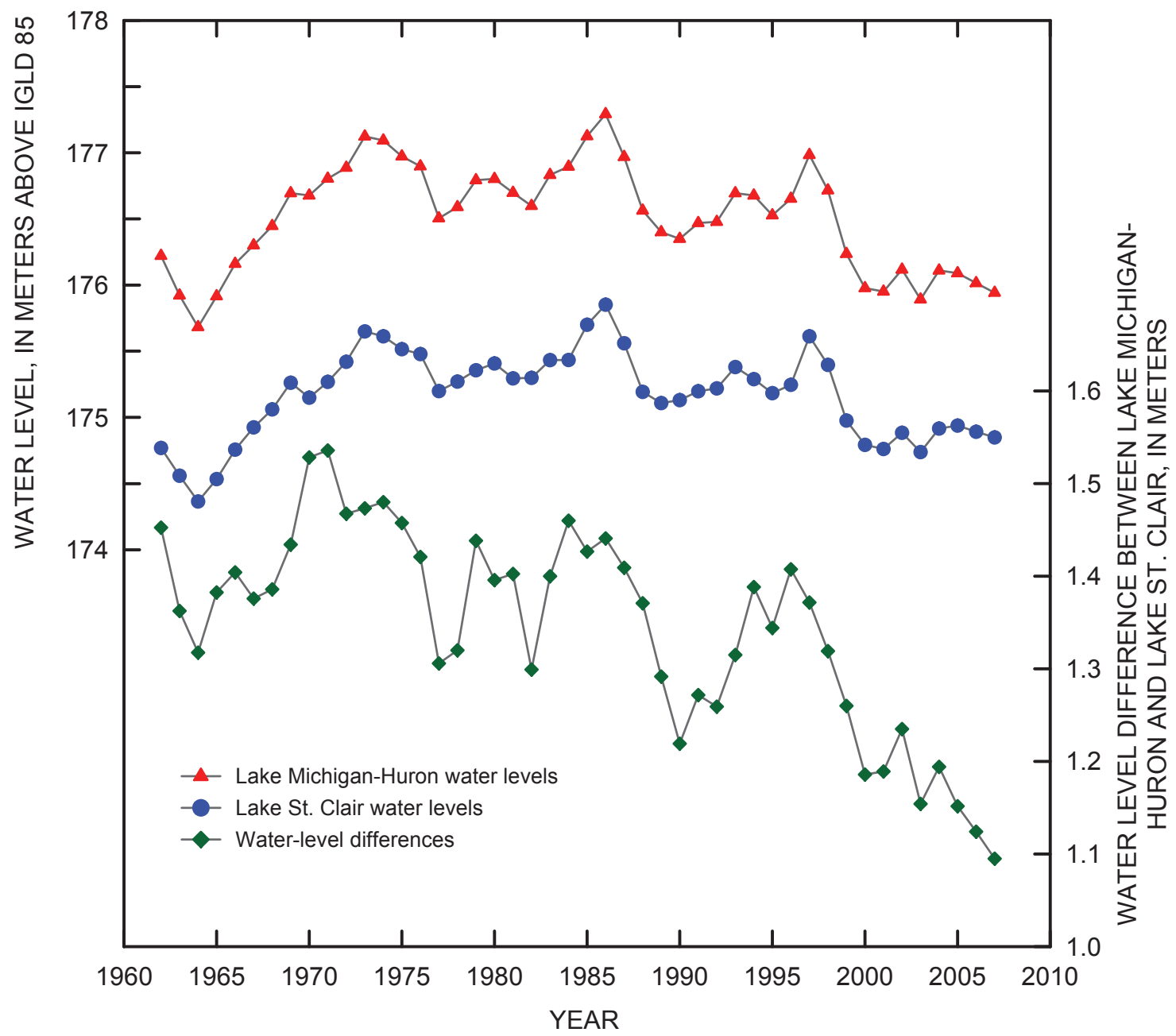

Figure 3. Water levels and water-level differences between Lake Michigan-Huron and Lake St. Clair from 1962 to 2007. 
during the study period. Therefore, any systematic changes in estimated conveyances are associated with the combined effects of changes in channel-roughness characteristics, cross-sectional area, and hydraulic radius. Although nominally attributed to channel roughness, the methods used in this study do not provide a basis for identifying which component or components affecting conveyance may be changing with time or location. In this report, the term 'effective channel roughness' refers to the combined effect of physical channelroughness characteristics, changes in cross-sectional area, and wetted perimeter from those described based on a bathymetry survey in 2007. Effective channel roughness is expressed in units of Manning's " $n$."

This study was part of an integrated, multi-agency analysis of water levels and flows on the St. Clair River. In particular, the water-level and flow data were compiled and adjusted, as needed, by Nanette Noorbakhsh of the U.S. Army Corps of Engineer-Detroit District, Michigan. The data and models developed by other agencies were used without modification, except as indicated.

\section{Data and Models Provided by Other Agencies}

A brief description of the flow and water-level data compiled, and the hydrodynamic model initially developed by other agencies is provided in the following paragraphs.

\section{Flow Data}

The U.S. Army Corps of Engineers (USACE) has measured flow on the St. Clair River since 1856 (Coordinating Committee for Great Lakes Basic Hydraulic and Hydrologic Data, 1994). In Canada, Environment Canada also measures flow on the St. Clair River. Other U.S. Federal agencies, including the Great Lakes Environmental Research Laboratory (GLERL), and the USGS have occasionally contributed limited or experimental flow measurements to verify the accuracy of USACE measurements or for special studies. Consistent with the study area, only St. Clair River flow measurements from cross sections between water-level gaging stations at Fort Gratiot, and Algonac, Mich., were used.

Flow measurements on the St. Clair River are only obtained during the ice-free season owing to special hazards associated with ice conditions. During the study period from 1962 to 2007, the earliest measurement in the year was obtained on April 26, and the latest measurement was obtained on December 5. Flow data were used to estimate the effective channel roughness by inverse hydrodynamic modeling. Flow measurements prior to 1995 generally were made with conventional current meters (Rantz and others, 1982), even though several moving-boat measurements are included. For ease of reference, all measurements prior to 1995 are referred to and included with the conventional measurements. After 1995, all measurements used in this study were made with acoustic Doppler current profilers (Simpson, 2001).

\section{Conventional Current-Meter Measurements}

Before 1995, flow measurements generally were made by use of the conventional current-meter method adapted for use on wide rivers (Rantz and others, 1982), although eight moving-boat measurements (Rantz and others, 1982) were made by the Water Survey of Canada (Environment Canada) in 1981. Applying current-meter methods involves subdividing a river cross section into a set of non-overlapping areas containing nearly equal amounts of flow. Within each area, horizontal velocities are profiled with depth to compute a weighted average that represents the depth-averaged horizontal velocity. Maintaining a stationary position long enough to measure an ensemble of horizontal velocities in deep, fast-moving water is complicated by the frequent need to yield to commercial shipping vessels.

Flow is computed by integrating the average velocity with depth across the flow-measurement section. Measurement of flow by use of conventional current meters is difficult on St. Clair River because flow varies over short periods of time in response to continuous changes in wind, water-level, and wave conditions. Boat crews deploying current meters were supported by on-shore surveying crews to determine the locations of velocity profiles. From 1962 to 1985, 351 conventional flow measurements are documented on St. Clair River. All documented conventional current-meter measurements occurred on the main stem of St. Clair River; no conventional measurements were available to describe flow partitioning around Stag or Fawn Islands.

\section{Acoustic Doppler Current Profiler Measurements}

After 1995, acoustic Doppler current profilers (ADCPs) generally have been used to measure flow on the St. Clair River (John A. Koschik, U.S. Army Corps of EngineersDetroit District, oral commun., 2001). ADCP uses sound to measure water velocity and channel-bottom depths. Positional information needed to complete the determination of crosssectional area corresponding to the velocity data generally are provided by a global positioning system (GPS) receiver, which is integrated with the ADCP unit. On the St. Clair River, the ADCP generally is attached to a boat that transects the selected measurement cross section. Measured flows are computed using the results from four or more transects of data in which similar flows are measured. ADCP provides more rapid measurements of flow than conventional current meters on the St. Clair River and can be obtained with a single boat crew.

From 1996 to 2007, 353 ADCP measurements were made on the St. Clair River within the study area. Although most measurements are on the main stem of the river, paired measurement sections CS-208 and CS-210 (fig. 1) at Stag Island and paired measurement sections CS-216 and CS-218 at Fawn Island provide a basis for determining the partitioning of flows around the islands. 


\section{Water-Level Data}

Water levels on the St. Clair River are monitored continually through a network of water-level gaging stations operated by the National Oceanic and Atmospheric Administration (NOAA) and the Canadian Hydrographic Service (CHS, a division of Fisheries and Oceans Canada). Although the active gaging stations operating in this network have changed with time, eight gaging stations were selected that were operated throughout the study period. Selected stations (table 1) have been operated continuously from 1962 to 2007 (except for periods of missing record) and currently (2009) can provide water-level data at hourly or smaller time intervals in near real time through publicly accessible Internet sites. Water levels at all selected gaging stations are referenced to the International Great Lakes Datum of 1985 (IGLD85). Water-level data were used to investigate water-level fall between gages as indicators of conveyance change and provided boundary-condition information for model simulation and calibration data for estimation of effective channel roughness.

\section{The Standard 1-D Hydrodynamic Model of the St. Clair River}

In this report, the geometry and initial parameterization of the one-dimensional (1-D) hydrodynamic model provided by Jason P. Giovannettone (U.S. Army Corps of Engineers, Hydrologic Engineering Center, Davis, Calif., written commun., 2008) is referred to as the standard model of the St. Clair River. The standard model is based on the generic hydraulic code HEC-RAS (Hydrologic Engineering Center's River Analysis System) developed by the USACE (Brunner, 2008). A brief description of the standard model follows.

\section{Model Schematization}

The standard hydraulic model of the St. Clair River schematic defines seven channels and four junctions within the study reach from Fort Gratiot to Algonac, Mich. (fig. 4). Five channels are used to represent flow along the main stem, and two channels represent bifurcated flow around Stag and Fawn Islands. The four junctions provide a mechanism to rejoin flows and match water levels upstream and downstream from the two islands. Three-hundred and sixty-one cross sections represent the geometry of the St. Clair River within the study reach.

The most upstream channel is referred to as Main Ch-1, which extends $13.1 \mathrm{~km}$ from the outlet of Lake Huron at the NOAA water-level gaging station (9014098) at Fort Gratiot, Mich., downstream to the first junction, which is north of Stag Island. Flow from Black River is added to the outflow from Lake Huron to represent the total flow of St. Clair River. Hourly water-level data from the Fort Gratiot gaging station provide the upstream boundary for model simulations.

Flow splits at the junction around Stag Island into two channels: the western Main Ch-2, which is 5.2-km long, and the eastern Stag Island $\mathrm{Ch}$, which is $5.0-\mathrm{km}$ long. These two

Table 1. Selected water-level gaging stations along the St. Clair River.

[SPCS, State Plane Coordinate System; IGLD85, International Great Lakes Datum of 1985; NOAA, U.S. National Oceanic and Atmospheric Administration]

\begin{tabular}{|c|c|c|c|c|c|c|c|}
\hline \multirow{2}{*}{$\begin{array}{c}\text { Agency } \\
\text { operating the } \\
\text { gaging station }\end{array}$} & \multirow{2}{*}{$\begin{array}{l}\text { Gaging } \\
\text { station } \\
\text { number }\end{array}$} & \multirow{2}{*}{$\begin{array}{l}\text { Gaging station } \\
\text { name assigned } \\
\text { by operating } \\
\text { agency }\end{array}$} & \multirow{2}{*}{$\begin{array}{c}\text { State } \\
\text { or province } \\
\text { where gaging } \\
\text { station is } \\
\text { operated }\end{array}$} & \multirow{2}{*}{$\begin{array}{c}\text { Gaging } \\
\text { station } \\
\text { identifier used } \\
\text { in this report }\end{array}$} & \multicolumn{2}{|c|}{$\begin{array}{l}\text { Gaging station location, in } \\
\text { Michigan SPCS (zone 2113) } \\
\text { (meters) }\end{array}$} & \multirow{2}{*}{$\begin{array}{c}\text { Low wate } \\
\text { datum } \\
\text { (meters } \\
\text { above } \\
\text { IGLD85) }\end{array}$} \\
\hline & & & & & Easting & Northing & \\
\hline $\mathrm{NOAA}^{1}$ & 9014098 & Fort Gratiot & Michigan & $F G$ & $4,158,484$ & 169,156 & 175.93 \\
\hline NOAA & 9014096 & Dunn Paper & Michigan & $D P$ & $4,158,514$ & 168,817 & 175.78 \\
\hline CHS & 11940 & Point Edward & Ontario & $P E$ & $4,158,614$ & 167,431 & 175.65 \\
\hline NOAA & 9014090 & $\begin{array}{l}\text { Mouth of } \\
\text { Black River }\end{array}$ & Michigan & $B R$ & $4,158,681$ & 165,518 & 175.63 \\
\hline NOAA & 9014087 & Dry Dock & Michigan & $D D$ & $4,156,918$ & 162,330 & 175.50 \\
\hline NOAA & 9014080 & $\begin{array}{l}\text { St. Clair } \\
\text { State Police }\end{array}$ & Michigan & $S P$ & $4,153,803$ & 147,507 & 175.08 \\
\hline CHS & 11950 & Port Lambton & Ontario & $P L$ & $4,152,459$ & 130,218 & 174.65 \\
\hline NOAA & 9014070 & Algonac & Michigan & $A L$ & $4,150,907$ & 126,148 & 174.59 \\
\hline
\end{tabular}

${ }^{1}$ After 1970, NOAA assumed operation of all water-level gaging stations on the St. Clair River. These gaging stations had been built and operated by the U.S. Lake Survey, a division of the U.S. Army Corps of Engineers. 
channels rejoin at the second junction, which is south from Stag Island. Main Ch-3 extends 16.7-km downstream from the junction at the southern end of Stag Island to a third junction, which is upstream (north) of Fawn Island. Minor flows from Pine River and Belle River are added to the flow of St. Clair River in this reach. At the junction north of Fawn Island, flow splits into a western channel, referred to as Main Ch-4, which is $3.1-\mathrm{km}$ long, and the eastern channel, referred to as Fawn Island Ch. Downstream of Fawn Island, these two channels rejoin at the fourth junction.
Main Ch-5 extends 9.2-km downstream from the southern tip of Fawn Island to the northern tip of Russell Island (Michigan), where the St. Clair River branches into the North and South Channels. About 3.8 percent of the St. Clair River outflow flows into Chenal Ecarte upstream of Russell Island (Holtschlag and Koschik, 2001). Water-level data from the NOAA gaging station (9014070) at Algonac, Mich., provide the downstream boundary for model simulations.

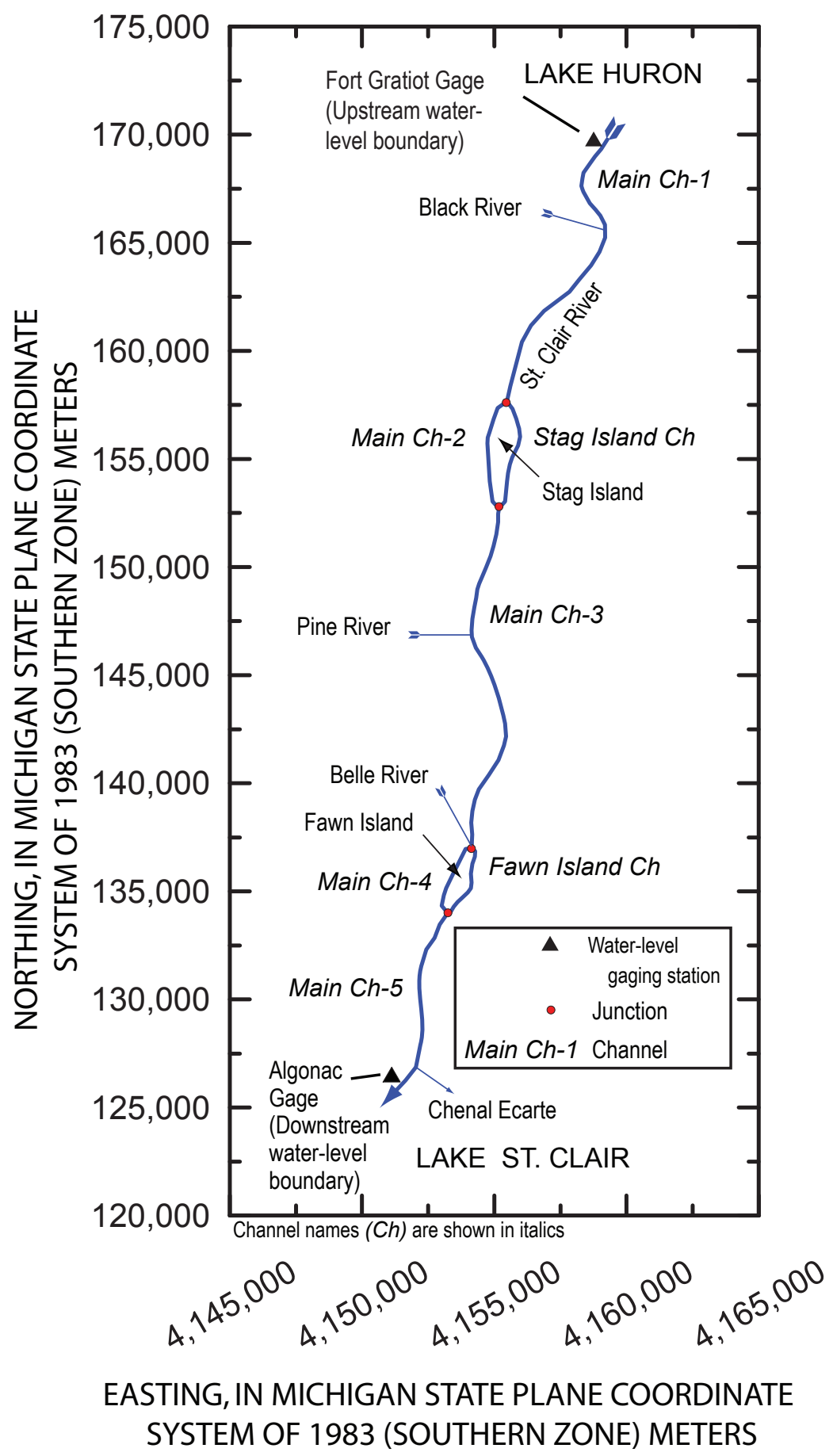

Figure 4. Schematic of the St. Clair River Hydrologic Engineering Center-River Analysis System (HEC-RAS) model showing channels and junctions defined in the standard model. 


\section{Model Geometry and Parameterization}

The geometry of the standard model is defined based on a 2007 multi-beam bathymetry survey obtained by the USACEDetroit District and interpreted by David Bennion (USGS Great Lakes Science Center, written commun., 2007). Information in the geometry tables was modified to remove areas of ineffective flow. Ineffective flow generally occurs near the shoreline where obstructions restrict flow or where channel curvature creates secondary flow patterns. Where available, identification of ineffective flow areas was guided by velocity data obtained during ADCP flow measurements.

The standard model was parameterized to account for energy losses associated with channel roughness and losses associated with expansion and contraction of flow. In the standard model, channel cross sections were assigned time-invariant channel-roughness values for left over-bank, main channel, and right over-bank areas. Given the limited range in water levels on the St. Clair River, over-bank areas tend to carry only a small percentage of the flow. In the standard model, channel-roughness values assigned to left and right over-bank areas were the same and within the study area ranged from 0.0263 to 0.0352 , with an average value of 0.0287 . Within the main channel, channel-roughness values ranged from 0.0240 to 0.030 , with an average value of 0.0258 . Contraction and expansion coefficients were 0.1 and 0.3 , respectively, for all cross sections in the study reach.

\section{Approach}

Conveyance is a measure of a stream's ability to transmit water with time and can be expressed in units of cubic meters per second. Conveyance is proportional to cross-sectional flow area and hydraulic radius of the channel (cross-sectional area divided by the wetted perimeter of the channel) and is inversely proportional to channel roughness. In general, conveyance $K$ increases monotonically with increasing water level $h$, because increases in water level increase the crosssectional area and hydraulic radius. This generally monotonically increasing functional relation can be expressed as $K(h)$. In this report, however, changes in conveyance generally refer to changes in conveyance with time $t$ that are not attributable to changes in water level. This conditional relation of conveyance with time for a given water level $K(t \mid h)$ may be constant or may contain deterministic or stochastic level or trend components, which appear monotonic or non-monotonic with time, and contain erratic (random) components. Trends may represent linear or nonlinear responses to continuous processes or discrete events that cause channel scour or fill or changes in actual channel-roughness characteristics. The generality of possible trend forms complicates the identification of trends in $K(t \mid h)$.

Changes in St. Clair River conveyance were investigated by (1) analysis of water-level data within reaches delimited at gaging stations, (2) inverse 1-D hydrodynamic modeling of flow and water levels to estimate annual reach-conveyance characteristics, and (3) simulation of flows using historical water-level boundary conditions with annual estimates of reach-conveyance characteristics. The approaches used for these investigations are described in the following paragraphs.

\section{Water Levels at Gaging Stations}

Eight water-level gaging stations delimit seven reaches along the St. Clair River (table 2). Within each reach, waterlevel differences between upstream and downstream stations describe the fall of the water level over the reach. Trends in annual water-level fall, computed for the ice-free period April 1 to November 30, were investigated to identify possible changes in conveyance and flow. Periods potentially affected by ice were not included because backwater caused by ice can increase water levels without corresponding increases in flow. Water-surface fall and reach lengths also were used to investigate relative conveyance changes among reaches.

\section{Water-Level Fall between Gages}

Conveyance is generally a monotonically increasing function of water level $K(h)$ and is characteristically related to flow. For various flow magnitudes, longitudinal water-surface profiles tend to be parallel. Thus, water-level differences between gaging stations (the fall in water levels) are more nearly constant and less sensitive to changes in flow magnitudes than water levels themselves. In this report, trends in water-level fall between gages were used as an indicator of trends in $K(t \mid h)$.

The statistical significance and magnitudes of monotonic trends in water-level fall were investigated by use of two nonparametric procedures: Kendall's tau rank correlation coefficient (Kendall's tau) and Sen's slope estimator. Kendall's tau provides a measure of the degree of correspondence between year and water-level fall. Kendall's tau $(\tau)$ is computed as:

$$
\tau=\frac{n_{c}-n_{d}}{1 / 2 \cdot n \cdot(n-1)}
$$

where

$$
\begin{gathered}
n_{c} \text { and } n_{d} \quad \begin{array}{c}
\text { are the number of concordant and discordant } \\
\text { pairs, respectively, and }
\end{array} \\
n \quad \text { is the number of observations. }
\end{gathered}
$$

A set of bivariate data pairs of length $n(n-1) / 2$ can be formed from $n$ time values $t$ and fall values $f$ indexed by $i$ and $j$ such that $1 \leq i \leq j \leq n$. Data pairs are considered concordant if $\operatorname{sgn}\left(t_{j}-t_{i}\right)=\operatorname{sgn}\left(f_{j}-f_{i}\right)$ and discordant if $\operatorname{sgn}\left(t_{j}-t_{j}\right)=-\operatorname{sgn}\left(f_{j}-f_{i}\right)$. The $s g n$ function is the sign function such that $\operatorname{sgn}(\mathrm{x})=-1$ if $x<0,0$ if $x=0$, and 1 if $x>0$. Kendall's tau can be interpreted as the probability of a random pair being concordant minus the probability of the pair being discordant. In addition to the Kendall's tau statistic, a probability ( $p$-value) is computed for the likelihood that the null hypothesis that tau is equal to zero 
Table 2. St. Clair River reaches delimited by water-level gaging stations and used for this study.

[ID, identification; $F G$, Fort Gratiot; $D P$, Dunn Paper; $P E$, Point Edward; $B R$, Black River; $D D$, Dry Dock; SP, State Police; EStag, East Stag Island; $P L$, Port Lambton; EFawn, East Fawn Island, and $A L$, Algonac]

\begin{tabular}{|c|c|c|c|c|c|}
\hline \multirow[t]{2}{*}{ Reach number } & \multirow[t]{2}{*}{ Reach ID } & \multicolumn{2}{|c|}{$\begin{array}{l}\text { Reach limits for the inverse model of } \\
\text { St. Clair River (Gaging station name abbreviations } \\
\text { used in italics where appropriate) }\end{array}$} & \multirow{2}{*}{$\begin{array}{c}\text { Channel designation(s) } \\
\text { for the standard hydraulic } \\
\text { model of } \\
\text { St. Clair River }\end{array}$} & \multirow[t]{2}{*}{$\begin{array}{l}\text { Reach length } \\
\text { (kilometers) }\end{array}$} \\
\hline & & Upstream & Downstream & & \\
\hline 1 & $F G \_D P$ & $F G$ & $D P$ & Main Ch-1 & 0.447 \\
\hline 2 & $D P \_P E$ & $D P$ & $P E$ & Main Ch-1 & 1.47 \\
\hline 3 & $P E_{-} B R$ & $P E$ & $B R$ & Main Ch-1 & 2.44 \\
\hline 4 & $B R \_D D$ & $B R$ & $D D$ & Main Ch-1 & 3.89 \\
\hline 5 & $D D \_S P$ & $D D$ & $S P$ & Main Ch-1,2,3 & 15.6 \\
\hline 5.5 & EStag & $\begin{array}{l}\text { Upstream limit } \\
\text { of Stag Island }\end{array}$ & $\begin{array}{l}\text { Downstream limit } \\
\text { of Stag Island }\end{array}$ & Stag Island Ch & 5.03 \\
\hline 6 & $S P \_P L$ & $S P$ & $P L$ & Main Ch-3,4,5 & 18.5 \\
\hline 6.5 & EFawn & $\begin{array}{l}\text { Upstream limit } \\
\text { of Fawn Island }\end{array}$ & $\begin{array}{l}\text { Downstream limit } \\
\text { of Fawn Island }\end{array}$ & Fawn Island Ch & 3.15 \\
\hline 7 & $P L \_A L$ & $P L$ & $A L$ & Main Ch-5 & 5.09 \\
\hline
\end{tabular}

given the data is true. Small $p$-values $(<0.05)$ are commonly used to reject the null hypothesis of no correlation.

Should the hypothesis of no correlation be rejected, Sen's slope estimator provides an estimate of the rate at which water-level fall is changing with time. Sen's slope estimator is the median of $n(n-1) / 2$ estimates of slope computed as $\frac{f_{j}-f_{i}}{t_{j}-t_{i}}$, again for all $1 \leq i \leq j \leq n$.

\section{Reach Conveyance}

Manning's formula (Brunner, 2008) for computing flow $(Q)$ is a function of conveyance $(K)$ and the energy slope $\left(S_{f}\right)$

$$
Q=K \cdot S_{f}^{1 / 2},
$$

where conveyance can be expressed in metric units as

$$
K=\frac{1}{n} \cdot A \cdot R^{2 / 3} .
$$

The reach-average cross-sectional area $(A)$ and hydraulic radius $(R)$ (cross-sectional area divided by the wetted perimeter) can be determined from field measurements. In contrast, effective channel roughness, which nominally describes channel roughness, can be ascertained quantitatively by inverse hydrodynamic modeling using flow and water-level data or estimated subjectively based on bed-material characteristics and channel form (Barnes, 1967, Arcement and Schneider, 1989).
Within a river reach of length $L$, the energy slope is $S_{f}=\sqrt{h_{f} / L}$. The energy head equals

$$
h_{f}=\Delta h+k \cdot\left(\alpha_{u} \cdot V_{u}^{2} / 2 g-\alpha_{d} \cdot V_{d}^{2} / 2 g\right),
$$

where

$\Delta h \quad$ is the water-surface fall or the increase in water level from the downstream $(d)$ limit of the reach to the upstream $(u)$ limit;

$k \quad$ is coefficient of contraction or expansion for gradual transitions, generally taken as 0.1 and 0.3 , respectively (Brunner, 2008);

$\alpha_{u}$ and $\alpha_{d}$ are velocity weighting coefficients, which vary with the velocity distribution in a reach; $V_{u}$ and $V_{d} \quad$ are the average velocities at the upstream and downstream reach limits, respectively; and

$g \quad$ is the constant of gravitational acceleration $\left(9.806 \mathrm{~m}^{2} / \mathrm{s}\right)$.

In reaches with steady uniform flow, the energy slope equals the change in water level divided by the reach length as $S_{f}=S=\Delta h / L$. Although flow in the St. Clair River is not strictly uniform, the small bias introduced by assuming that the second term on the right-hand side of equation 4 is negligible would not significantly affect trend analyses, which are of primary interest in this study component.

To identify local changes in the conditional conveyance $K(t \mid h)$, the St. Clair River was subdivided into seven reaches at gaging stations between Fort Gratiot and Algonac, Mich. (table 2). In additional, two reaches around the east sides of 
Stag and Fawn Islands were included to describe the partitioning of flows measured around the islands with ADCP after 1995.

\section{Conveyance Ratios}

Within the St. Clair River, inflows and outflows from intervening tributaries and distributaries generally constitute a small percentage of the total flow of the river. Over extended periods of time, the unsteadiness of flow has little effect on the average flow, so that, for the $i^{\text {th }}$ April 1 to November 30 period, the average flow in all reaches $j$ are approximately equal $Q_{i, j}$ $\simeq \bar{Q}_{i}$. By further assuming that the change in average velocities between reaches is small (thus that the second term on the right-hand side of equation 4 is negligible) with respect to the change in water-surface elevation over the reach, equation 2 can be applied to pairs of reaches and solved for flow to compute conveyance ratios as:

$$
\frac{K_{i, j \in\{1,2, \cdots 6\}<j^{\prime}}}{K_{i, j^{\prime} \in\{j \cap 2,3, \cdots 7\}}} \simeq \sqrt{\frac{\Delta h_{i, j^{\prime}} / L_{j^{\prime}}}{\Delta h_{i, j} / L_{j}}}, i=\{1962,1963, \ldots 2007\}
$$

A time series of conveyance ratios provides an indication of the relative change in conveyance among reaches based on direct measurements of water level over time. Monotonic trends in the annual series of conveyance ratios with time were evaluated based on the statistical significance of Kendall's tau rank correlation coefficient (Conover, 1980). Where significant, the linear relation between conveyance ratios and time was estimated by use of Sen's nonparametric estimator of slope $\hat{\beta}_{\text {Sen }_{1}}$ (Gilbert, 1987). The slope was fitted through the point defined by the median conveyance ratio and median time to define the intercept $\left(\hat{\beta}_{\text {Sen }_{0}}\right)$.

The annual series of conveyance ratios $K_{, j} / K_{, j}$ may depend on estimates of average flow magnitudes in each year. Estimates of average flow magnitudes $\left(\hat{\bar{Q}}_{i, .}\right)$ for April through November were computed by use of monthly flows for the St. Clair River (Croley and Hunter, [2006]), which were developed by the Coordinating Committee for Great Lakes Basic Hydraulic and Hydrologic Data (Coordinating Committee). The statistical significance of Kendall's tau correlation coefficient between conveyance ratios and annual-flow estimates was used to identify flow dependency. Where significant, a conditional estimate of conveyance ratios on flows was computed as:

$$
\begin{gathered}
\frac{K_{i, j \in\{1,2, \cdots 6\}<j^{\prime}}}{K_{i, j^{\prime}=\in\{j \cap 2,3, \cdots 7\}}} \mid \hat{Q}_{1}=\hat{\beta}_{\operatorname{Sen}_{0}\left(j, j^{\prime}\right)}+\hat{\beta}_{\operatorname{Sen}_{1}\left(j, j^{\prime}\right)} \cdot i+\varepsilon_{i}\left(j, j^{\prime}\right), \\
i=\{1962,1963, \ldots 2006\} .
\end{gathered}
$$

Otherwise, the conditional estimate of the conveyance ratio was the median conveyance ratio of the time series.
Innovations of the conveyance series were computed as the differences between the computed conveyance ratios and conditional conveyance ratios (equation 7). Innovations series were used to investigate the sensitivity of interpretations of changes in conveyance based on the conveyance ratios to estimates of the annual variations in flow.

$$
\begin{gathered}
\frac{\tilde{K}_{i, j \in\{1,2, \cdots 6\}<j^{\prime}}}{\tilde{K}_{i, j^{\prime}=\in\{j \cap 2,3, \cdots 7\}}}=\frac{K_{i, j \in\{1,2, \cdots 6\}<j^{\prime}}}{K_{i, j^{\prime}=\in\{j \cap 2,3 \cdots 7\}}}-\frac{K_{i, j \in\{1,2, \cdots 6\}<j^{\prime}}}{K_{i, j^{\prime}=\in\{j \cap 2,3 \cdots 7\}}} \mid \hat{Q}_{i}(7) \\
i=\{1962,1963, \ldots 2006\}
\end{gathered}
$$

\section{Inverse 1-D Hydrodynamic Modeling of the St. Clair River}

Inverse modeling applies statistical techniques to estimate parameters of physically based models from sets of measurements. In this report, the physically based model is the HECRAS 1-D flow model of the St. Clair River. Water levels at the six intervening gaging stations and flow-measurement data are used to estimate model parameters that varied annually and parameters that were fixed over discrete intervals. Model parameters are values of the effective channel roughness within the main channel of reaches delimited by water-level gaging stations along the river. In this report, channel roughness is adjusted to improve the match among simulated and measured water levels and flows.

Both water-level and flow data are needed to estimate unique values of effective channel roughness when water-level data are used as boundary conditions. When too few flow measurements are available, parameter estimates are highly correlated and depend on arbitrary, initial parameter values. This dependency is not a result of the inverse modeling approach, but is revealed in the output statistics. Highly correlated estimates of effective roughness parameters cannot reliably be used to infer reach conveyance. Although water-level data are generally available throughout the 46-year period of study from 1962-2007, one or more flow measurements are only available in 24 of these years. The availability of flow measurements necessarily limits the estimation of annual conveyance characteristics to these 24 years.

\section{1-D Hydrodynamic Model of the St. Clair River}

Unsteady flow and water levels were simulated for selected years during periods from April 1 to November 30 by use of the standard version of the HEC-RAS model of the St. Clair River. Hourly water-level data from the Fort Gratiot and Algonac, Michigan, gaging stations were used as boundary conditions. Assigned channel-roughness values in the main channel of the standard version were replaced with effective channel-roughness parameters estimated by inverse modeling techniques. Channel-roughness values in over-bank areas, and contraction and expansion energy-loss coefficients (specified 
in the standard model of 0.1 and 0.3 , respectively), were used without modification. Flow augmentations for tributaries and diversions for distributaries described in the standard model were used.

\section{Inverse Modeling}

In this report, inverse modeling applied a nonlinearregression technique referred to as universal parameter estimate code (UCODE) (Poeter and others, 2005) to iteratively modify parameters representing the effective channel roughness for selected reaches in a 1-D hydrodynamic model of the St. Clair River. The objective of the inverse modeling analysis was to minimize the sum of squared weighted residuals (differences) between simulated and measured water levels and flows. The iterative process was terminated when the parameter-estimation process converged or the specified number of maximum parameter iterations was exceeded. To assess whether parameters converged uniquely, two sets of starting values were used to initialize the parameter-estimation process, and converged pairs of estimates were compared. Annual-varying parameters were estimated to identify trends in the effective channel-roughness values that are needed to account for systematic differences between measured and simulated water levels and flows. A brief overview of inverse modeling is provided to aid in understanding the interpretations presented in this report.

\section{Nonlinear Regression}

Nonlinear regression provides a generally applicable method for calibrating models in which simulated values vary nonlinearly with model parameters (Hill, 1998). In this study, the objective was to minimize the sum of squared weighted residuals as

$$
S(\underline{b})=\sum_{i=1}^{N} \omega_{i}\left[y_{i}-\tilde{y}_{i}(\underline{b})\right]^{2},
$$

where

$$
\begin{aligned}
& S(\underline{b}) \quad \text { is the sum of squared weighted residuals } \\
& \text { between measured and simulated values; } \\
& \underline{b} \quad \text { is a vector of model parameters of length } p \text {; } \\
& N \text { is the number of measurements in a particular } \\
& \text { year; } \\
& y_{i} \quad \text { is the } i^{\text {th }} \text { measurement of water level or flow; } \\
& \tilde{y}_{i}(\underline{b}) \text { is the } i^{\text {th }} \text { simulated value, which is a function } \\
& \text { of the underlying model and associated } \\
& \text { parameters; and } \\
& \omega_{i} \quad \text { is the weight for the } i^{\text {th }} \text { measurement. }
\end{aligned}
$$

The difference $\left[y_{i}-\tilde{y}_{i}(b)\right]$ is referred to as a residual; the difference $\omega_{i}^{\prime \prime}\left[y_{i}-\tilde{y}_{i}(\underline{b})\right]$ is a weighted residual. Measurement weights $\omega$ provide a mechanism for expressing the uncertainty of individual measurements and for including measurements in different scales (for example, flow, in cubic meters per second and water-surface elevation, in meters) within the same objective function. In this report, the weight matrix $\Omega$ was described as a diagonal matrix with elements $\omega_{i i}$, which does not account for correlations among measurement errors.

The potential for temporal correlation in the errors of water-level residuals was reduced by comparing water-level measurements with simulated values at 8-hour sampling intervals. This 8 -hour sampling interval provided 3 measurements per day for the 244-day periods from April 1 to November 30, or 732 measurements per year at each water-level gaging station. For the 6 water-level gages used in the calibrations, this nominally provided 4,390 water-levels annually for parameter estimation. Water-level values were assigned a weight $\omega$ equal to $(1 / 0.025)^{2}$ or 1,600 , which is inversely proportional to a standard deviation of $0.025 \mathrm{~m}$ associated with water-level measurements.

In contrast, 351 conventional and $353 \mathrm{ADCP}$ flow measurements during selected years from 1962 to 2007 provided an average of 28 flow measurements per year for model calibration. Measured flows $Q m$ were assigned a weight $\omega$ that varied with flow magnitude and was equal to $\left(1 / 0.05 \cdot Q_{m}\right)^{2}$. This weight is inversely proportional to a 5 -percent coefficient of variation associated with measured flows.

\section{Parameter Convergence}

Parameter convergence is based on three criteria that control the iterative procedure in the UCODE developed by Poeter and others (2005). First, the keyword TolPar specifies the maximum fractional change in parameter values between parameter-estimation iterations required for termination. If changes in all the parameters are less than the specified TolPar of 0.015, the criterion is satisfied. Second, the keyword TolSOSC specifies the fractional decline in the SOSC, here $S(\underline{b})$, over three parameter-estimation iterations. In this report, a TolSOSC of 1 percent was used. Third, the keyword MaxIter specifies the maximum number of parameter-estimation iterations, which was set to 50. If the TolPar and TolSOSC criteria are both satisfied before the specified maximum number of parameter-estimation iterations are exceeded, the parameter estimates are considered to have converged for the specified initial values. Otherwise, parameter estimates are not considered to have converged.

To reduce the possible dependence of final parameter estimates on the arbitrary initial values, two sets of effective channel-roughness values were used to initialize the parameter-estimation process. In the first set, effective channel-roughness values for all reaches were initialized at a value of 0.015 , which is relatively low compared with the expected roughness characteristic of the channel. The corresponding parameter estimate for the $y^{\text {th }}$ year and $r^{\text {th }}$ reach resulting from this starting value is symbolized $\hat{n}_{y, r, 0.015}$. In the second set, effective channel-roughness values were initialized at a relatively high value of 0.040 . Similarly, the corresponding parameter estimate resulting from this starting value is symbolized $\hat{n}_{y, 0.0040}$. Percent relative differences $(P R D)$ were computed for 
each year $y$ and each reach $r$ for which parameter estimation converged as

$$
\begin{gathered}
\operatorname{PRD}\left(\hat{n}_{y, r 0.040}, \hat{n}_{y, r, 0.015}\right)= \\
\left|\hat{n}_{y, r, 0.040}-\hat{n}_{y, r, 0.015}\right| \mid \max \left(\left|\hat{n}_{y, r, 0.040}\right|,\left|\hat{n}_{y, r, 0.015}\right|\right) \cdot 100 .
\end{gathered}
$$

If the $P R D$ between converged parameter estimates were less than 3 percent for all reaches, parameters were considered to have converged uniquely for that year. If the $P R D$ for only one reach exceeded 3 percent, parameters were considered to have converged uniquely for the year except for the identified reach. If the $P R D$ exceeded 3 percent for more than one reach, parameters were not considered uniquely converged for that year.

Minimum variance estimates of the effective channelroughness parameters were computed as

$$
\hat{n}_{y, r}=\frac{\frac{\hat{n}_{y, r, 0.015}}{\operatorname{var}\left(\hat{n}_{y, r, 0.015}\right)}+\frac{\hat{n}_{y, r, 0.040}}{\operatorname{var}\left(\hat{n}_{y, r, 0.040}\right)}}{\frac{1}{\operatorname{var}\left(\hat{n}_{y, r, 0.015}\right)}+\frac{1}{\operatorname{var}\left(\hat{n}_{y, r, 0.040}\right)}}
$$

where

$$
\begin{gathered}
\operatorname{var}\left(\hat{n}_{y, r .}\right) \quad \begin{array}{l}
\text { is the estimated variance of the corresponding } \\
\text { parameter. }
\end{array}
\end{gathered}
$$

\section{Parameter Magnitudes and Uncertainties}

For years of data in which parameters converged, several overall statistical measures of fit were computed. In particular, the estimated error variance is computed as

$$
s^{2}=S\left(\underline{b}_{f}\right) /(N-p),
$$

where

$$
\begin{aligned}
& S\left(\underline{b}_{f}\right) \quad \text { is the weighted sum of squared residuals } \\
& \text { computed with the final estimate of the } \\
& \text { parameter vector. }
\end{aligned}
$$

This variance, together with the final estimate of the sensitivity matrix, is used to compute the symmetrical covariance matrix of the parameter vector as $V\left(\underline{b}_{f}\right)=s^{2}\left(X_{f}^{T} \cdot \Omega \cdot X_{f}\right)^{-1}$. The standard error of the regression is the square root of the estimated-error variance. The diagonal elements are the variances of the individual parameters $s_{b_{j}}^{2}$ and the off-diagonal elements are covariances between parameter pairs. An (1- $\alpha)$-level linear confidence interval is computed for each parameter as $b_{j} \pm t_{N-p, 1-\alpha / 2} \cdot s_{b_{j}}$, where $t$ is the Student- $t$ statistic with $N-p$ degrees of freedom. Finally, the parameter-correlation matrix is computed from covariance elements of $\operatorname{cov}_{i j}=V\left(\underline{b}_{f}\right)_{i j}$ and the correlation between the $i^{\text {th }}$ and $j^{\text {th }}$ parameter $\operatorname{cor}_{i j}=$ $\operatorname{cov}_{i j} / \sqrt{\operatorname{cov}_{i i} \bullet \operatorname{cov}_{j j}}$. Parameter correlations can vary in the interval $[-1,1]$. Parameter correlations with an absolute value greater than 0.95 indicate that some degradation in parameter estimates may have occurred because of the ambiguity of the effects caused by two model parameters on simulated results.

\section{Parameterization Strategy}

In this report, the model-parameterization strategy refers to the flexibility of parameters to vary annually. Each period from April 1 to November 30 with adequate flow and waterlevel data provides a basis for independent model calibration by inverse modeling. Patterns of change in annual sequences of parameters were used to identify time-varying conveyance characteristics at individual reaches. Although persistent changes need not be monotonic to be significant, non-monotonic changes are difficult to confirm unambiguously unless the timings of likely changes in trends are known before they are revealed by the analysis. To help identify both monotonic and non-monotonic persistent changes, a minimum annual sequence of parameters representing five or more contiguous years was required.

A fixed-parameter strategy follows a similar calibration approach as the time-varying strategy, but requires the additional assumption that reach conveyance is invariant over the time interval used in parameter estimation. For the fixed-parameter model, the validity of this assumption was investigated by analyzing the flow residuals formed as the differences between measured and simulated values. In particular, the annual sequence of effective channel-roughness values for reaches estimated in the time-varying models were used as basis functions for estimating trend components in the flow residuals. Those reaches whose basis function was significantly associated with flow residuals were considered to have significant time variability.

\section{Simulation of Flow under Annual Parameterizations Derived from Inverse Modeling}

Each set of annual parameters for the 1-D hydrodynamic model of the St. Clair River characterized the conveyance during that year based on the available water-level and flow data. If conveyance were invariant with time, each annual parameterization would result in simulations that produce similar average flows for each set of water-level boundary conditions. Under conveyance invariance, variability among average simulated flows for specified water-level boundary conditions should only reflect parameter uncertainty. In contrast, persistence or trends in average simulated flow with annual parameterization would indicate conveyance change. Furthermore, because the water-level boundaries are invariant with the annual parameterization, the relative changes in flow with parameterization are identical to relative changes in conveyance.

Following equation 2, average flow simulated under conveyance characteristics estimated for the $i^{\text {th }}$ year using waterlevel boundary conditions from the $j^{\text {th }}$ year approximately 
equals the conveyance described in the $i^{\text {th }}$ year multiplied by the square root of the water-surface slope between the two gaging stations as $Q_{i, j} \approx K_{i} \cdot S_{j}^{\prime \prime}$. The set $Q_{. j}$ represents the set of average flows simulated under all annual parameterizations $i \in\{1962,1963, \ldots 2007\}$ using boundary conditions for only the $j^{\text {th }}$ year.

For the parameterization set $P$ indexed by $p$, say $\mathrm{p}=$ $\{1,2\}$, and an annual boundary-condition set $B$ indexed by $b$, say $b=\{1\}$, we can write $Q_{p, b}=Q_{1,1}=K_{1} \cdot S_{1}^{1 / 2}$ and $Q_{p 2, b}=Q_{2,1}=$ $K_{2} \cdot S_{1}^{1 / 2}$. Solving for $S_{1}^{1 / 2}$, we can write $\frac{Q_{2,1}}{Q_{1,1}}=\frac{K_{2}}{K_{1}}$.

Subtracting 1 from both sides allows us to write

$$
\begin{aligned}
& \frac{Q_{2,1}}{Q_{1,1}}-1=\frac{K_{2}}{K_{1}}-1 \text {, or equivalently, } \\
& \qquad \frac{Q_{2,1}-Q_{1,1}}{Q_{1,1}}=\frac{K_{2}-K_{1}}{K_{1}} .
\end{aligned}
$$

Thus, with respect to changes in parameterizations for fixed-boundary conditions, relative changes in flow are identical to relative changes in conveyance. The base year for parameterization can arbitrarily be taken as 1962, which provides a basis for describing the percent relative change in conveyance since 1962.

Generally, the relative change in simulated flow for any parameterization set $p^{\prime}>1 \in P$ with respect to $p=1$ for boundary conditions $b$ can be written $\frac{\Delta\left(Q_{\left\{p^{\prime}, 1\right\}}\right)_{b}}{Q_{1, b}}$.

The maximum relative changes in average flow for all sets of boundary conditions $b \in B$ can be represented by the set

$\left\{\max _{\forall b \in B} \frac{\Delta\left(Q_{\left\{p^{\prime}, 1\right\}}\right)_{b}}{Q_{1, b}}\right\}$,

the minimum relative change as $\left\{\min _{\forall b \in B} \frac{\Delta\left(Q_{\left\{p^{\prime}, 1\right\}}\right)_{b}}{Q_{1, b}}\right\}$, and the average relative change as

$\left\{\underset{\forall b \in B}{\operatorname{ave}} \frac{\Delta\left(Q_{\left\{p^{\prime}, 1\right\}}\right)_{b}}{Q_{1, b}}\right\}$ for all $p^{\prime}>1 \in P$.

\section{Results of Conveyance Analyses}

Conveyance changes within reaches were evaluated based on water-level measurements at gaging stations and 1-D hydrodynamic-model simulations. Water-level measurements were used to compute water-surface fall and conveyance ratios among reaches. Analyses of these data provide a nearly continuous description of relative conveyance changes from 1962 to 2007. Inverse 1-D hydrodynamic modeling was used to estimate a partial annual series of effective channel-roughness parameters from 1962 to 2007 for periods when both flow and water-level data were available to support estimation. Both analyses indicate systematic variations in conveyance within some reaches. Annual parameterizations of the 1-D hydrodynamic model also were used to evaluate changes in river conveyance from 1962 to 2007.

\section{Inferring Reach-Conveyance Changes from Water-Level Measurements}

Synchronized water-level differences among eight gaging stations spanning the St. Clair River were used to characterize the annual fall in water levels within seven reaches forming the study area (table 2). Average water-surface falls between adjacent gages divided by their corresponding reach lengths were used to approximate annual energy slopes. The square root of the ratio of energy slopes along two reaches is inversely proportional to their corresponding conveyance ratios. The time series of conveyance ratios provide a basis for interpreting relative conveyance changes among reaches.

\section{Water-Surface Fall}

Monthly average water-level data from the eight selected gaging stations along the St. Clair River were used to compute average annual water-surface falls through the corresponding reaches. When one or more months of data during this period were missing, the corresponding year of data also was considered missing and not used in the analysis.

Some difficulties were encountered interpreting the reported monthly average water-level fall data. In the Point Edward to Black River reach ( $P E \_B R$ ), negative average monthly water-level falls were reported in 1964 for July, August, and September; in 1965 for April, July, August, October, and November; in 1966 for May through September; in 1967 for April through November (with July and August data missing); in 1968 for April through July, and October and November; in 1969 for April through July and November; in 1970 for May and July; in 1971 for July and August; in 1973 for April and August; in 1974 for June through August; and in 1982 for June. Negative monthly average water-level falls indicate that water would be flowing upstream within the reach for extended periods within the month, which is physically impossible. April to November periods when computed water-level falls were negative were not used to assess conveyance change.

Opposite trends in water-level fall were detected in two adjacent reaches on St. Clair River. Water-level falls generally decreased from 1962 to 1992 in the Dunn Paper to Point Edward reach ( $\left.D P \_P E\right)$, and falls generally increased from 1962 to 1994 in the Point Edward to Black River reach $\left(P E \_B R\right)$ (fig. 5). Trends in water-surface fall may be associated with changes in either flow or conveyance or both. Opposite (decreasing and increasing) trends in water-surface fall through adjacent reaches, however, are inconsistent with the null hypothesis of no conveyance changes in either reach, because all reaches pass essentially the same annual flow. 


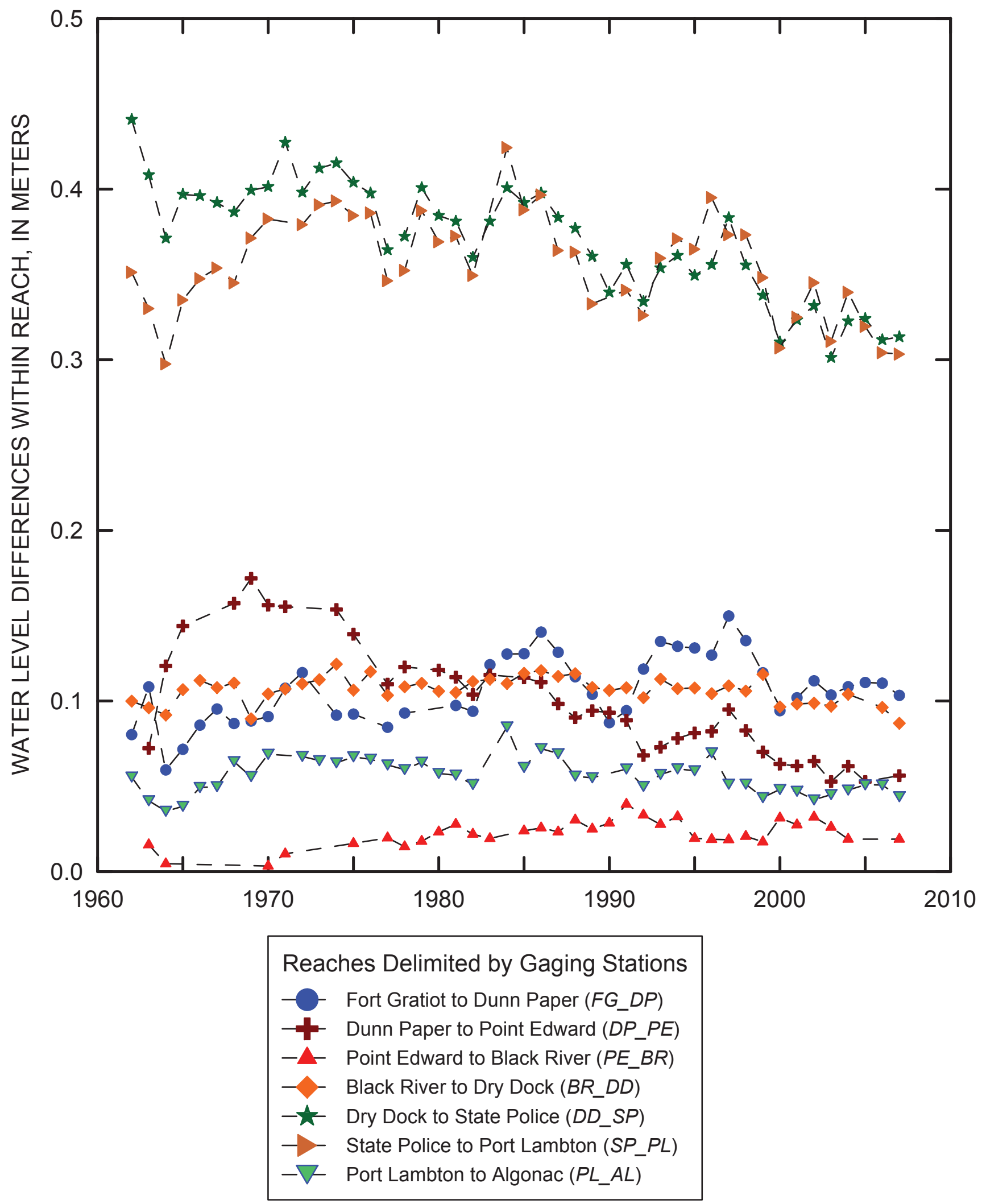

Figure 5. Differences in average April 1 to November 30 water levels between adjacent reaches on the St. Clair River. 
Table 3. Trends in water-level fall within St. Clair River reaches delimited by water-level gaging stations, $1962-2007$.

[Reach ID, reach identification; $F G_{-} D P$, Fort Gratiot to Dunn Paper; $D P \_P E$, Dunn Paper to Point Edward; $P E \_B R$, Point Edward to Black River; $B R \_D D$, Black River to Dry Dock; $D D \_S P$, Dry Dock to State Police; $S P \_P L$, State Police to Port Lambton; $P L \_A L$, Port Lambton to Algonac]

\begin{tabular}{|c|c|c|c|c|c|}
\hline Reach ID & Kendall's tau & $p$-value ${ }^{1}$ & $\begin{array}{c}\text { Slope (change in } \\
\text { average water-level } \\
\text { fall, in meters, per year) }\end{array}$ & $\begin{array}{c}\text { Median fall } \\
\text { (meters per } \\
\text { kilometer) }\end{array}$ & $\begin{array}{l}\text { Median year } \\
\text { of data }\end{array}$ \\
\hline$F G \_D P$ & 0.3169 & 0.0004 & 0.000708 & 0.106 & 1986.5 \\
\hline DP_PE & -.4831 & .0000 & -.00253 & .0942 & 1988.0 \\
\hline$P E \_B R$ & .1652 & .0084 & .000353 & .0219 & 1989.0 \\
\hline$B R \_D D$ & -.1159 & .2444 & -.000107 & .107 & 1984.0 \\
\hline$D D \_S P$ & -.6570 & .0000 & -.00227 & .379 & 1984.5 \\
\hline$S P \_P L$ & -.1604 & .0842 & -.000732 & .354 & 1985.0 \\
\hline$P L_{\&} A L$ & -.1778 & .0555 & -.000294 & .0559 & 1985.0 \\
\hline
\end{tabular}

${ }^{1} p$-value indicates the likelihood that the null hypothesis of no trend in water-level falls with time is true given the measured water level data. A small $p$-value (less than 0.05 ) indicates that the null hypothesis may be rejected.

Based on the available water-level data, a trend in conveyance is indicated at one or more of these adjacent reaches. Given the reflective symmetry of the trends, however, the possibility of an undocumented datum change at one or more of the water-level gaging stations cannot be definitively dismissed as a factor associated with the apparent trends in water-level fall and conveyance.

Of the seven reaches investigated, negative monotonic trends in water-surface fall were detected $(p$-value $<0.05)$ at the reaches from Dunn Paper to Point Edward DP_PE and Dry Dock to State Police $D D \_S P$, while positive monotonic trends in water-surface fall were detected at the reaches from Fort Gratiot to Dunn Paper FG DP and Point Edward to Black River $P E B R$ (table 3). Even for reaches from State Police to Port Lambton $S P \_P L$ and Port Lambton to Algonac $P L_{-} A L$ where the evidence of trends was less compelling ( $p$-value $<$ 0.10 ), inspection of the convergence between water-surface fall profiles from 1962 to 1975 indicates that rates of changes in conveyance ratios may be time varying.

Monthly estimates of flow through the St. Clair River have been computed for the period 1860 to 2006 by the Coordinating Committee, although values after 1990 are considered provisional. Use of the equation $K_{i, j}=Q_{i, .} / \sqrt{S_{f i, j}}$ would provide a basis for directly computing annual conveyance estimates for each reach. These estimates of flow, however, are based on stable relations assumed between measured water level and fall. The stability (time invariance) of conveyance (and hence the relation between flow, water level, and fall) is the subject of this investigation; therefore, interpretation of the resulting estimates would be problematic and are not used as a direct estimate of conveyance in this report.

\section{Conveyance Ratios}

Conveyance ratios were computed by use of equation 5 and water-level data from 1962-2007 (fig. 6). Results indicate that the conveyance in the $F G_{-} D P$ reach decreased significantly $(\alpha=0.05)$ with time (table 4$)$ relative to all reaches except $P E \_B R$, where the relative conveyance may have increased $(p$-value $=0.0661)$. The relative decrease in conveyance at $F G_{-} D P$ with respect to $D P P_{-} P E$ was greater than other reaches (-0.00949), because of the increase in conveyance at $D P P E$ relative to all downstream reaches. The tendency for an increased conveyance at $F G_{-} D P$ relative to $P E_{-} B R$ is thought to be related to the larger negative trend at $P E_{-} B R$ relative to all downstream reaches. The conveyance at $B R_{-} D D$ decreases significantly with respect to conveyance at $D D \_S P$. Much of this relative decrease in conveyance is attributable to the sharp increase in conveyance of $D D \_S P$ relative to $S P \_P L$, which is particularly evident in data prior to 1970 . The increase in conveyance of $D D \_S P$ with respect to $P L \_A L$ in the pre-1970 data is consistent with increasing relative conveyance at $D D \_S P$, although not statistically significant over the entire period. Furthermore, the decrease in conveyance of $B R \_D D$ relative to $D D \_S P$ is not evident in reaches further downstream. The patterns in relative conveyance at $P L_{-} A L$ are consistent with patterns in other reaches indicating that $P L \_A L$ may be one of the more stable reaches in the St. Clair River.

Possible relations between annual conveyance ratios and flow magnitudes were analyzed to determine whether systematic variations in flow might affect the interpretation of trends in conveyance ratios. In particular, greater flows likely would be associated with greater conveyance and water-level falls 

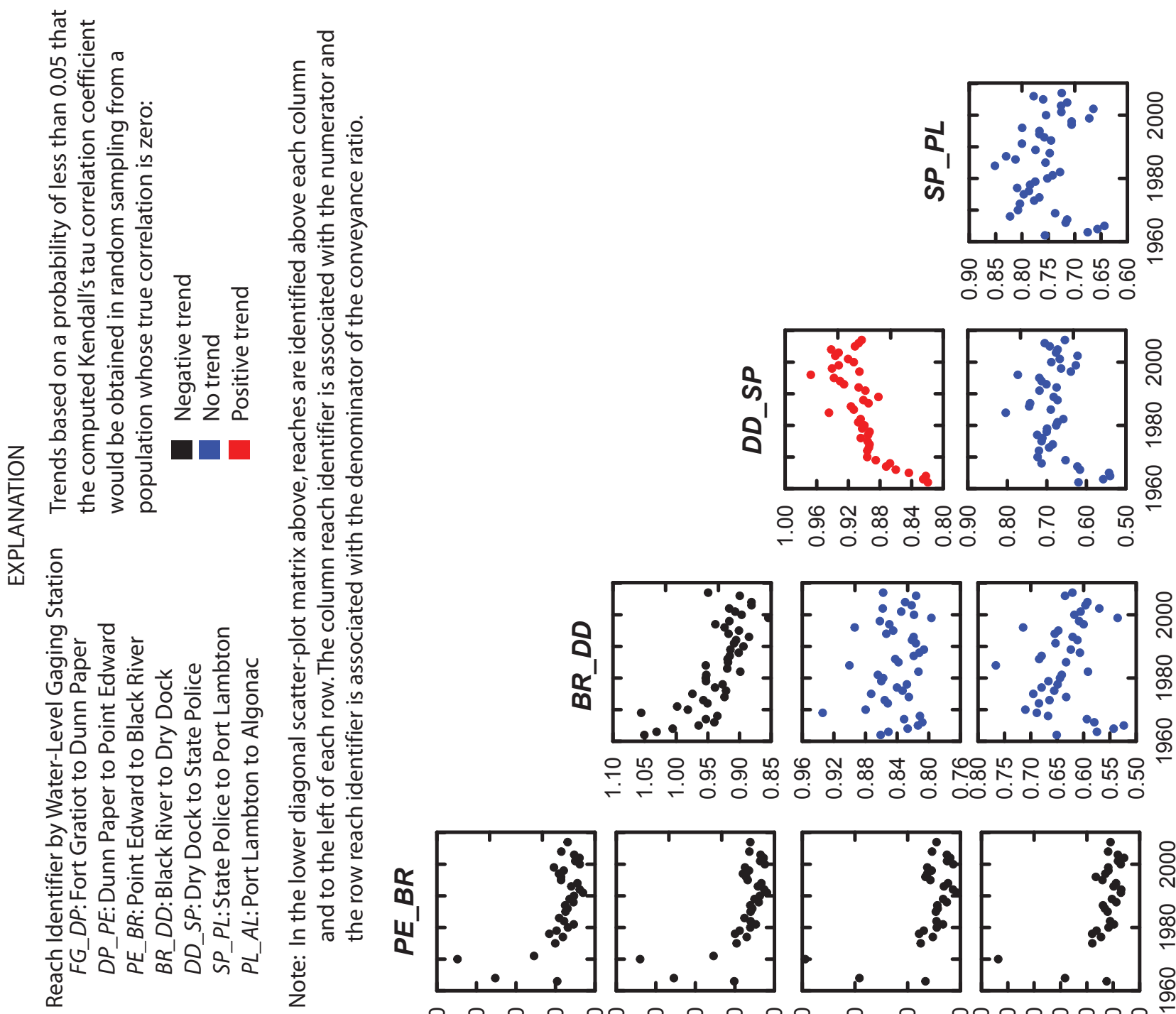

은 능 용 \&
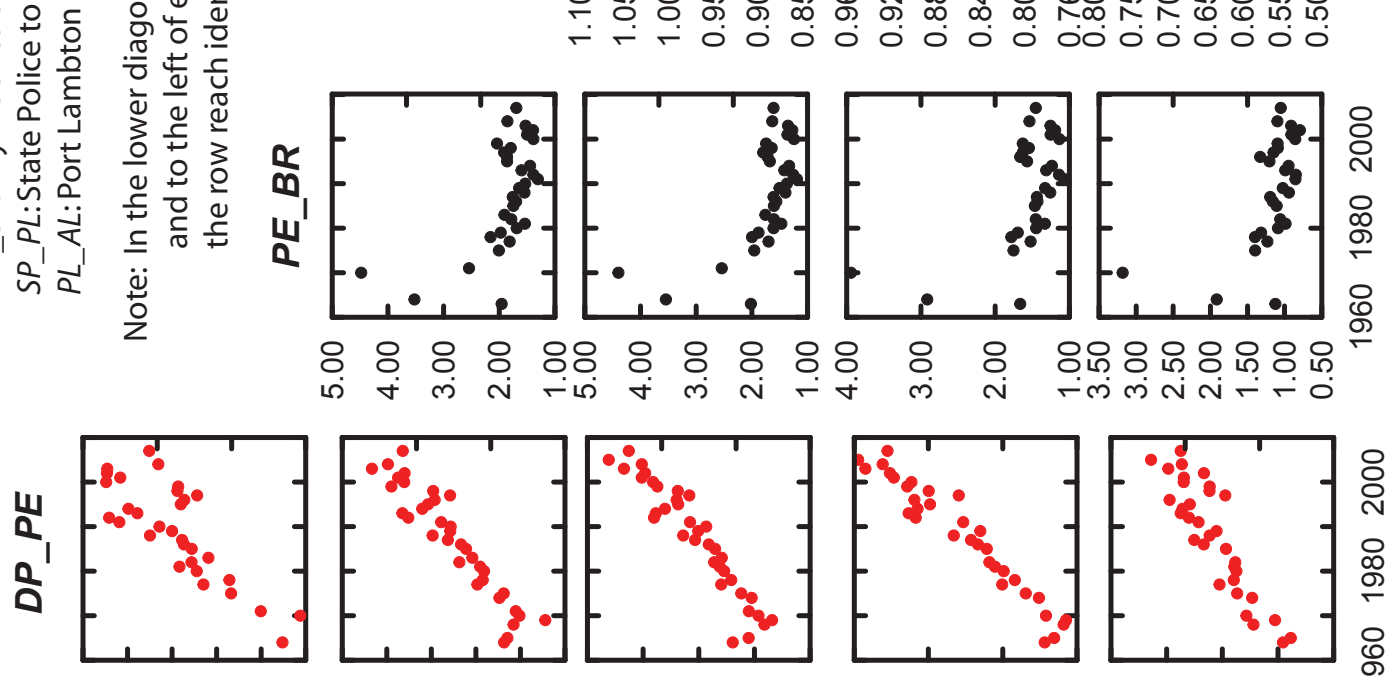

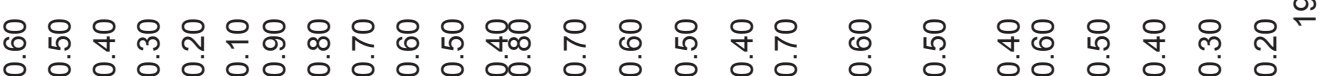
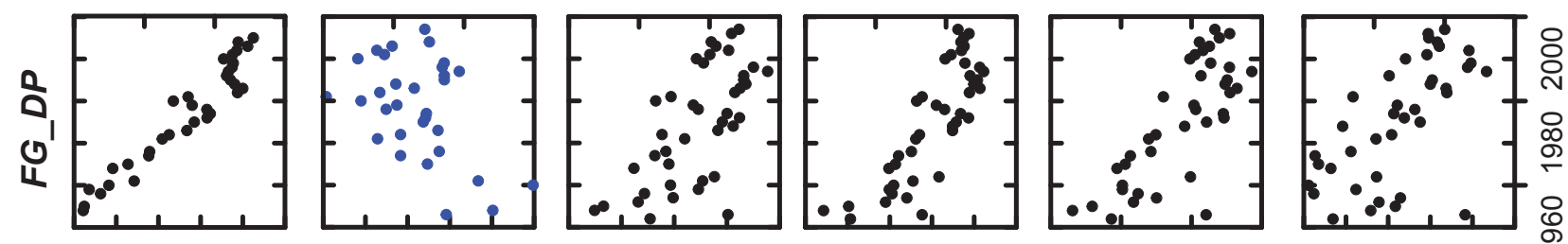

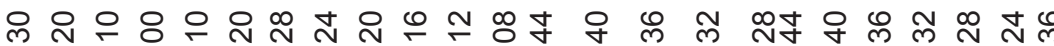

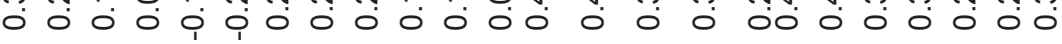

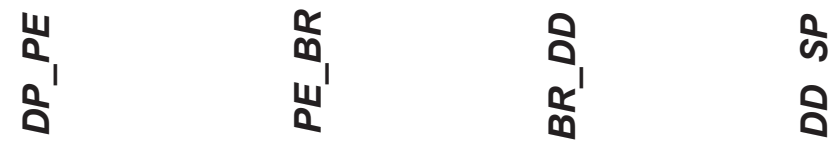

के

กิ

莳贲 
Table 4. Trends in conveyance ratios among paired reaches on the St. Clair River.

[Reach ID, reach identification; $F G \_D P$, Fort Gratiot to Dunn Paper; $D P \_P E$, Dunn Paper to Point Edward; $P E \_B R$, Point Edward to Black River; $B R \_D D$, Black River to Dry Dock; $D D_{-} S P$, Dry Dock to State Police; $S P \_P L$, State Police to Port Lambton; $P L \_A L$, Port Lambton to Algonac]

\begin{tabular}{|c|c|c|c|c|c|c|c|}
\hline $\begin{array}{l}\text { Upstream } \\
\text { reach }\end{array}$ & $\begin{array}{c}\text { Downstream } \\
\text { reach }\end{array}$ & Kendall's tau & $p$-value & Intercept & Median slope & Median ratio & Median year \\
\hline \multirow[t]{6}{*}{$F G \_D P$} & $D P \_P E$ & -0.8050 & $<0.0001$ & 19.4 & -0.00949 & 0.490 & 1989.0 \\
\hline & $P E \_B R$ & .2344 & .0661 & -2.33 & .00126 & .184 & 1990.0 \\
\hline & $B R \_D D$ & -.4659 & $<.0001$ & 3.46 & -.00157 & .338 & 1986.0 \\
\hline & $D D \_S P$ & -.6051 & $<.0001$ & 4.34 & -.00203 & .308 & 1986.5 \\
\hline & $S P P_{-} P L$ & -.5385 & $<.0001$ & 3.15 & -.00145 & .278 & 1987.0 \\
\hline & $P L \_A L$ & -.4656 & $<.0001$ & 2.49 & -.00114 & .214 & 1987.0 \\
\hline \multirow[t]{5}{*}{ DP_PE } & $P E \_B R$ & .6172 & $<.0001$ & -16.9 & .00867 & .383 & 1990.0 \\
\hline & $B R \_D D$ & .7916 & $<.0001$ & -15.1 & .00794 & .658 & 1988.0 \\
\hline & $D D \_S P$ & .8381 & $<.0001$ & -11.8 & .00622 & .604 & 1988.5 \\
\hline & $S P_{-} P L$ & .8674 & $<.0001$ & -12.5 & .00657 & .553 & 1989.0 \\
\hline & $P L \_A L$ & .7159 & $<.0001$ & -8.23 & .00435 & .423 & 1989.0 \\
\hline \multirow[t]{4}{*}{$P E_{-} B R$} & $B R \_D D$ & -.3826 & .0015 & 32.9 & -.01565 & 1.76 & 1989.0 \\
\hline & $D D \_S P$ & -.4394 & .0002 & 38.7 & -.01866 & 1.61 & 1989.0 \\
\hline & $S P \_P L$ & -.3609 & .0047 & 24.5 & -.01157 & 1.45 & 1990.0 \\
\hline & $P L \_A L$ & -.4069 & .0013 & 23.6 & -.01132 & 1.09 & 1990.0 \\
\hline \multirow[t]{3}{*}{$B R \_D D$} & $D D \_S P$ & -.5960 & .0000 & 5.18 & -.00214 & .9234 & 1984.0 \\
\hline & $S P_{-} P L$ & -.0662 & .5462 & 1.28 & -.000222 & .837 & 1984.5 \\
\hline & $P L \_A L$ & -.1684 & .1191 & 2.95 & -.00117 & .634 & 1984.5 \\
\hline \multirow[t]{2}{*}{$D D \_S P$} & $S P_{-} P L$ & .6146 & $<.0001$ & -2.37 & .00165 & .903 & 1985.0 \\
\hline & $P L \_A L$ & .0964 & .3765 & -0.556 & .000626 & .687 & 1984.5 \\
\hline$S P \_P L$ & $P L \_A L$ & -.1042 & .3304 & 1.88 & -.000568 & .756 & 1985.0 \\
\hline
\end{tabular}




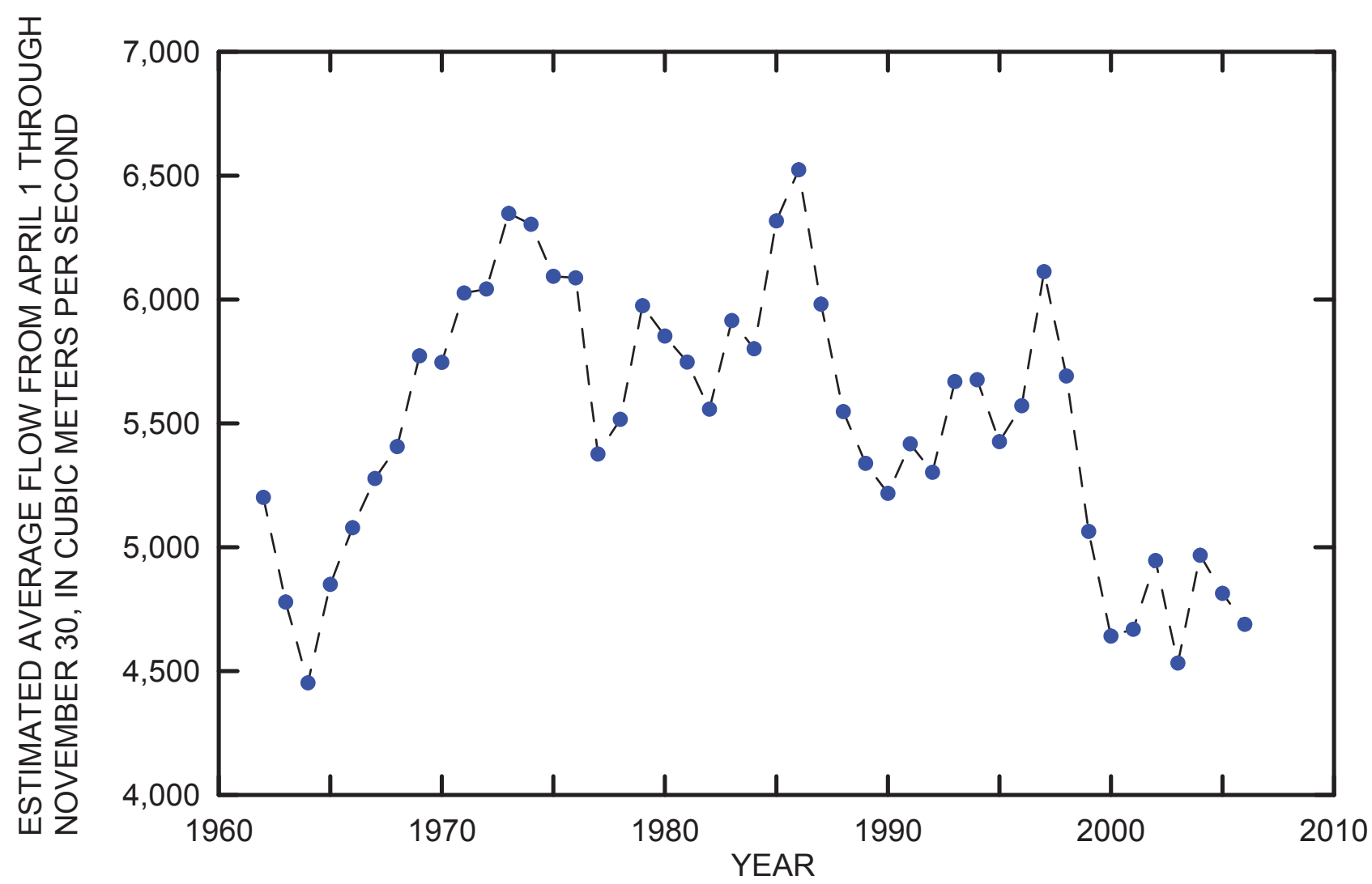

Figure 7. Average flow of the St. Clair River for 1962-2006 based on coordinated monthly flow estimates.

than would lesser flows. Monotonic relations between conveyance ratios and average April 1 to November 30 flows from monthly values for 1962-2006 published by the Coordinating Committee (fig. 7) were investigated by use of nonparametric Kendall's tau correlation coefficient and Sen's slope estimator (table 5). The five conveyance ratios for reaches downstream from $D P \_P E$ generally were negatively associated with flow. In contrast, conveyance ratios at the three reaches downstream from $B R_{-} D D$ generally were positively associated with flow, as were the conveyance ratios between $D D \_S P$ and $P L \_A L$, and $S P \_P L$ and $P L \_A L$. No other statistically significant correlations were detected. Relations between conveyance ratios and flow magnitudes were not consistent among reaches.

Innovations in the conveyance ratios (equation 7) also were analyzed for trends. Despite significant associations between conveyance ratios and estimates of average flow for some pairs of reaches, the lower diagonal scatter-plot matrix of conveyance-ratio innovations (fig. 8) showed similar trends (table 6) as the conveyance ratios themselves. Other than scaling changes associated with different means of the two ratios, the primary difference between the two sets of plots occurred for the reaches $D D \_S P$ and $P L_{-} A L$. In particular, the trend in the conveyance ratios was not significant, while the trend in the conveyance-ratio innovations was positive ( $p$-value $=$ $0.0017)$. Thus, available flow information provides only minor changes in the interpretation of conveyance change than evidence based on the ratios themselves.

\section{Inferring Changes in Reach Conveyance from 1-D Hydrodynamic-Model Parameters}

Two strategies were implemented to ascertain possible changes in reach conveyance from inverse 1-D hydrodynamic modeling of the St. Clair River. First, time-varying parameter estimation was used to describe possible continual changes in reach conveyance by use of annual estimates of model parameters describing effective channel roughness. Second, fixed-parameter estimation was used to describe possible discrete changes in reach conveyance from 1962 to 1968 , 1981 to 1985 , and 1996 to 2007 . Annual estimates of effective channel roughness from 1996 to 2007 in reaches were used as a basis for estimating variations in flow not accounted for by the fixed-parameter model. The results were used to identify reaches where conveyance changes are affecting river-flow estimates. 
Table 5. Relation among estimated flow from April 1 to November 30 and conveyance ratios of reaches on St. Clair River.

[Reach ID, reach identification; $F G_{-} D P$, Fort Gratiot to Dunn Paper; $D P \_P E$, Dunn Paper to Point Edward; $P E \_B R$, Point Edward to Black River; $B R \_D D$, Black River to Dry Dock; $D D \_S P$, Dry Dock to State Police; $S P \_P L$, State Police to Port Lambton; $P L \_A L$, Port Lambton to Algonac]

\begin{tabular}{|c|c|c|c|c|c|c|c|}
\hline $\begin{array}{l}\text { Upstream } \\
\text { reach }\end{array}$ & $\begin{array}{l}\text { Downstream } \\
\text { reach }\end{array}$ & Kendall's tau & $p$-value & Intercept & Median slope & Median ratio & Median year \\
\hline \multirow[t]{6}{*}{$F G \_D P$} & $D P \_P E$ & 0.1872 & 0.1237 & 0.224 & 0.0000509 & 0.505 & $5,531.9$ \\
\hline & $P E \_B R$ & -.2046 & .1170 & .320 & -.0000246 & .184 & $5,531.9$ \\
\hline & $B R \_D D$ & -.1846 & .0959 & .434 & -.0000175 & .338 & $5,471.2$ \\
\hline & $D D \_S P$ & -.0683 & .5391 & .345 & -.0000068 & .308 & $5,426.2$ \\
\hline & $S P_{-} P L$ & -.0384 & .7455 & .296 & -.0000033 & .278 & $5,421.9$ \\
\hline & $P L \_A L$ & .1778 & .1195 & .146 & .0000128 & .215 & $5,421.9$ \\
\hline \multirow[t]{5}{*}{$D P \_P E$} & $P E_{-} B R$ & -.4069 & .0013 & .991 & -.000110 & .382 & $5,552.5$ \\
\hline & $B R \_D D$ & -.3226 & .0069 & 1.18 & -.0000949 & .657 & $5,552.5$ \\
\hline & $D D \_S P$ & -.3479 & .0030 & 1.03 & -.0000782 & .601 & $5,547.5$ \\
\hline & $S P_{-} P L$ & -.3105 & .0123 & .986 & -.0000791 & .548 & $5,531.9$ \\
\hline & $P L \_A L$ & -.2339 & .0618 & .671 & -.0000448 & .423 & $5,531.9$ \\
\hline \multirow[t]{4}{*}{$P E_{-} B R$} & $B R \_D D$ & .1976 & .1162 & .834 & .000169 & 1.77 & $5,552.5$ \\
\hline & $D D \_S P$ & .2137 & .0887 & .548 & .000191 & 1.61 & $5,552.5$ \\
\hline & $S P_{-} P L$ & .1576 & .2397 & .753 & .000126 & 1.45 & $5,547.5$ \\
\hline & $P L \_A L$ & .2512 & .0576 & .256 & .000151 & 1.09 & $5,547.5$ \\
\hline \multirow[t]{3}{*}{$B R \_D D$} & $D D \_S P$ & .1966 & .0610 & .826 & .0000174 & .922 & $5,552.5$ \\
\hline & $S P_{-} P L$ & .2683 & .0132 & .730 & .0000188 & .835 & $5,547.5$ \\
\hline & $P L \_A L$ & .4293 & .0000 & .323 & .0000561 & .635 & $5,547.5$ \\
\hline \multirow[t]{2}{*}{$D D \_S P$} & $S P_{-} P L$ & .0523 & .6355 & .874 & .0000054 & .904 & $5,531.9$ \\
\hline & $P L \_A L$ & .3217 & .0024 & .458 & .0000415 & .687 & $5,531.9$ \\
\hline$S P \_P L$ & $P L \_A L$ & .3393 & .0016 & .506 & .0000453 & .757 & $5,531.9$ \\
\hline
\end{tabular}



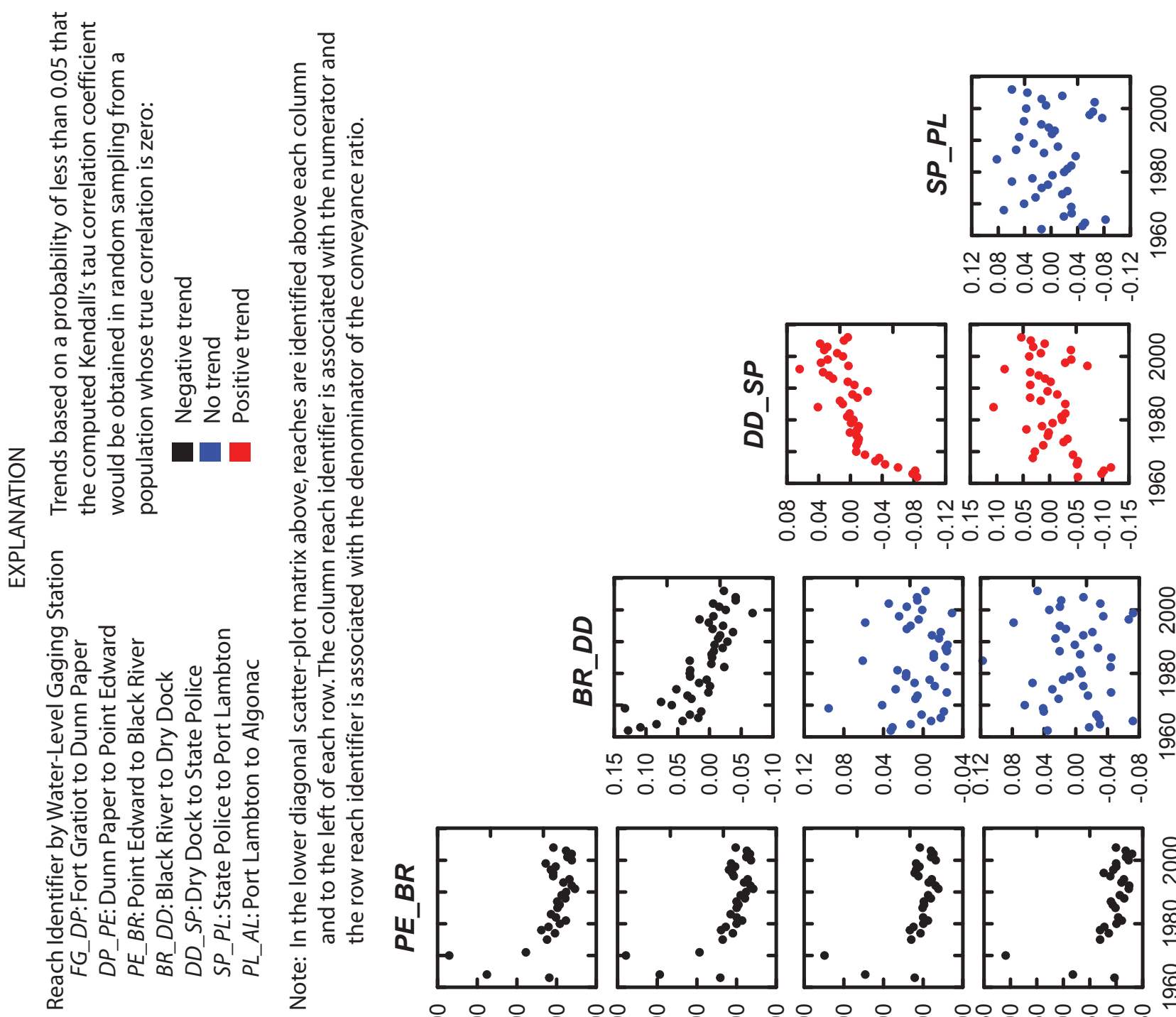

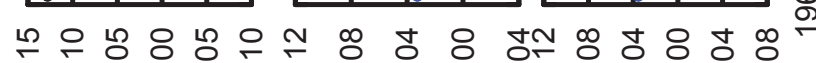

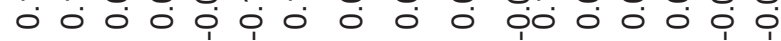
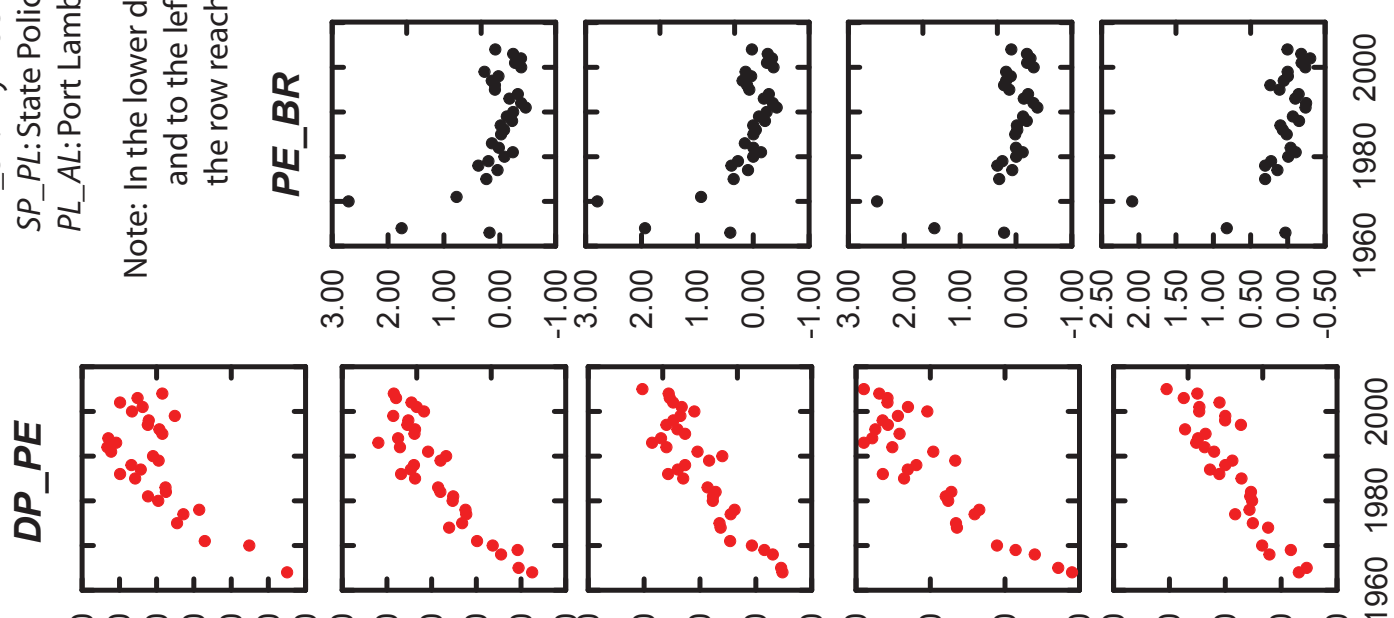

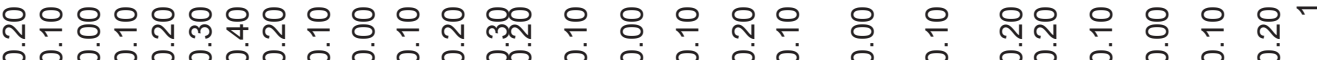
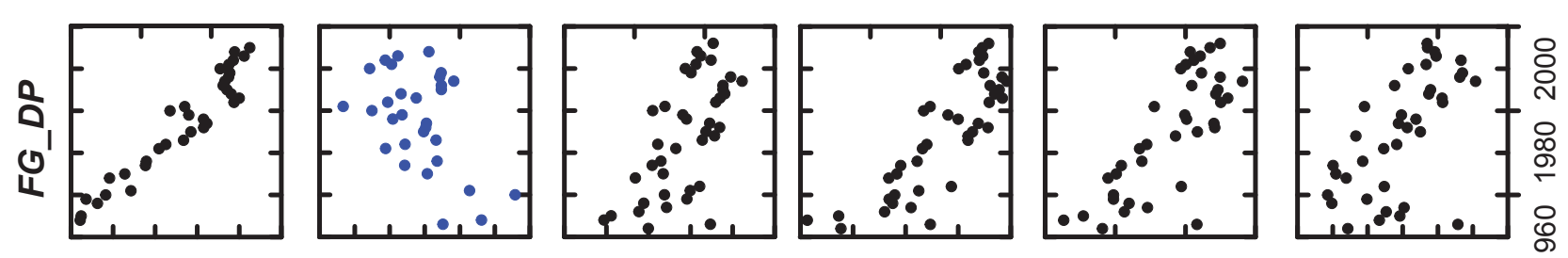

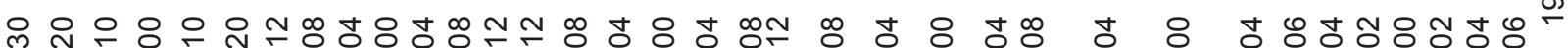

○ 000 o

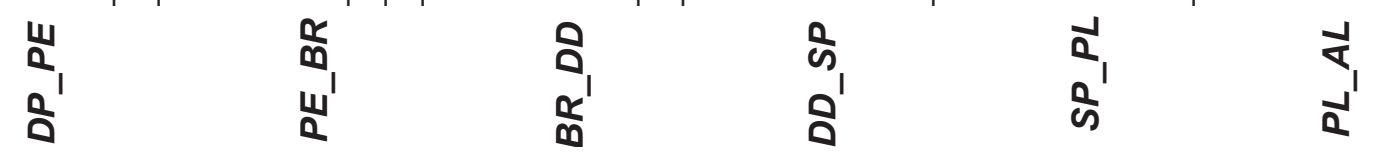

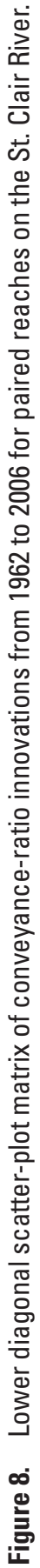


Table 6. Trends in conveyance ratio innovations among paired reaches on the St. Clair River.

[Reach ID, reach identification; $F G \_D P$, Fort Gratiot to Dunn Paper; $D P \_P E$, Dunn Paper to Point Edward; $P E \_B R$, Point Edward to Black River; $B R \_D D$, Black River to Dry Dock; $D D \_S P$, Dry Dock to State Police; $S P \_P L$, State Police to Port Lambton; $P L \_A L$, Port Lambton to Algonac]

\begin{tabular}{|c|c|c|c|c|c|c|c|}
\hline $\begin{array}{l}\text { Upstream } \\
\text { reach }\end{array}$ & $\begin{array}{l}\text { Downstream } \\
\text { reach }\end{array}$ & Kendall's tau & $p$-value & Intercept & Median slope & Median ratio & Median year \\
\hline \multirow[t]{6}{*}{$F G \_D P$} & $D P \_P E$ & -0.8039 & $<0.0001$ & 19.5 & -0.00978 & 0.000004 & 1988.5 \\
\hline & $P E \_B R$ & .2506 & .0534 & -2.70 & .00136 & .000001 & 1989.5 \\
\hline & $B R \_D D$ & -.4564 & $<.0001$ & 3.13 & -.00158 & .000000 & 1985.5 \\
\hline & $D D \_S P$ & -.6220 & $<.0001$ & 4.21 & -.00212 & -.000004 & 1986.0 \\
\hline & $S P \_P L$ & -.5420 & $<.0001$ & 2.93 & -.00148 & -.000001 & 1986.5 \\
\hline & $P L \_A L$ & -.4566 & $<.0001$ & 2.28 & -.00115 & .000004 & 1986.5 \\
\hline \multirow[t]{5}{*}{$D P_{-} P E$} & $P E \_B R$ & .3977 & .0017 & -11.0 & .00555 & .0157 & 1989.5 \\
\hline & $B R \_D D$ & .6815 & $<.0001$ & -12.8 & .00646 & .0125 & 1987.5 \\
\hline & $D D \_S P$ & .6728 & $<.0001$ & -9.43 & .00475 & .0100 & 1988.0 \\
\hline & $S P \_P L$ & .6734 & $<.0001$ & -10.2 & .00516 & .0247 & 1988.5 \\
\hline & $P L \_A L$ & .7137 & $<.0001$ & -9.01 & .00453 & .000002 & 1988.5 \\
\hline \multirow[t]{4}{*}{$P E \_B R$} & $B R \_D D$ & -.3952 & .0012 & 34.3 & -.0173 & .000005 & 1988.5 \\
\hline & $D D \_S P$ & -.4677 & .0001 & 40.0 & -.0201 & .000002 & 1988.5 \\
\hline & $S P \_P L$ & -.3842 & .0031 & 25.4 & -.0128 & -.000002 & 1989.0 \\
\hline & $P L \_A L$ & -.4187 & .0012 & 25.1 & -.0126 & .000004 & 1989.0 \\
\hline \multirow[t]{3}{*}{$B R \_D D$} & $D D \_S P$ & -.6385 & $<.0001$ & 4.41 & -.00222 & .000000 & 1983.5 \\
\hline & $S P \_P L$ & -.0707 & .5244 & 0.356 & -.00018 & .00576 & 1984.0 \\
\hline & $P L \_A L$ & .0073 & .9555 & -0.120 & .00006 & -.00475 & 1984.0 \\
\hline \multirow[t]{2}{*}{$D D \_S P$} & $S P \_P L$ & .6446 & $<.0001$ & -3.44 & .00173 & .000003 & 1984.5 \\
\hline & $P L \_A L$ & .3370 & .0017 & -3.49 & .00176 & .00255 & 1984.5 \\
\hline$S P_{-} P L$ & $P L \_A L$ & .0964 & .3765 & -1.11 & .00056 & .000948 & 1984.5 \\
\hline
\end{tabular}




\section{Time-Varying Parameter Estimation}

Inverse modeling techniques were used to estimate the annual effective channel-roughness coefficients for years from 1962 to 2007 when water-level boundary and flow data were available to support estimation. Tabled results are presented separately for conventional measurements collected prior to 1986 and ADCP measurements obtained from 1996 to 2007. No flow measurements were documented for 1986 to 1995 . Conventional flow measurements and water-level data supported estimation of roughness coefficients in seven reaches delimited by water-level gaging stations. ADCP flow measurements and water-level data supported estimation of the seven reaches estimated with conventional flow measurements, plus two additional reaches representing the east branches of Stag and Fawn Islands where flow was measured with ADCP instruments.

\section{Effective Channel Roughness Estimated from Conventional Measurements}

Annual parameter estimates for seven reaches associated with years of conventional flow measurements (prior to 1986) are shown in table 7 . Of the 13 years in which one or

Table 7. Effective channel roughness estimated for reaches spanning the study area of the St. Clair River in years with one or more conventional flow measurements from 1962 to 1985.

[PRD, is the percent relative difference. An " $n$ " prepended to the reach identifier indicates the effective channel roughness coefficient of the corresponding reach. Reach identifiers include: $F G_{-} D P$, Fort Gratiot to Dunn Paper; $D P \_P E$, Dunn Paper to Point Edward; $P E \_B R$, Point Edward to Black River; $B R \_D D$, Black River to Dry Dock; $\bar{D} D_{-} S P$, Dry Dock to State Police; $S P \_P L$, State Police to Port Lambton; $P L \_A L, P o r t$ Lambton to Algonac]

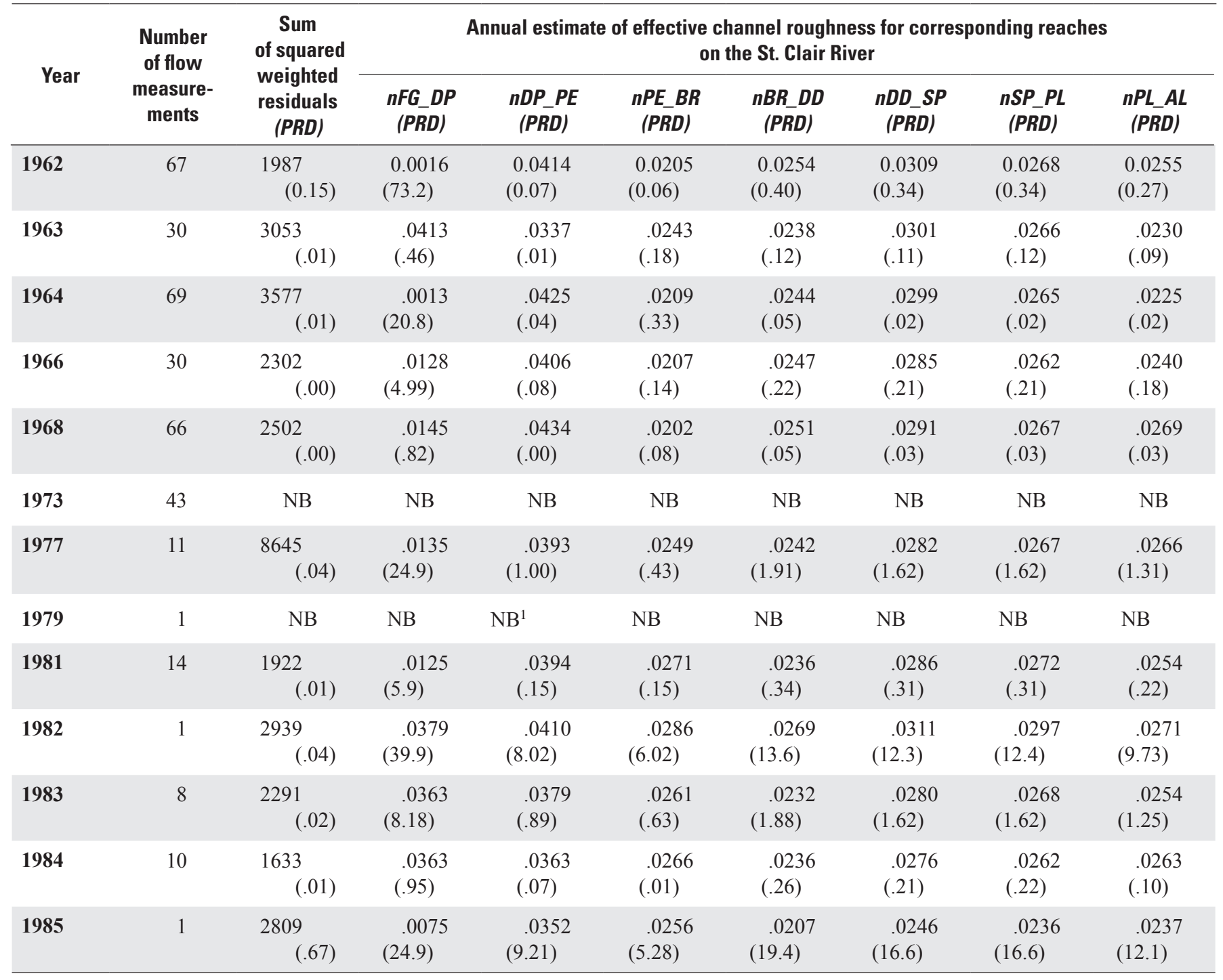

${ }^{1}$ NB - No boundaries: Indicates that insufficient water-level boundary data were available at Fort Gratiot or Algonac for flow simulation and parameter estimation. 
more flow measurements were available to support parameter estimation, 11 years had sufficient hourly water-level data at the Fort Gratiot, Mich., and Algonac, Mich., gaging stations to provide boundary conditions needed for simulation and inverse modeling. In addition to the parameter estimate, the percent relative difference $(P R D)$ is shown for each parameter. The $P R D$ was computed between converged-parameter estimates based on starting values of 0.015 and 0.040 . If the $P R D$ was greater than 3 , the corresponding parameter estimates were considered un-converged and un-interpretable with respect to conveyance. Based on this criterion, parameter estimates for all reaches in 1982 and 1985, when only one flow measurement was available for estimation, are considered un-interpretable. For the remaining years, parameter estimates for all reaches downstream from Fort Gratiot to Dunn Paper $\left(F G \_D P\right)$ converged uniquely. Among these years, however, parameter estimates for 1977 and 1983 had the greatest relative differences. Parameter estimates for the $F G \_D P$ reach converged uniquely for 1963, 1968, and 1984. The high variability in parameter estimates for these 3 years may be

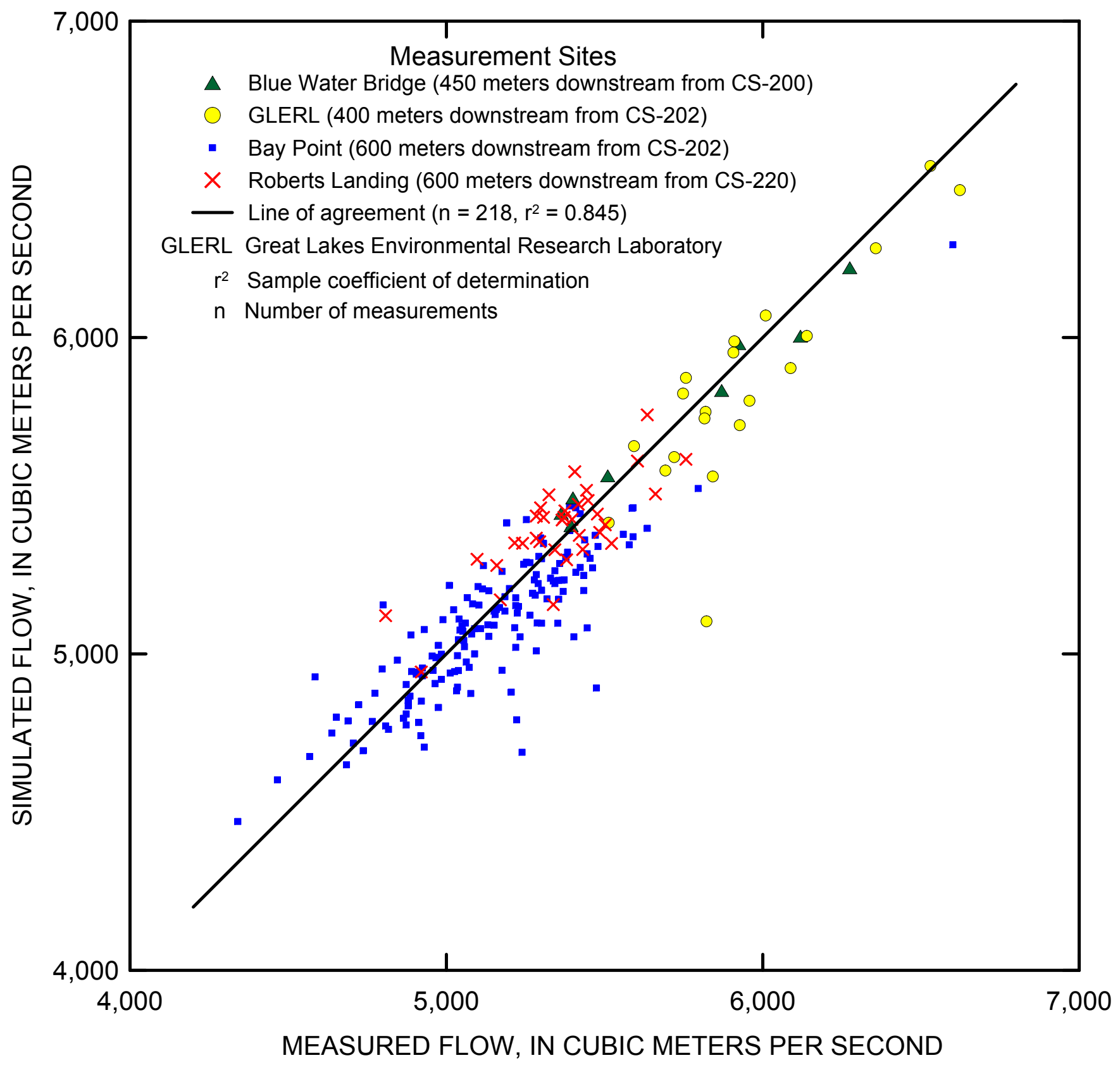

Figure 9. Relation between simulated flow and flow measured on the St. Clair River from 1962 to 1985 using conventional current meters. 
associated with possible datum instability at some water-level gaging stations in upper St. Clair River, as discussed in the analysis of water-level falls. In particular, for 1968, the estimated parameter of 0.0145 is considered physically implausible and therefore un-interpretable with respect to conveyance change.

In general, conventionally measured flows closely match flows simulated with time-varying parameterization from 1962 and 1985 (fig. 9). Differences between average flows among measurement sites are attributed to long-term variations in flow. In particular, flow measurements at the Bay Point and Roberts Landing sections generally occurred from 1962 to
1968 when average flows were less than average flows from 1981 to 1984, when measurements at the Blue Water Bridge and GLERL sections were obtained. The standard deviation of flow residuals is $144 \mathrm{~m}^{3} / \mathrm{s}$.

\section{Effective Channel Roughness Estimated from Acoustic Doppler Current Profiler Measurements}

Annual parameter estimates for nine reaches associated with years of ADCP flow measurements (1996 to 2007) are shown in table 8 . The nine reaches include the seven previously estimated, with the two additional reaches representing flows in the east branches around Stag and Fawn Islands. In

Table 8. Estimates of effective channel-roughness values for reaches spanning the study area of the St. Clair River in years with one or more acoustic Doppler current profiler flow measurements from 1996 to 2007.

$[P R D$, is the percent relative difference. An " $n$ " prepended to the reach identifier indicates the effective channel roughness coefficient of the corresponding reach. Reach identifiers include: $F G \_D P$, Fort Gratiot to Dunn Paper; $D P \_P E$, Dunn Paper to Point Edward; $P E \_B R$, Point Edward to Black River; $B R \_D D$, Black River to Dry Dock; $D D \_S P$, Dry Dock to State Police; $S P \_P L$, State Police to Port Lambton; $P L \_A L$, Port Lambton to Algonac]

\begin{tabular}{|c|c|c|c|c|c|c|c|c|c|c|c|}
\hline \multirow[b]{2}{*}{ Year } & \multirow{2}{*}{$\begin{array}{l}\text { Number of } \\
\text { flow } \\
\text { measure- } \\
\text { ments }\end{array}$} & \multirow{2}{*}{$\begin{array}{l}\text { Sum of } \\
\text { squared } \\
\text { weighted } \\
\text { residuals } \\
\text { (PRD) }\end{array}$} & \multicolumn{9}{|c|}{ Effective channel-roughness values for corresponding St. Clair River reaches } \\
\hline & & & $\begin{array}{c}n F G \_D P \\
\text { (PRD) }\end{array}$ & $\begin{array}{c}\text { nDP_PE } \\
\text { (PRD) }\end{array}$ & $\begin{array}{c}\text { nPE_BR } \\
\text { (PRD) }\end{array}$ & $\begin{array}{c}\text { nBR_DD } \\
\text { (PRD) }\end{array}$ & $\begin{array}{c}n D D \_S P \\
\text { (PRD) }\end{array}$ & $\begin{array}{c}\text { nEStag } \\
\text { (PRD) }\end{array}$ & $\begin{array}{c}n S P \_P L \\
\text { (PRD) }\end{array}$ & $\begin{array}{c}\text { nEFawn } \\
\text { (PRD) }\end{array}$ & $\begin{array}{c}n P L \_A L \\
\text { (PRD) }\end{array}$ \\
\hline 1996 & 20 & $\begin{array}{l}1918 \\
\quad(0.00)\end{array}$ & $\begin{array}{l}0.0381 \\
(1.29)\end{array}$ & $\begin{array}{l}0.0341 \\
(0.13)\end{array}$ & $\begin{array}{l}0.0253 \\
(0.04)\end{array}$ & $\begin{array}{l}0.0232 \\
(0.42)\end{array}$ & $\begin{array}{l}0.0269 \\
(0.18)\end{array}$ & $\begin{array}{l}0.0265 \\
(1.56)\end{array}$ & $\begin{array}{l}0.0266 \\
(0.33)\end{array}$ & $\begin{array}{l}0.0240 \\
(0.29)\end{array}$ & $\begin{array}{l}0.0248 \\
(0.25)\end{array}$ \\
\hline 1997 & 59 & $\begin{array}{l}2186 \\
\quad(.01)\end{array}$ & $\begin{array}{l}.0435 \\
(.48)\end{array}$ & $\begin{array}{l}.0347 \\
(.03)\end{array}$ & $\begin{array}{l}.0255 \\
(.04)\end{array}$ & & & & $\begin{array}{l}.0262 \\
(.12)\end{array}$ & $\begin{array}{l}.0226 \\
(.31)\end{array}$ & $\begin{array}{l}.0242 \\
(.09)\end{array}$ \\
\hline 1998 & 46 & $\begin{array}{l}2167 \\
\quad(.01)\end{array}$ & $\begin{array}{l}.0427 \\
(.16)\end{array}$ & $\begin{array}{l}.0339 \\
(.02)\end{array}$ & $\begin{array}{l}.0262 \\
(.09)\end{array}$ & $\begin{array}{l}.0236 \\
(.03)\end{array}$ & $\begin{array}{l}.0273 \\
(.04)\end{array}$ & $\begin{array}{l}.0283 \\
(.14)\end{array}$ & $\begin{array}{l}.0270 \\
(.02)\end{array}$ & $\begin{array}{l}.0242 \\
(2.49)\end{array}$ & $\begin{array}{l}.0251 \\
(.04)\end{array}$ \\
\hline 1999 & 44 & $\begin{array}{l}2447 \\
\quad(.00)\end{array}$ & $\begin{array}{l}.0395 \\
(.20)\end{array}$ & $\begin{array}{l}.0332 \\
(.03)\end{array}$ & $\begin{array}{l}.0250 \\
(.10)\end{array}$ & $\begin{array}{l}.0257 \\
(.11)\end{array}$ & $\begin{array}{l}.0271 \\
(.05)\end{array}$ & $\begin{array}{l}.0290 \\
(.69)\end{array}$ & $\begin{array}{l}.0270 \\
(.13)\end{array}$ & $\begin{array}{l}.0281 \\
(.85)\end{array}$ & $\begin{array}{l}.0228 \\
(.07)\end{array}$ \\
\hline 2000 & 8 & $\begin{array}{l}2010 \\
\quad(.00)\end{array}$ & $\begin{array}{l}.0356 \\
(2.83)\end{array}$ & $\begin{array}{l}.0324 \\
(.24)\end{array}$ & $\begin{array}{l}.0278 \\
(.40)\end{array}$ & $\begin{array}{l}.0244 \\
(.75)\end{array}$ & $\begin{array}{l}.0269 \\
(.79)\end{array}$ & $\begin{array}{l}.0277 \\
(.40)\end{array}$ & $\begin{array}{l}.0265 \\
(.67)\end{array}$ & $\begin{array}{l}.0248 \\
(.92)\end{array}$ & $\begin{array}{l}.0251 \\
(.53)\end{array}$ \\
\hline 2001 & 32 & $\begin{array}{l}1640 \\
\quad(.01)\end{array}$ & $\begin{array}{l}.0314 \\
(.02)\end{array}$ & $\begin{array}{l}.0323 \\
(.00)\end{array}$ & $\begin{array}{l}.0265 \\
(.02)\end{array}$ & $\begin{array}{l}.0229 \\
(.02)\end{array}$ & $\begin{array}{l}.0262 \\
(.08)\end{array}$ & $\begin{array}{l}.0278 \\
(.78)\end{array}$ & $\begin{array}{l}.0258 \\
(.00)\end{array}$ & $\begin{array}{l}.0256 \\
(.19)\end{array}$ & $\begin{array}{l}.0242 \\
(.01)\end{array}$ \\
\hline 2002 & 9 & $\begin{array}{l}1364 \\
\quad(.00)\end{array}$ & $\begin{array}{l}.0327 \\
(.35)\end{array}$ & $\begin{array}{l}.0317 \\
(.01)\end{array}$ & $\begin{array}{l}.0271 \\
(.06)\end{array}$ & $\begin{array}{l}.0224 \\
(.10)\end{array}$ & $\begin{array}{l}.0258 \\
(.07)\end{array}$ & $\begin{array}{l}.0277 \\
(.11)\end{array}$ & $\begin{array}{l}.0259 \\
(.06)\end{array}$ & $\begin{array}{l}.0265 \\
(1.25)\end{array}$ & $\begin{array}{l}.0225 \\
(.06)\end{array}$ \\
\hline 2003 & 39 & $\begin{array}{l}1662 \\
\quad(.02)\end{array}$ & $\begin{array}{l}.0335 \\
(1.10)\end{array}$ & $\begin{array}{l}.0311 \\
(.17)\end{array}$ & $\begin{array}{l}.0264 \\
(.11)\end{array}$ & $\begin{array}{l}.0231 \\
(.34)\end{array}$ & $\begin{array}{l}.0258 \\
(.15)\end{array}$ & $\begin{array}{l}.0265 \\
(1.51)\end{array}$ & $\begin{array}{l}.0257 \\
(.26)\end{array}$ & $\begin{array}{l}.0267 \\
(1.76)\end{array}$ & $\begin{array}{l}.0241 \\
(.23)\end{array}$ \\
\hline 2004 & 14 & $\begin{array}{l}3688 \\
\quad(.01)\end{array}$ & $\begin{array}{c}.0314 \\
(1.28)\end{array}$ & $\begin{array}{l}.0320 \\
(.09)\end{array}$ & $\begin{array}{l}.0251 \\
(.06)\end{array}$ & $\begin{array}{l}.0232 \\
(.29)\end{array}$ & $\begin{array}{l}.0259 \\
(.31)\end{array}$ & $\begin{array}{l}.0282 \\
(.40)\end{array}$ & $\begin{array}{l}.0261 \\
(.27)\end{array}$ & $\begin{array}{l}.0238 \\
(1.21)\end{array}$ & $\begin{array}{l}.0241 \\
(.13)\end{array}$ \\
\hline 2005 & 43 & $\begin{array}{l}1843 \\
\quad(.00)\end{array}$ & $\begin{array}{l}.0380 \\
(.05)\end{array}$ & $\begin{array}{l}.0308 \\
(.02)\end{array}$ & $\begin{array}{l}.0261 \\
(.02)\end{array}$ & $\begin{array}{l}.0232 \\
(.00)\end{array}$ & $\begin{array}{l}.0266 \\
(.02)\end{array}$ & $\begin{array}{l}.0288 \\
(.02)\end{array}$ & $\begin{array}{l}.0261 \\
(.02)\end{array}$ & $\begin{array}{l}.0274 \\
(.16)\end{array}$ & $\begin{array}{l}.0251 \\
(.03)\end{array}$ \\
\hline 2006 & 19 & $\begin{array}{l}2046 \\
\quad(.00)\end{array}$ & $\begin{array}{l}.0412 \\
(.76)\end{array}$ & $\begin{array}{l}.0293 \\
(.02)\end{array}$ & $\begin{array}{l}.0275 \\
(.14)\end{array}$ & $\begin{array}{l}.0237 \\
(.20)\end{array}$ & $\begin{array}{l}.0267 \\
(.02)\end{array}$ & $\begin{array}{l}.0286 \\
(2.28)\end{array}$ & $\begin{array}{l}.0261 \\
(.22)\end{array}$ & $\begin{array}{l}.0290 \\
(.27)\end{array}$ & $\begin{array}{l}.0256 \\
(.15)\end{array}$ \\
\hline 2007 & 20 & $\begin{array}{l}2412 \\
\quad(.00)\end{array}$ & $\begin{array}{c}.0403 \\
(1.13)\end{array}$ & $\begin{array}{l}.0322 \\
(.17)\end{array}$ & $\begin{array}{l}.0252 \\
(.02)\end{array}$ & $\begin{array}{l}.0229 \\
(.47)\end{array}$ & $\begin{array}{l}.0273 \\
(.04)\end{array}$ & $\begin{array}{l}.0305 \\
(3.55)\end{array}$ & $\begin{array}{l}.0266 \\
(.30)\end{array}$ & $\begin{array}{l}.0296 \\
(2.11)\end{array}$ & $\begin{array}{l}.0248 \\
(.29)\end{array}$ \\
\hline
\end{tabular}


particular, the EStag reach represents a subdivision of the $D D \_S P$ reach, and the EFawn reach represents a subdivision of the $S P$ PL reach. Estimation of flow-resistance characteristics in the EStag and EFawn reaches was not possible before flows in the east branches were measured systematically with ADCP instruments. Parameter estimates converged uniquely for all years based on the PRD for SSWR of 1 percent and for parameters of 3 percent.

In general, ADCP-measured flows closely match flows simulated with time-varying parameterization from 1996 and
2007 (fig. 10). Lower-magnitude flows measured in the east branches around Stag and Fawn Islands contributed significantly to the increase in the estimated coefficient of determination $\left(r^{2}\right)$ from the conventional measurements of 0.845 to 0.996 for the ADCP measurements. The standard deviation of ADCP-flow residuals of $105 \mathrm{~m}^{3} / \mathrm{s}$ is somewhat lower, however, than the standard deviation of conventional flow-measurement residuals of $144 \mathrm{~m}^{3} / \mathrm{s}$.

Converged estimates of effective annual channel-roughness characteristics in the reach from Fort Gratiot to Dunn

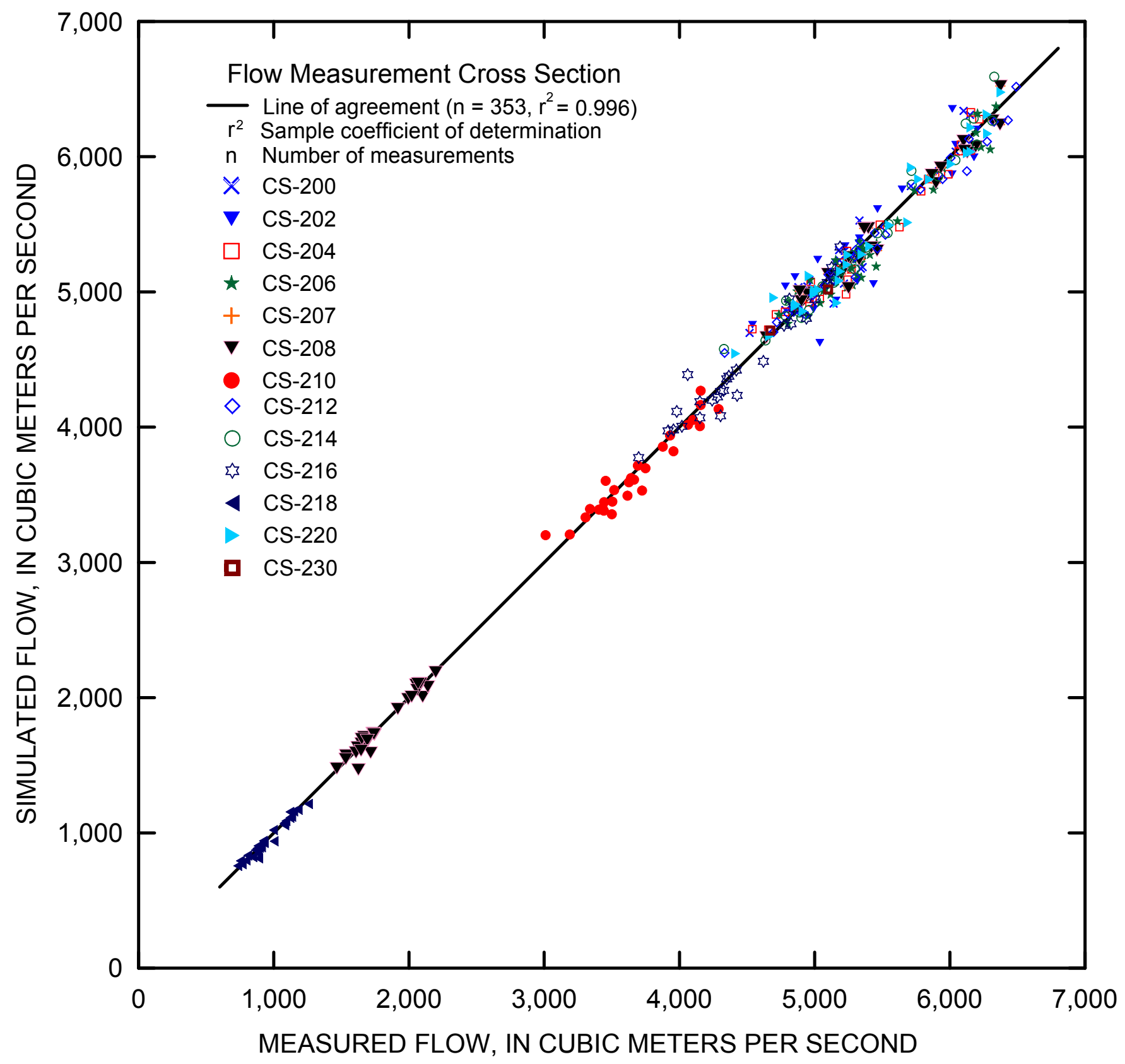

Figure 10. Relation between simulated flow and flow measured on the St. Clair River from 1996 to 2007 using acoustic Doppler current profilers. 
Paper $\left(F G \_D P\right)$ are shown on fig. 11. Limited years with flow measurements prior to 1996 , limited the years in which annual estimates of effective channel roughness could be developed. The physically improbable estimate of effective channel roughness of 0.0145 for 1968 and its departure from effective channel-roughness values of 0.04125 and 0.03634 estimated for 1963 and 1984, respectively, may have been affected by local datum irregularities associated with a negative fall of $0.0145 \mathrm{~m}$ from Point Edward to Black River $\left(P E \_B R\right)$ from April 1 to November 30, 1968. A pattern of continual change, however, is evident as a decreasing trend in channel roughness (increasing conveyance) from 1996 to 2001 and an increasing trend in channel roughness (decreasing conveyance) from 2002 to 2007. The non-monotonic pattern of change from 1996 to 2007 would be difficult to associate with dredging prior to 1962 . As indicated by the width of the 95-percent confidence interval about the expected parameter value, the median standard deviation for parameters in this reach is 0.001157 .

For the St. Clair River reach from Dunn Paper to Point Edward ( $\left.D P \_P E\right)$, the effective channel roughness generally decreased with time (fig. 12), indicating generally increasing channel conveyance since 1962. The 1963 estimate of channel roughness of 0.0337 is less than other estimates for the $1960 \mathrm{~s}$. Coincidently, the average water-level fall indicated by gagingstation records for April 1 to November 30, 1963, of $0.072 \mathrm{~m}$ was less than water-level falls of $0.124,0.121,0.144,0.141$, $0.148,0.157$, and $0.172 \mathrm{~m}$ for the corresponding period in 1962, and 1964-1969, respectively. The lower channel-rough-
Figure 11. Annual estimates of effective channel roughness with 95-percent confidence intervals for the St. Clair River reach from Fort Gratiot to Dunn Paper, Michigan.

Figure 12. Annual estimates of effective channel roughness with 95-percent confidence intervals for the St. Clair River reach from Dunn Paper, Michigan, to Point Edward, Ontario.
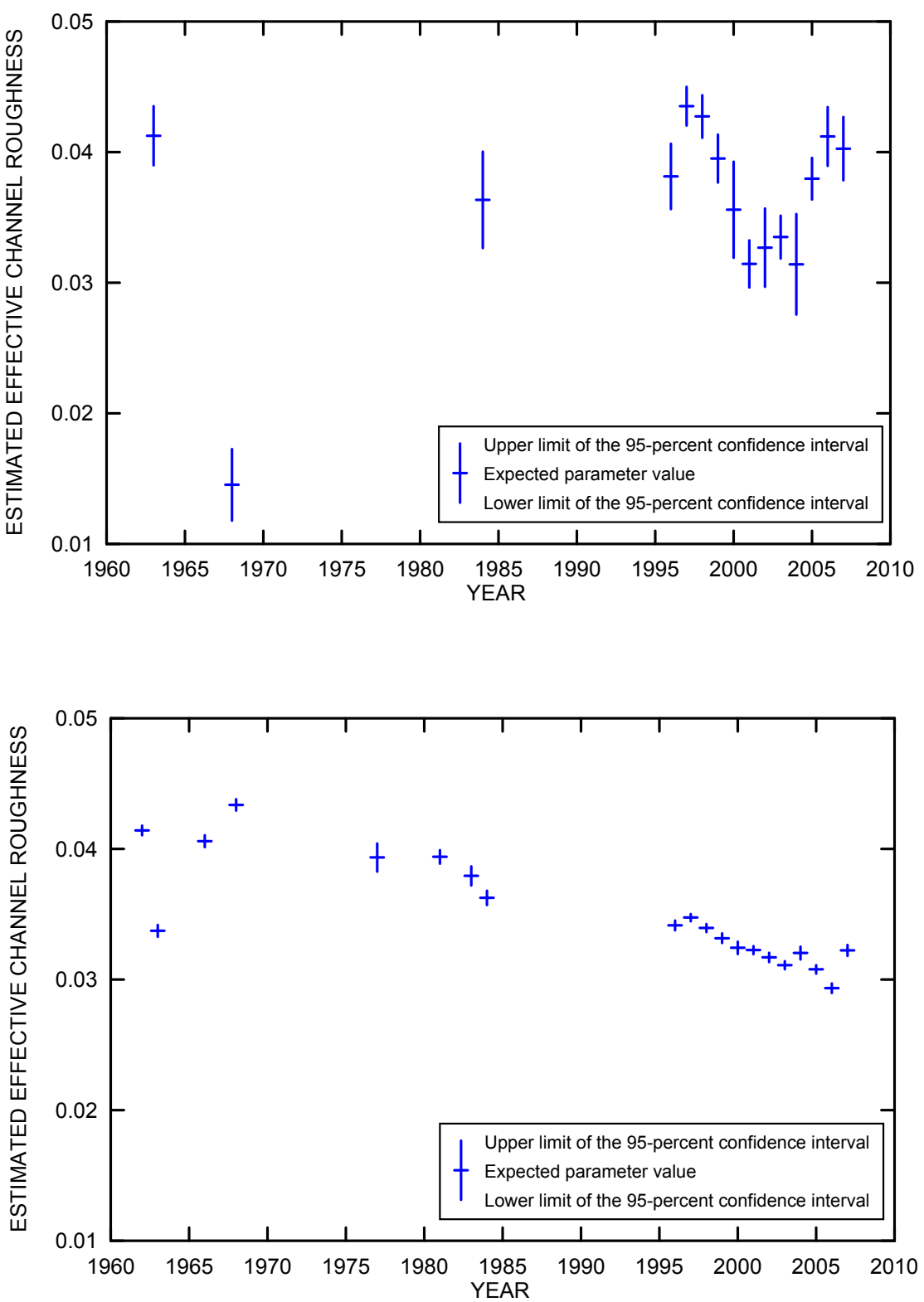
ness value would facilitate matching measured with simulated water levels at Dunn Paper.

In contrast, the effective channel roughness for the St. Clair River reach from Point Edward to Black River ( $P E \_B R$ ) was a substantially higher value of 0.0243 in 1963 than values of $0.0205,0.0209,0.0207$, and 0.0202 estimated for the years 1962, 1964, 1966, and 1968, respectively (fig. 13). Similarly, the water-level fall for April 1-November 30, 1963, of $0.0157 \mathrm{~m}$ was substantially greater than reported water-level falls of $0.0110,0.0046,-0.0160,-0.0139,-0.0105,-0.0145$, and $-0.0026 \mathrm{~m}$ in 1962, and 1964-1969, respectively. Given the greater consistency of the estimated values for 1963 conditions with post-1960s conditions on both reaches and with expected physical characteristics of channel roughness, it is possible that datum anomalies at the Dunn Paper or Point Edward water-level gaging stations degraded the estimates of effective channel roughness in other years during the 1960s.

The median standard deviation of parameters in the DP $P E$ and $P E \_B R$ reaches were 0.000213 and 0.000246 , which are substantially less than the standard deviation of parameters in the $F G_{-} D P$ reach, which was 0.00116 . The generally greater parameter uncertainty in the $F G_{-} D P$ reach may be attributable to higher variability in water levels near Fort Gratiot, where water levels are affected by wind-induced waves on Lake Huron.

The effective channel roughness in the St. Clair River reach from Black River to Dry Dock ( $B R[D D)$ generally decreased (fig. 14) from 1962 to 2007, indicating slightly
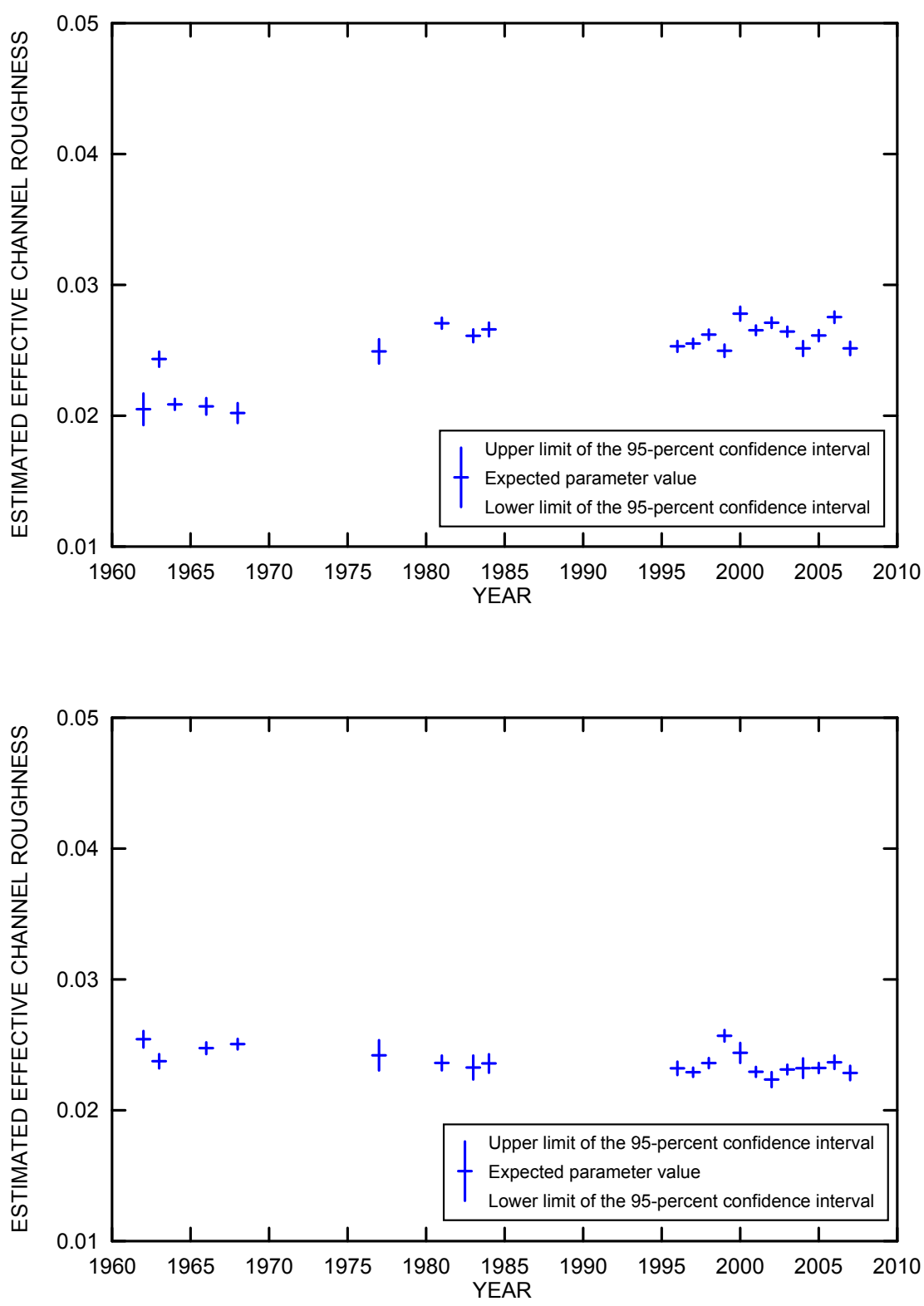

Figure 13. Annual estimates of effective channel roughness with 95-percent confidence intervals for the St. Clair River reach from Point Edward, Ontario, to the mouth of Black River, Michigan.
Figure 14. Annual estimates of effective channel roughness with 95-percent confidence intervals for the St. Clair River reach from the mouth of Black River to Dry Dock, Michigan. 
Figure 15. Annual estimates of effective channel roughness with 95-percent confidence intervals for the St. Clair River reach from Dry Dock to St. Clair State Police, Michigan.

Figure 16. Annual estimates of effective channel roughness with 95-percent confidence intervals for the St. Clair River reach from St. Clair State Police, Michigan, to Port Lambton, Ontario.

Figure 17. Annual estimates of effective channel roughness with 95-percent confidence intervals for the St. Clair River reach from Port Lambton, Ontario, to Algonac, Michigan.
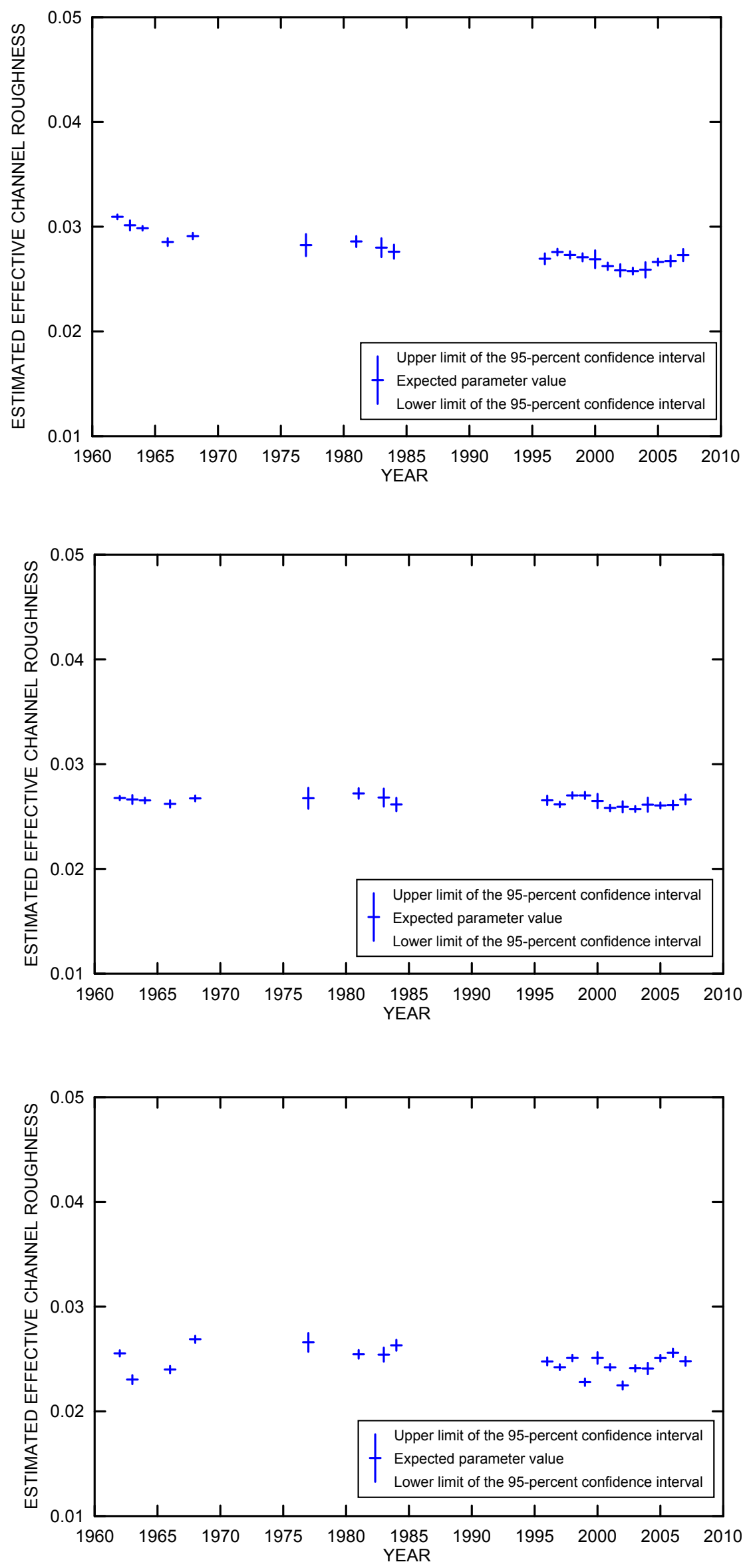
increasing conveyance with time. Some short-term instability in effective roughness may be apparent from 1998 to 2003. The median standard deviation of effective channel roughness is 0.0002612 .

In the St. Clair River reach from Dry Dock to St. Police $\left(D D \_S P\right)$, the effective channel roughness generally decreased from 1962 to 2003 and then increased to 2007 (fig. 15). From 1996 to 2007, the pattern in effective channel roughness in the reach from $D D \_S P$ was similar to the pattern of variability in effective channel roughness at the $F G_{-} D P$ reach (fig. 11). The median standard deviation in the roughness parameters for the DD_SP reach was 0.000241 .

There is limited evidence of trends or patterns in the effective channel roughness in the reach from St. Police to Port Lambton (SP_PL) (fig. 16) or in the reach from Port Lambton to Algonac ( $\left.P L_{-} A L\right)$ (fig. 17). The median standard deviations of parameter estimates in the $S P \_P L$ and $P L \_A L$ reaches were 0.000215 and 0.000194 , respectively.

\section{Fixed-Parameter Estimation}

Three scenarios were analyzed to estimate the average effective channel-roughness values for three periods: 1962-68, 1981-85, and 1996-2007. In particular, the effective channelroughness value for each specified reach was considered fixed or constant during the period. The results of fixed-parameter estimation were compared with those of time-varying parameter estimation to better understand temporal variations in conveyance.

\section{Scenario 1962 to 1968}

Seven parameters for the 1-D HEC-RAS model of the St. Clair River were estimated (table 9) based on water-level and conventional flow measurements obtained in 1962-64, 1966, and 1968 at the Bay Point (600 m downstream from CS-202) and Roberts Landing (600 m downstream from CS-220) sections (fig. 1). Intervening years without flow measurements or water-level data for boundary-condition specification were not used in parameter estimation. The sum of squared weighted residuals for the 19,221 water-level and 259 flow measurements used in the estimation was 16,605. Parameter estimates converged uniquely, with the largest magnitude correlation of 0.8967 between the effective channel-roughness parameter for the reach $D D \_S P\left(n D D \_S P\right)$ and the parameter for the reach $S P \_P L\left(n S P \_P L\right)$. The magnitude of this correlation is not thought to substantially degrade the estimation results. The match between simulated and measured flow (fig. 18) describes 83.9 percent of the variability in the flow measurements. The standard deviations of differences between measured and simulated water levels at the intervening gaging stations averaged $0.023 \mathrm{~m}$.

Table 9. Fixed-parameter estimates of effective channel roughness for St. Clair River reaches based on measurements from 1962 to 1968.

[An " $n$ " prepended to the reach identifier indicates the effective channel roughness coefficient of the corresponding reach. Reach identifiers include: $F G_{-} D P$, Fort Gratiot to Dunn Paper; $D P_{-} P E$, Dunn Paper to Point Edward; $P E_{-} B R$, Point Edward to Black River; $B R \_D D$, Black River to Dry Dock; $D D \_S P$, Dry Dock to State Police; $S P \_P L$, State Police to Port Lambton; $P L \_A L$, Port Lambton to Algonac]

\begin{tabular}{cccccc}
\hline $\begin{array}{c}\text { Name of effective } \\
\text { channel-roughness } \\
\text { parameter }\end{array}$ & $\begin{array}{c}\text { Parameter } \\
\text { estimate }\end{array}$ & $\begin{array}{c}\text { 95-percent confidence limits } \\
\text { about the parameter estimate }\end{array}$ & $\begin{array}{c}\text { Standard } \\
\text { deviation of } \\
\text { parameter } \\
\text { estimate }\end{array}$ & $\begin{array}{c}\text { Coefficient } \\
\text { of variation } \\
\text { of parameter } \\
\text { estimate }\end{array}$ \\
\hline nFG_DP & 0.0177 & 0.0164 & 0.0191 & 0.000698 & 0.0394 \\
nDP_PE & .0403 & .0401 & .0405 & .000110 & .00272 \\
nPE_BR & .0228 & .0226 & .0233 & .000163 & .00709 \\
nBR_DD & .0241 & .0239 & .0243 & .000116 & .00481 \\
nDD_SP & .0298 & .0295 & .0298 & .0000867 & .00292 \\
nSP_PL & .0265 & .0264 & .0267 & .0000786 & .00296 \\
nPL_AL & .0246 & .0244 & .0248 & .0000924 & .00376 \\
\hline
\end{tabular}


Figure 18. Relation between measured flow and flow simulated on the St. Clair River by use of a fixed, sevenparameter version of the 1-D HEC-RAS (One-dimensional Hydrologic Engineering CenterRiver Analysis System) model developed using data obtained from1962 and 1968.

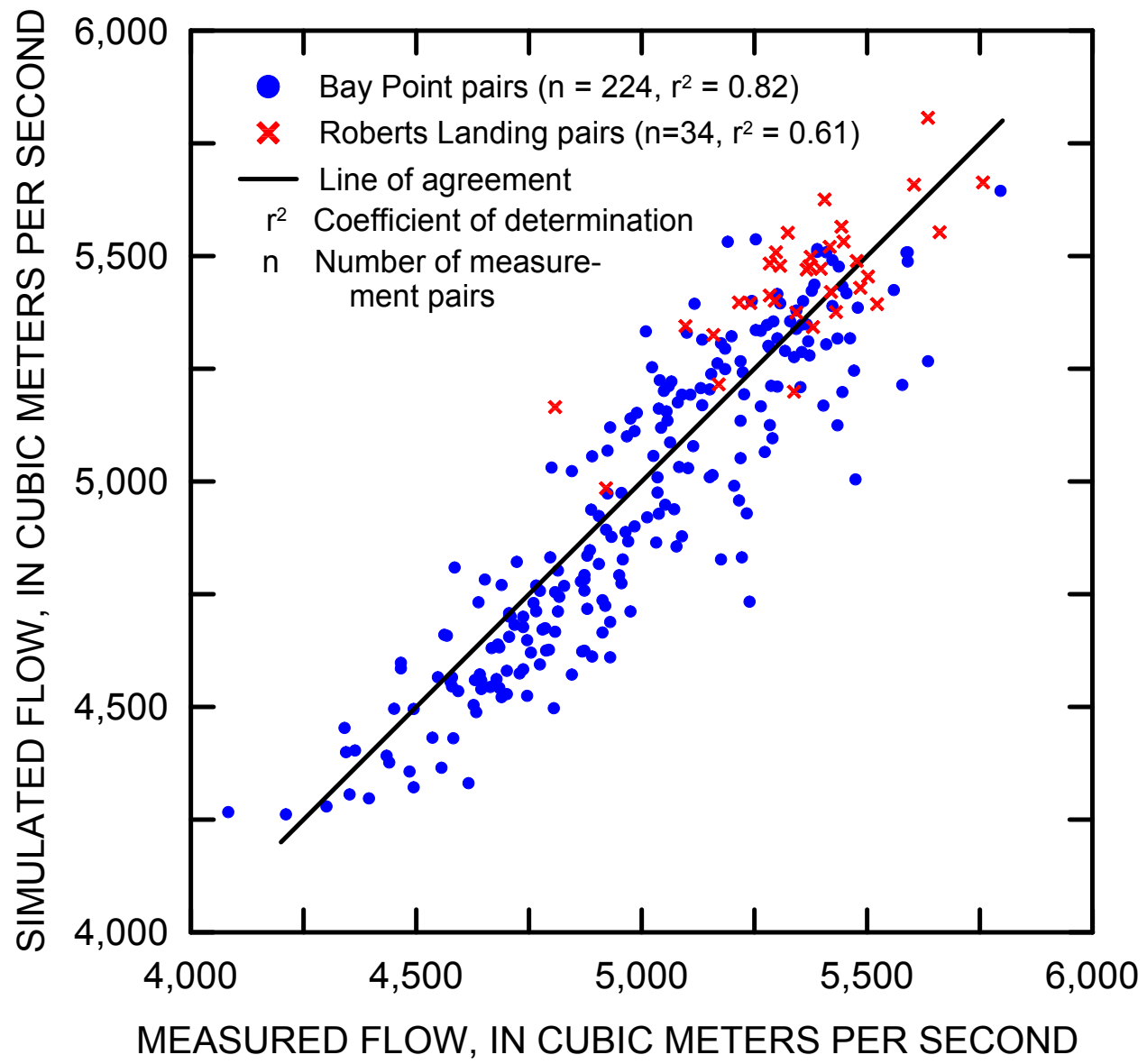

2007. The sum of squared weighted residuals for the 50,546 water-level and 346 flow measurements used in the estimation was 29,595. Parameters converged uniquely (table 10), with the largest magnitude correlation of 0.8983 (table 11) between the effective channel-roughness parameter for the reach $F G \_D P\left(n F G \_D P\right)$ and the parameter for the reach $S P \_P L$ ( $\left.n S \bar{P}_{-} P L\right)$. The magnitude of this correlation is not thought to substantially degrade the estimation results.

Simulated and measured flows match closely $\left(r^{2}=0.992\right)$ (fig. 19). Also, simulated and measured water levels match closely at all intervening gaging stations with coefficients of determination at all gaging stations exceeding 0.996 . The standard deviations of the water-level residuals for all gaging stations average less than $0.019 \mathrm{~m}$.

Fixed-parameter estimates were computed for two subintervals from 1996-2001 and 2001-07, which spanned the period of available ADCP flow-measurement data. Results indicate that parameter estimates for individual reaches generally were similar for the two subintervals (fig. 20), except for the reach from $D P P_{-} P$, where the channel roughness decreased (conveyance increased) with time (fig. 12). At $F G_{-}$ $D P$ (fig. 11) and $D D \_S P$ (fig. 15), negative trends in annual estimates of effective channel roughness during the first half of this interval were averaged with positive trends during the second half to produce similar average values for the two 
Table 10. Fixed-parameter estimates of effective channel roughness on reaches of St. Clair River for the period 1996-2007.

[An " $n$ " prepended to the reach identifier indicates the effective channel roughness coefficient of the corresponding reach. Reach identifiers include: $F G_{-} D P$, Fort Gratiot to Dunn Paper; $D P \_P E$, Dunn Paper to Point Edward; $P E \_B R$, Point Edward to Black River; $B R \_D D$, Black River to Dry Dock; $D D_{-} S P$, Dry Dock to State Police; EStag, East Stag Island; $S P \_P L$, State Police to Port Lambton; EFawn, East Fawn Island; $P L \_A L$, Port Lambton to Algonac]

\begin{tabular}{|c|c|c|c|c|c|}
\hline \multirow{2}{*}{$\begin{array}{c}\text { Name of effective } \\
\text { channel-roughness } \\
\text { parameter }\end{array}$} & \multirow{2}{*}{$\begin{array}{l}\text { Parameter } \\
\text { estimate }\end{array}$} & \multicolumn{2}{|c|}{$\begin{array}{l}\text { 95-percent confidence limits } \\
\text { about the parameter estimate }\end{array}$} & \multirow{2}{*}{$\begin{array}{c}\text { Standard } \\
\text { deviation of } \\
\text { parameter } \\
\text { estimate }\end{array}$} & \multirow{2}{*}{$\begin{array}{c}\text { Coefficient } \\
\text { of variation } \\
\text { of parameter } \\
\text { estimate }\end{array}$} \\
\hline & & Lower limit & Upper limit & & \\
\hline$n F G \_D P$ & 0.0367 & 0.0360 & 0.0373 & 0.000320 & 0.00871 \\
\hline$n D P \_P E$ & .0325 & .0324 & .0326 & .0000539 & .00166 \\
\hline$n P E \_B R$ & .0260 & .0259 & .0262 & .0000659 & .00253 \\
\hline$n B R \_D D$ & .0232 & .0231 & .0233 & .0000696 & .00300 \\
\hline$n D D \_S P$ & .0265 & .0264 & .0266 & .0000653 & .00246 \\
\hline nEStag & .0282 & .0276 & .0287 & .000270 & .00958 \\
\hline$n S P \_P L$ & .0261 & .0260 & .0262 & .0000557 & .00213 \\
\hline nEFawn & .0263 & .0256 & .0269 & .000336 & .0128 \\
\hline$n P L \quad A L$ & .0242 & .0241 & .0243 & .0000538 & .00222 \\
\hline
\end{tabular}

Table 11. Lower diagonal elements of the symmetric correlation matrix for fixed-parameter estimates of effective channel roughness coefficients on St. Clair River for the period 1996-2007.

[An " $n$ " prepended to the reach identifier indicates the effective channel roughness coefficient of the corresponding reach. Reach identifiers include: $F G_{-} D P$, Fort Gratiot to Dunn Paper; $D P \_P E$, Dunn Paper to Point Edward; $P E \_B R$, Point Edward to Black River; $B R \_D D$, Black River to Dry Dock; $D D_{-} S P$, Dry Dock to State Police; EStag, East Stag Island; SP PL, State Police to Port Lambton; EFawn, East Fawn Island; $P L \_A L$, Port Lambton to Algonac]

\begin{tabular}{|c|c|c|c|c|c|c|c|c|c|}
\hline $\begin{array}{c}\text { Name of effective } \\
\text { channel-roughness } \\
\text { parameter }\end{array}$ & $n F G \_D P$ & $n D P \_P E$ & $n P D \_B R$ & nBR_DD & $n D D \_S P$ & $n E S t a g$ & $n S P P_{-} P L$ & nEFawn & $n P L \_A L$ \\
\hline$n F G \_D P$ & 1.0000 & -- & -- & -- & -- & -- & -- & -- & -- \\
\hline$n D P \_P E$ & .2303 & 1.0000 & -- & -- & -- & -- & -- & -- & -- \\
\hline$n P D \_B R$ & .2860 & -.2172 & 1.0000 & -- & -- & -- & -- & -- & -- \\
\hline nBR_DD & .7359 & .4423 & -.0776 & 1.0000 & -- & -- & -- & -- & -- \\
\hline$n D D \_S P$ & .8177 & .4641 & .2783 & .6519 & 1.0000 & -- & -- & -- & -- \\
\hline nEStag & .0732 & .0415 & .0257 & .0490 & -.3422 & 1.0000 & -- & -- & -- \\
\hline$n S P P_{-} P L$ & .8983 & .5102 & .3024 & .7794 & .8458 & .0759 & 1.0000 & -- & -- \\
\hline nEFawn & .0646 & .0367 & .0224 & .0561 & .0564 & .0054 & -.0079 & 1.0000 & -- \\
\hline$n P L \_A L$ & .6224 & .3534 & .2093 & .5397 & .5998 & .0541 & .5587 & .0192 & 1.0000 \\
\hline
\end{tabular}


subintervals (fig. 20). The standard deviations of flow residuals for the periods 1996-2001 and 2002-07 were 122, and 141 $\mathrm{m}^{3} / \mathrm{s}$, respectively.

\section{Integration of Time-Varying and Fixed-Parameter Estimation Results}

Although patterns are evident in some of the annual series of parameter estimates, the significance of any pattern for flow simulation was difficult to establish directly. In this analysis, the annual series of parameter estimates from 1996 to 2007 are used as a basis for vectors to help explain the difference between measured and simulated flows in the fixed, nineparameter model also developed with data from 1996 to 2007. In particular, the regression design matrix is composed of nine columns corresponding to the nine reaches for which annual variations in effective channel roughness were estimated, plus a vector of ones for the intercept term. The vectors have a length equal to the number of flow measurements. The value in each row of the basis vectors corresponds to the estimated

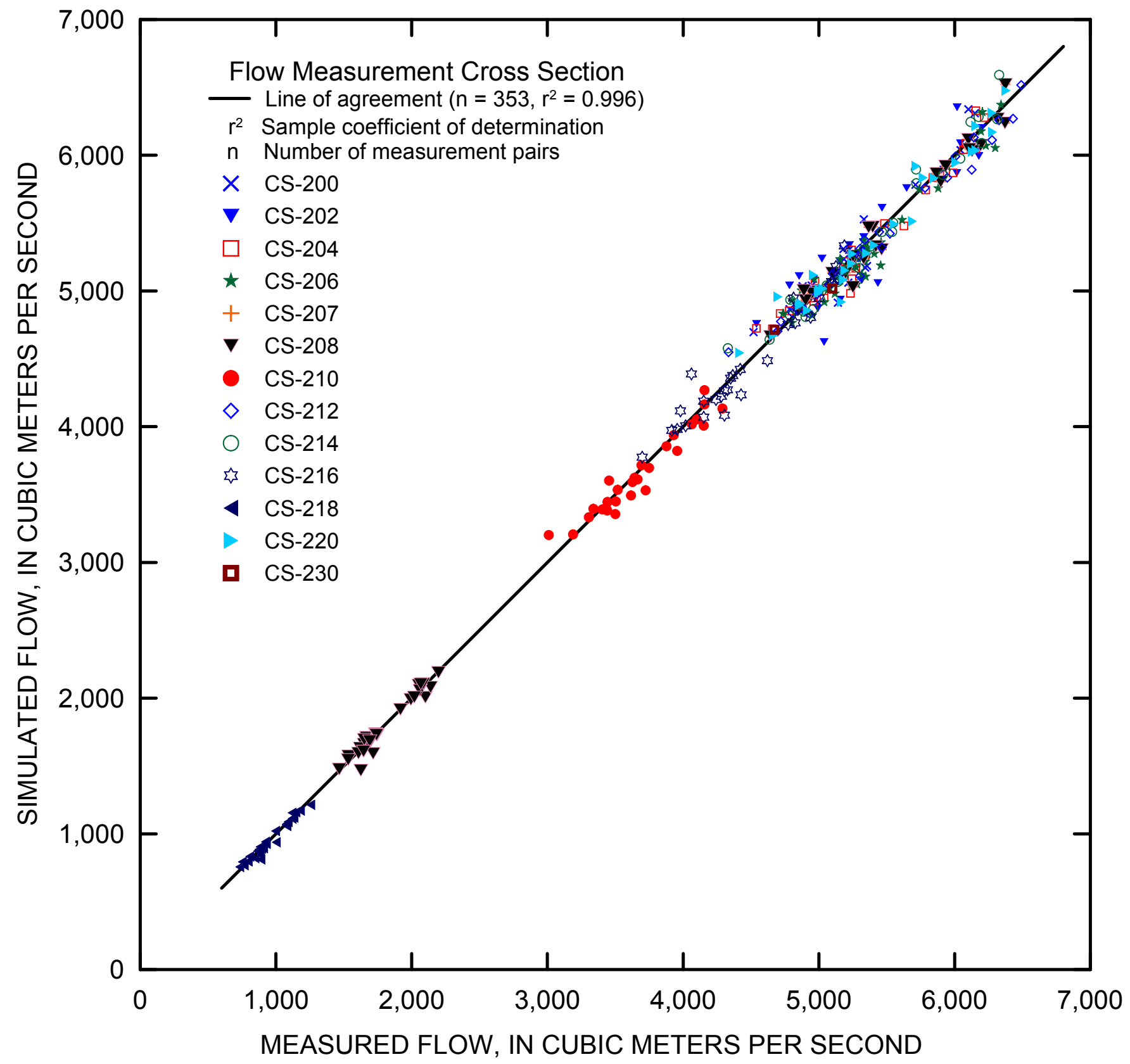

Figure 19. Relation between measured flow and flow simulated on the St. Clair River by use of a fixed, nine-parameter version of the hydrodynamic model for the period 1996-2007. 
effective channel-roughness value in the year of the flow measurement. A stepwise variable-selection process in a multiple-regression analysis was used to identify reaches where patterns in annual effective channel-roughness estimates were related to flow residuals. The basis vectors corresponding to the annual series of effective channel-roughness values are distinguished by a leading $b$ rather than an $n$ preceding the reach designator. For example, $b F G_{-} D P$ is the basis vector created from the annual series of effective channel-roughness estimates in $n F G \_D P$.

Results indicate that four basis vectors- $-b F G_{-} D P$, $b D P \_P E, b P E_{-} B R$, and $b S P_{-} P L-\operatorname{explain} 38.1$ percent of the variability in the flow residuals (table 12). Analysis of variance indicates that the overall model is statistically significant ( $p$-value $<0.0001$ ) based on an $F$ statistic of 54.15 with 341 degrees of freedom in the model error. Of the four included basis vectors, the non-monotonic variations in the annual series $n F G \_D P$ are associated with the basis vector with the largest significance. Although differing in scale, the annual series $n D D \_S P$ shows a similar pattern of variation as $n F G \_D P$. The corresponding basis vectors have a correlation coefficient of 0.9201 . This similarity (co-linearity) between the two basis vectors may mask the contribution of $n D D \_S P$ in explaining the variability of flow residuals.

To assess the possible significance of annual variations in effective channel roughness at $D D \_S P$, the stepwise multiple regression was re-run excluding the basis vector $b F G \_D P$. Again, four basis vectors were selected with an $\alpha=0.10$ such that $b D D \_S P$ had the greatest significance of the eight available basis vectors (table 12). Furthermore, the same three basis vectors $b D P P E, b P E B R$, and $b S P P L$ are included in both models, and the estimated parameters associated with these variables are similar between the two regression analyses.

The results of the regression analyses are used to ascertain that annual variations in effective channel-roughness values at reaches $F G \_D P, D P \_P E, P E \_B R, D D \_S P$, and $S P \_P L$ contribute to the understanding of variability in flows measured from 1996 to 2007, which are not accounted for by flows simulated using the fixed, nine-parameter HEC-RAS model of the St. Clair River. Patterns in the annual series $n F G \_D P$ and $n \_D D \_S P$ are similar, showing a gradual decrease in effective channel-roughness values (increase in conveyance) from 1996 to about 2002 , followed by an increase in effective channel roughness (decrease in conveyance) from 2003 to 2007. The annual series $n D P_{-} P E$ indicates a general decrease in effective channel roughness (increase in conveyance) from 1996 to 2007, which is consistent with the pattern indicated by earlier estimates of $n D P \_P E$. Annual variations in effective channel roughness in the series $n P E_{-} B R$ and $n S P \_P L$ show less persistence than variations at other selected reaches. Variations in effective channel roughness at non-selected reaches may contribute to unexplained variability in water levels, but have no demonstrable relation to flows.

Stepwise regression tends to over indicate the statistical significance of individual selected variables, so the effective alpha value is likely less than 0.1 . Based on the significance of the overall models, however, annual variations in effective channel roughness account for flow variability not explained by the fixed, nine-parameter HEC-RAS model of the St. Clair River.

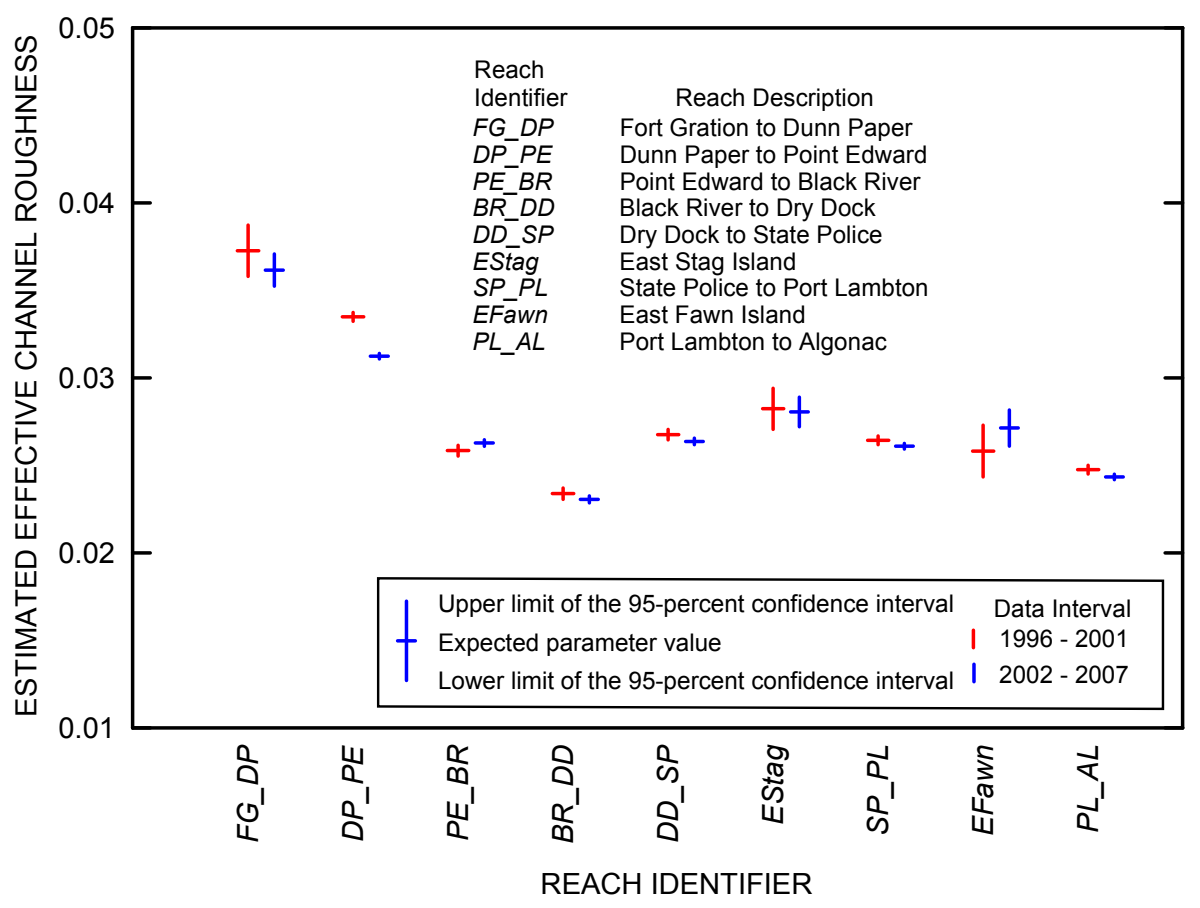

Figure 20. Fixed-parameter channel roughness estimates for nine St. Clair River reaches for the periods 1996-2001 and 2002-2007. 
Table 12. Basis vectors selected in a stepwise-regression analysis of flow residuals from the 1996 to 2007 fixed, nine-parameter model of St. Clair River.

[An " $b$ " prepended to the reach identifier indicates a basis vector for the corresponding reach. Reach identifiers include: $F G_{-} D P$, Fort Gratiot to Dunn Paper; $D P \_P E$, Dunn Paper to Point Edward; $P E_{-} B R$, Point Edward to Black River; $B R \_D D$, Black River to Dry Dock; $D D \_S P$, Dry Dock to State Police; $S P \_P L$, State Police to Port Lambton; $P L_{-} A L$, Port Lambton to Algonac]

\begin{tabular}{|c|c|c|c|c|c|}
\hline Variable & $\begin{array}{l}\text { Degrees } \\
\text { of freedom }\end{array}$ & $\begin{array}{c}\text { Parameter } \\
\text { estimate }\end{array}$ & $\begin{array}{c}\text { Standard } \\
\text { error }\end{array}$ & t-value & $\operatorname{Pr}>\operatorname{abs}(\mathbf{t})$ \\
\hline \multicolumn{6}{|c|}{ Results of a stepwise-regression analysis using all nine basis vectors } \\
\hline Intercept & 1 & 3,142 & 606 & 5.19 & $<0.0001$ \\
\hline bFG_DP & 1 & $-12,602$ & 1,926 & -6.54 & $<.0001$ \\
\hline$b P E \_B R$ & 1 & $-18,760$ & 10,396 & -1.80 & .072 \\
\hline$b S P \_P L$ & 1 & $-53,923$ & 17,334 & -3.11 & .002 \\
\hline \multicolumn{6}{|c|}{ Results of stepwise-regression analysis using eight basis vectors, excluding $b F G \_D P$} \\
\hline$b P E \_B R$ & 1 & $-23,279$ & 10,370 & -2.24 & .0254 \\
\hline bDD_SP & 1 & $-102,757$ & 16,213 & -6.34 & $<.0001$ \\
\hline bSP_PL & 1 & $-50,895$ & 17,705 & -2.87 & .004 \\
\hline
\end{tabular}

\section{Effective Channel Roughness Ratios and Conveyance Ratios}

Equation 2 was used to compute conveyance ratios as a function of measured water levels (and reach lengths). Alternatively, conveyance ratios can be computed by use of equation 3 and the effective channel roughness values estimated by use of inverse modeling as

$$
\frac{\tilde{K}_{1}}{\tilde{K}_{2}}=\frac{1 / \hat{n}_{1} \cdot A_{1} \cdot R_{1}^{2 / 3}}{1 / \hat{n}_{2} \cdot A_{2} \cdot R_{2}^{2 / 3}} \simeq c_{1,2} \frac{\hat{n}_{2}}{\hat{n}_{1}} \propto \frac{K_{1}}{K_{2}}
$$

provided the ratios of cross-sectional areas $\left(A_{1}, A_{2}\right)$ and hydraulic radii $\left(R_{1}, R_{2}\right)$ in any two reaches 1 and 2 , given $\hat{\mathrm{n}}$, are approximately constant $c_{1,2}$ with time.

In the estimation of effective channel roughness values by use of inverse modeling techniques, the bathymetry data, used to compute cross-sectional areas and hydraulic radii, did not vary with time. Therefore, the assumption of a constant cross sectional properties is reflected in the estimated effective roughness values. Although the reach-pair specific values of the proportionality constant $c$ cannot be determined directly, $c$ can be assumed to be positive because it is a function of channel cross section values that only take on positive values. Thus, conveyance ratios are assumed to be positively associated with the inverse of estimated effective roughness ratios (equation 13).

To test this assumption, ratios of annual estimates of channel roughness values were computed for all possible reach pairs using inverse modeling results for the period from 1996 through 2007 . For 20 of the 21 pairs of these reaches, the ratios of channel roughness values were inversely proportional to conveyance ratios computed by use of water-level data (table 13). Thus, conveyance ratios computed on the basis of water level data (equation 2) are directly proportional (fig. 21) to conveyance ratios based on effective channel roughness estimated (equation 3).

This consistency between estimators of conveyance ratios is thought to apply to data prior to 1996, when limited flow measurement data were available to support continual annual estimation of effective channel roughness values by use of inverse modeling analysis. Given the time-invariance of this relation, the conveyance ratios computed from water-surface data provide a basis for understanding and extending trends in conveyance ratios that are consistent with conveyance ratios computed by use of inverse modeling techniques. 
Table 13. Relation between ratios of effective channel roughness and conveyance ratios among reaches of the St. Clair River based on data from 1996 to 2007 ..

[Reach ID, reach identification; $F G_{-} D P$, Fort Gratiot to Dunn Paper; $D P \_P E$, Dunn Paper to Point Edward; $P E \_B R$, Point Edward to Black River; $B R \_D D$, Black River to Dry Dock; $D D \_S P$, Dry Dock to State Police; $S P \_P L$, State Police to Port Lambton; $P L \_A L$, Port Lambton to Algonac]

\begin{tabular}{|c|c|c|c|c|c|c|c|c|}
\hline $\begin{array}{l}\text { Upstream } \\
\text { reach }\end{array}$ & $\begin{array}{l}\text { Downstream } \\
\text { reach }\end{array}$ & $\begin{array}{c}\text { Kendall's } \\
\text { tau }\end{array}$ & $p$-value ${ }^{1}$ & Intercept & $\begin{array}{l}\text { Median } \\
\text { slope }\end{array}$ & $\begin{array}{c}\text { Median } \\
\text { ratio }\end{array}$ & $\begin{array}{c}\text { Median } \\
\text { year }\end{array}$ & $N^{2}$ \\
\hline \multirow[t]{6}{*}{$F G \_D P$} & $D P \_P E$ & -0.0182 & 0.560 & 0.432 & -0.00455 & 0.428 & 0.895 & 11 \\
\hline & $P E \_B R$ & 0.4667 & .0363 & -0.0116 & .267 & .182 & .722 & 10 \\
\hline & $B R \_D D$ & 0.7091 & .0008 & 0.222 & .157 & .319 & .612 & 11 \\
\hline & $D D \_S P$ & 0.5758 & .0044 & .221 & .0970 & .290 & .704 & 12 \\
\hline & $S P_{-} P L$ & 0.697 & .0005 & .198 & .103 & .269 & .691 & 12 \\
\hline & $P L_{-} A L$ & 0.4545 & .0224 & .122 & .113 & .196 & .655 & 12 \\
\hline \multirow[t]{5}{*}{$D P_{-} P E$} & $P E \_B R$ & 0.9556 & $<.0001$ & -.829 & 1.62 & .441 & .783 & 10 \\
\hline & $B R \_D D$ & 0.7333 & .0011 & -.543 & 1.84 & .762 & .710 & 10 \\
\hline & $D D \_S P$ & 0.5273 & .0132 & -.767 & 1.80 & .696 & .815 & 11 \\
\hline & $S P \_P L$ & 0.7455 & .0004 & -.515 & 1.42 & .647 & .816 & 11 \\
\hline & $P L \_A L$ & 0.6727 & .0016 & -.191 & .880 & .470 & .751 & 11 \\
\hline \multirow[t]{4}{*}{$P E \_B R$} & $B R \_D D$ & 0.6000 & .0083 & -1.98 & 4.14 & 1.74 & .899 & 10 \\
\hline & $D D \_S P$ & 0.6889 & .0023 & -2.14 & 3.63 & 1.62 & 1.04 & 10 \\
\hline & $S P \_P L$ & 0.6444 & .0046 & -2.76 & 4.14 & 1.49 & 1.03 & 10 \\
\hline & $P L \_A L$ & 0.6000 & .0083 & -2.26 & 3.58 & 1.07 & .931 & 10 \\
\hline \multirow[t]{3}{*}{$B R \_D D$} & $D D \_S P$ & 0.8545 & $<.0001$ & .184 & .632 & .907 & 1.14 & 11 \\
\hline & $S P \_P L$ & 0.7455 & .0004 & .084 & .667 & .835 & 1.13 & 11 \\
\hline & $P L \_A L$ & 0.6727 & .0016 & -.0298 & .602 & .606 & 1.06 & 11 \\
\hline \multirow[t]{2}{*}{$D D \_S P$} & $S P \_P L$ & 0.697 & .0005 & -.0379 & .979 & .926 & .985 & 12 \\
\hline & $P L \_A L$ & 0.7576 & .0001 & -.0919 & .827 & .670 & .922 & 12 \\
\hline SP_PL & $P L \_A L$ & 0.7176 & .0008 & -.205 & .997 & .725 & .932 & 12 \\
\hline
\end{tabular}

${ }^{1} p$-value is the probability that the null hypothesis that the correlation coefficient is not greater than zero, given the sample data pairs, is true.

${ }^{2} \boldsymbol{N}$ is the number of sample data pairs. 

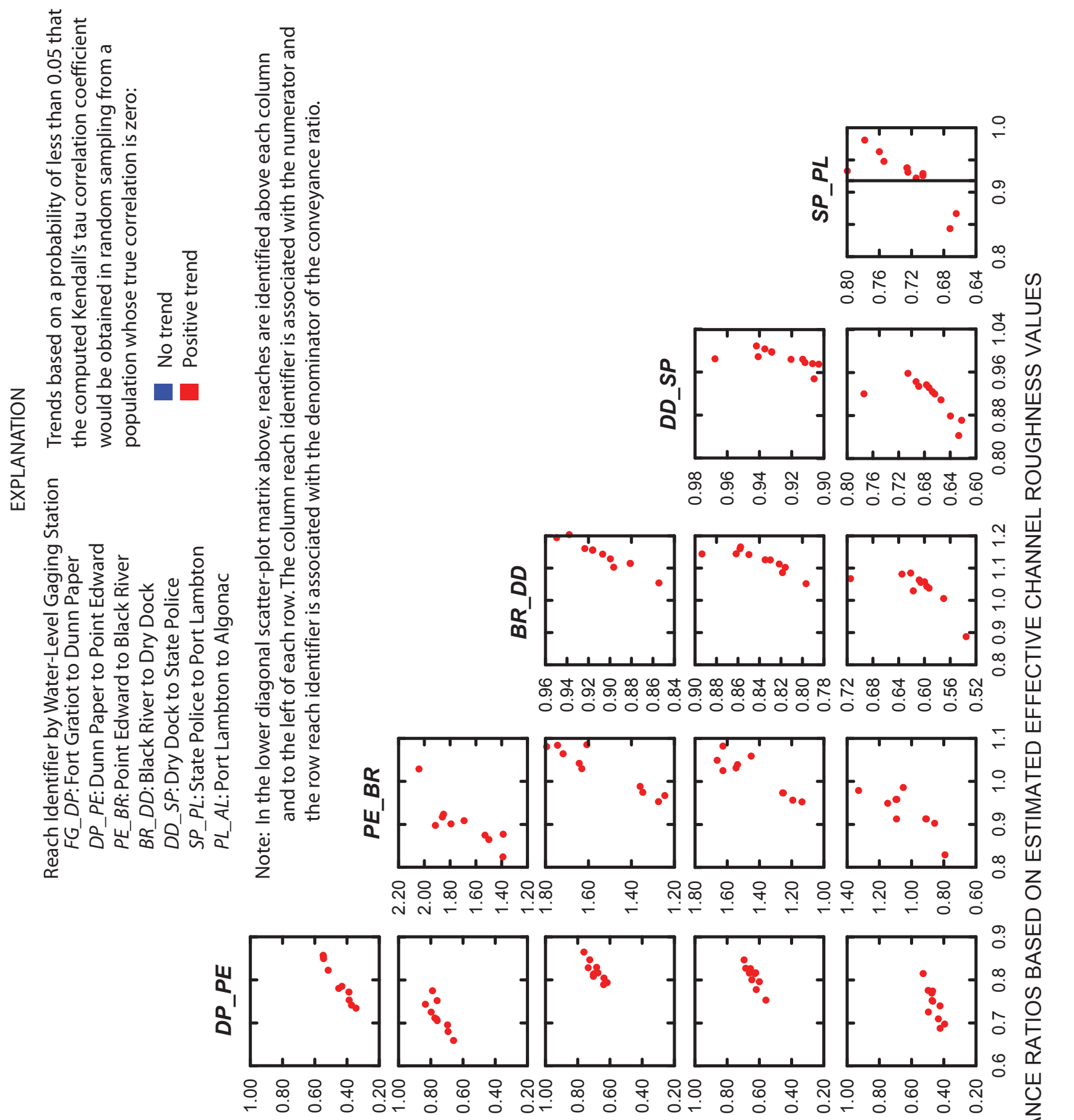

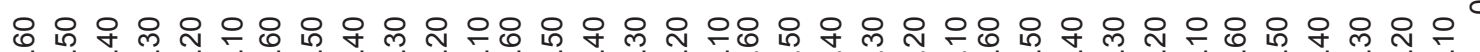

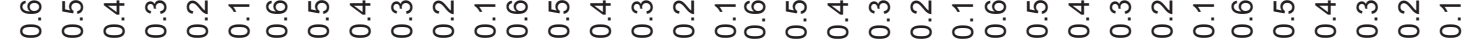

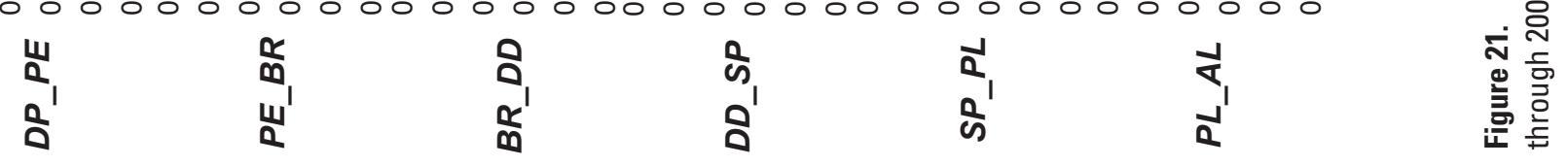




\section{Inferring Changes in River Conveyance from 1-D Hydrodynamic Simulations}

The previous section described annual estimates of effective channel-roughness parameters that were consistently determined for each reach from water-level and flow measurements by statistical inference. These annual parameter estimates are used with historical water-level boundary conditions to show how the change in parameters from 1962 to 2007 would affect corresponding estimates of average flow. Changes in flow with parameterization indicate changes in conveyance with time, because the boundary conditions are consistent across annual parameterizations.

Hourly flows were simulated for all years from 1962 to 2007 in which parameter estimates converged under all sets of converged parameters. Average annual flows from April 1 to November 30 simulated near the water-level gaging station at Dry Dock, Mich., (HEC-RAS cross-section 125) were computed to provide a basis of comparison. Results indicate that simulated flows for 2007 water-level boundary conditions averaged $675 \mathrm{~m}^{3} / \mathrm{s}$ (12.5 percent) less than simulated flows for 1962 water-level boundary conditions for all annual sets of parameters estimated (fig. 22). Simulated flows for both 1962 and 2007 water-level boundary conditions, however, generally increased with annual parameter estimates of hydraulic conditions for 1962 to 2003, but decreased monotonically for conditions from 2004 to 2007. Likewise, simulated average flows generally increased for boundary conditions from 1963 to 2003 with annual estimates of parameters relative to values simulated for parameters associated with 1962 hydraulic conditions.

The relative increase in simulated flows from 1962 hydraulic conditions varied from about 0.87 to 10 percent (fig. 23) from 1963 to 2003 and decreased to about 5.8 percent
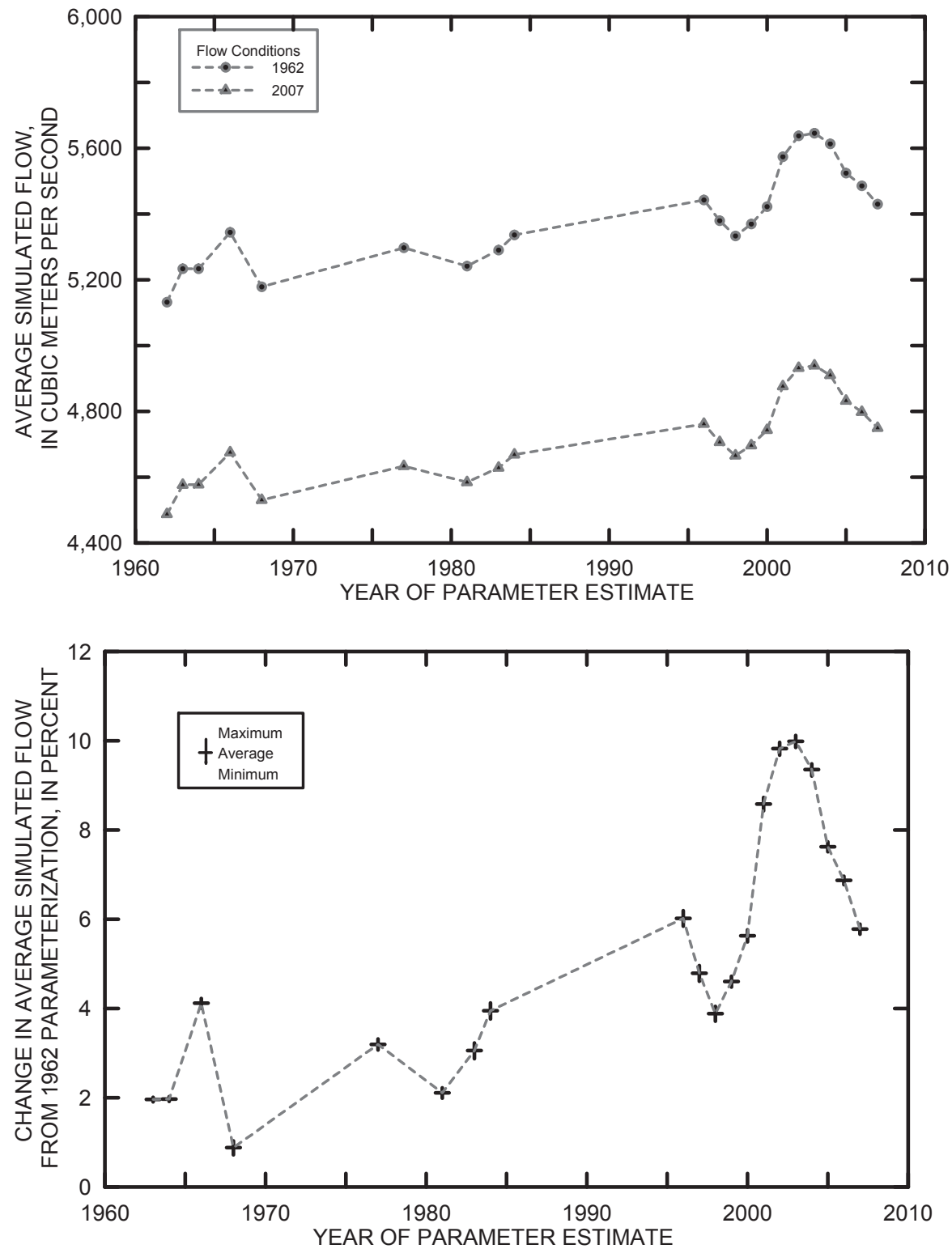

Figure 22. Relation between annual model-parameter estimates and simulated average flow from 1962 to 2007 for 1962 and 2007 water-level boundary conditions.
Figure 23. Relation between annual parameter estimates and changes in average simulated flow from the 1962 parameterization. 
by 2007. Changes in average and relative flows with year of parameterization are associated with changes in conveyance because water-level boundary conditions were consistent. As demonstrated by use of equation 12 , the relative changes in simulated flows indicate the relative annual changes in conveyance (fig. 23).

\section{Summary and Conclusions}

Water levels on Lakes Michigan and Huron (MichiganHuron) are controlled by flow through the St. Clair River. In 2007, water levels on Lake Michigan-Huron were 0.5-meters below historical averages for 1918-2007. Although no trends were detected in Lake Michigan-Huron or Lake St. Clair water levels, annual differences between these water levels were decreasing from 1962 to 2007. This decrease indicates that conveyance is increasing if average annual flow is constant or that flow is decreasing if conveyance is constant. This study was done to investigate possible conveyance changes from 1962 to 2007 by use of water-level and flow data with an inverse hydrodynamic model of the St. Clair River.

A 47.3-kilometer reach of St. Clair River was investigated from the northern limit near Fort Gratiot, Michigan, to the southern limit near Algonac, Michigan. The river was subdivided into seven reaches delimited by the locations of eight water-level gaging stations. Monotonic trends in average water-level differences (water-surface fall) within reaches were analyzed. Positive trends in water-surface fall were detected in two reaches, and negative trends were detected in two other reaches. The presence of both positive and negative trends in fall is inconsistent with the hypothesis of no conveyance change regardless of possible trends in flow.

Flow within a reach approximately equals the product of conveyance and the square root of the water-surface slope. Given that the annual flow through all reaches in the St. Clair River is approximately the same, annual conveyance ratios between reaches can be computed without knowing the magnitude of this flow. Analysis of trends in annual conveyance ratios indicates that conveyance in the reach from Fort Gratiot to Dunn Paper is decreasing with respect to all other reaches except Point Edwards to Black River. In contrast, conveyance in the reach from Dunn Paper to Point Edward is increasing with respect to all downstream reaches. Conveyance in the reach from Point Edward to Black River is decreasing with respect to all downstream reaches. If conveyances in the reach from Fort Gratiot to Dunn Paper and in the reach from Point Edward to Black River are both decreasing with time, the lack of significant change in conveyance between the two reaches is not unexpected. Conveyance in the reach from Black River to Dry Dock is decreasing with respect to conveyance from State Police to Port Lambton; conveyance from Dry Dock to State Police is increasing with respect to conveyance from State Police to Port Lambton. Although conveyance ratios were sometimes positively or negatively related to estimated flow in different reaches, adjusting conveyance ratios for flow did not substantially alter the interpretation of conveyance ratios that were not adjusted for flow.

Inverse one-dimensional (1-D) hydrodynamic modeling of the St. Clair River was used to investigate conveyance change from 1962 to 2007, although missing water-level or limited flow-measurement data prior to 1996 limited annual estimation. In particular, inverse modeling techniques were used to estimate the magnitude and uncertainty of parameters associated with the effective channel roughness in each reach for selected time intervals under a fixed geometry model. Patterns in the time series of estimated parameters were interpreted as evidence of conveyance change by all factors that affect conveyance, including cross-sectional area, hydraulic radius, and channel roughness. Hourly water-level measurements were used as boundary conditions for unsteady flow simulations from April 1 to November 30 of each year, a period selected to avoid variable ice-induced backwater effects.

Conveyance ratios can be computed for reach pairs on the basis of water-level measurements or effective channel roughness values estimated by use of inverse modeling. Comparison of annual conveyance ratios computed by use of both techniques for the period 1996 through 2007 showed that the two estimates are, in general, directly proportional. The consistency between estimates for the 1996-2007 periods supports the interpretation of trends in conveyance ratios computed by use of water-level data from 1962-2007.

Possible changes in river conveyance cannot be ascertained directly from positive and negative changes in reach conveyances. To assess changes in river conveyance, annual flows were simulated under all available annual parameterizations for each corresponding water-level boundary-condition set. Over all boundary-condition sets, results show the relative simulated flows increased significantly with the year of parameterization from 1962 to 2002 by as much as 10 percent and decreased about 4.2 percent from 2002 to 2007 . These non-monotonic trends in conveyance are difficult to associate with a causative event.

\section{Acknowledgments}

This study was supported by the International Upper Great Lakes Study Board and U.S. Army Corps of Engineers. The authors are grateful to several individuals from the USACE Hydrologic Engineering Center in Davis, California. In particular, Jason Giovannettone developed the standard 1-D HEC-RAS model of the St. Clair River and responded to several requests for modifications from the authors. Mark Jensen developed a Visual Basic script that enabled the parameterestimation application-UCODE- to run HEC-RAS without user intervention. Gary Brunner, the developer of HEC-RAS, provided technical assistance to the authors in applying HECRAS to the St. Clair River. Nanette Noorbakhsh, USACEDetroit District compiled flow and water-level measurement 
data for the St. Clair River that were essential to this study. Aaron Thompson, Environment Canada at the Canada Center for Inland Waters, and Stephen Wiele, USGS Arizona Water Science Center provided technical reviews. Finally, the authors wish to acknowledge the contributions of numerous individuals from various local, State, and Federal agencies, including the Great Lakes Commission, who were instrumental in preserving NOAA's water-level gaging-station network when elimination of numerous gages on the St. Clair-Detroit River Waterway was proposed in 2000.

\section{References Cited}

Arcement, G.J., Jr., and Schneider, V.R., 1989, Guide for selecting Manning's roughness coefficients for natural channels and flood plains: U.S. Geological Survey Water-Supply Paper 2339, 38 p., accessed April 9, 2009 at http://pubs. er.usgs.gov/djvu/WSP/wsp_2339.djvu.

Barnes, H.H., Jr., 1967, Roughness characteristics of natural channels: U.S. Geological Survey Water-Supply Paper $1849,213 \mathrm{p}$.

Brunner, G.W., 2008, HEC-RAS, River Analysis System hydraulic reference manual, v. 4.0: Davis, Calif., U.S. Army Corps of Engineers, Hydrologic Engineering Center, 411 p.

Conover, W.J., 1980, Practical Nonparameteric Statistics (2d ed.): New York, Wiley, 493 p.

Coordinating Committee for Great Lakes Basic Hydraulic and Hydrologic Data, 1994, Hydraulic discharge measurements and regimen changes on the Great Lakes connecting channels and the international section of the St. Lawrence River, Appendix C-Table Summaries of Discharge Measurements: 1841-1993, March, 450 p.

Croley, T.E., II, and Hunter, T.S., [2006], Great Lakes monthly hydrologic data: National Oceanic and Atmospheric Administration, Great Lakes Environmental Research Laboratory, Technical Report GLERL-083, 13 p., accessed January 22, 2009, at ftp://ftp.glerl.noaa.gov/publications/tech_reports/ glerl-083/report.pdf

Gilbert, R.O., 1987, Statistical Methods for Environmental Pollution Monitoring: New York, Van Nostrand Reinhold Company, $320 \mathrm{p}$.

Hill, M. C., 1998, Methods and guidelines for effective model calibration: U.S. Geological Survey Water-Resources Investigations Report 98-4005, 90 p.
Hitt, K.J., and Miller, J.B., 1986, Great Lakes set record high water levels, in National Water Summary 1985-Hydrologic Events and Surface-Water Resources: U.S. Geological Survey Water Supply Paper 2300, pp. 35-40.

Holtschlag, D.J., and Koschik, J.A., 2001, Steady-state flow distribution and monthly flow duration in selected branches of St. Clair and Detroit Rivers within the Great Lakes Waterway: U.S. Geological Survey Water-Resources Investigations Report 01-4135, 58 p.

International Joint Commission, [2007], International Upper Great Lakes Study, accessed December 31, 2007, at http:// www.iugls.org/en/IUGLS\%20Brochure.pdf

National Oceanic and Atmospheric Administration, 1999, Recreational chart 14853-Detroit River, Lake St. Clair, and St. Clair River: U.S. Department of Commerce, National Ocean Service.

Poeter, E.P., Hill, M.C., Banta, E.R., Mehl, Steffen, and Christensen, Steen, 2005, UCODE_2005 and six other computer codes for universal sensitivity analysis, calibration, and uncertainty evaluation: U.S. Geological Survey Techniques and Methods 6-A11, 283 p.

Quinn, F.H., 1985, Temporal effects of St. Clair River dredging on Lakes St. Clair and Erie water levels and connecting channel flow: Journal of Great Lakes Research, v. 11, no. 3, pp. 400-3.

Rantz, S.E., and others, 1982, Measurement and computation of streamflow-Volume 1-Measurement of stage and discharge: U.S. Geological Survey Water-Supply Paper 2175, 284 p.

Simpson, M.R., 2001, Discharge measurements using a broadband acoustic Doppler current profiler: U.S. Geological Survey Open-File Report 2001-1, 123 p.

U.S. Army Corps of Engineers-Detroit District, 2006, Historic Great Lakes Levels, accessed November 6, 2008, at http://www.lre.usace.army.mil/greatlakes/hh/ greatlakeswaterlevels/historicdata/greatlakeshydrographs/.

U.S. Army Corps of Engineers-Detroit District, 2008, Long term average min-max water levels for the period of record 1918-2007, accessed November 6, 2008, at http://www. lre.usace.army.mil/greatlakes/hh/greatlakeswaterlevels/ historicdata/longtermaveragemin-maxwaterlevels/.

U.S. Army Corps of Engineers and Great Lakes Commission, 1999, Living with the Lakes: Understanding and Adapting to Great Lakes Water Level Changes, accessed April 9, 2009 at http://www.glc.org/living/pdf/lakelevels.pdf. 


